\title{
A COMPARISON OF THREE FIELD METHODS
}

\section{FOR MEASUURING SATURATED HYDRAULIC CONDUCTIVITY}

\author{
A Thesis \\ Presented in Partial Fulfillment of the Requirements for \\ the degree Master of Science in the \\ Graduate School of The Ohio State University
}

by

Jay Dunton Dorsey, B.S.

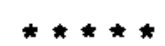

The Ohio State University

1989

Master's Examination Committee:

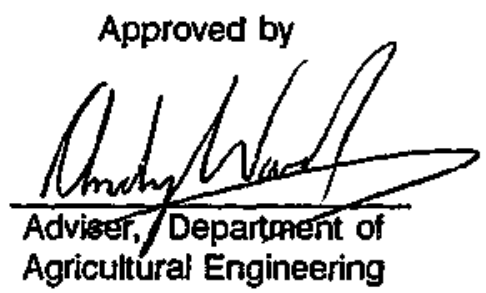

Dr. Andrew D. Ward

Dr. Norman R. Fausey

Dr. Rattan Lal

Dr. E. Scott Bair

Dr. Larry C. Brown

Agricultural Engineering 


\section{ACKNOWLEDGEMENTS}

I express my sincere appreciation to Dr. Andy ward for thoughtful advice, professional direction and unparalleled support. His knowledge, patience and resolve were the foundation of an experience well beyond the requisite master's education. Thanks go to the other members of my graduate committee, Drs. Norman Fausey, Scott Bair, Rattan Lal, and Larry Brown, for their suggestions and comments. Gratitude is expressed to Charles Schalk, Eric Desmond, John Maul, Bart Ray, Charley Roberts, David Rausch, Dr. Mike Lichtensteiger, Carl Cooper, and Dennis Albery for their technical assistance and friendship. To Judy Doty, Cindy Wallace, Deb Ebenhack, Sandy Smith, Norma Harper, sue Bartley, Rita Bowers, Carolyn Matthews, and Valerie stewart, I offer my sincere thanks for your help and tolerance. I thank my family for their continued support and sufferance. I thank Drs. Edwin Monke, and Charles Hinkle for their guidance leading up to my graduate program. Finally, I thank Dr. Kamyar Enshayan, Dr. Robert Holmes, Dr. Robert Gustafson, Mel Palmer, Randall Reeder, Dr. Ben Lamp, Dr. Terry Logan, Nancy Creamer, the Agricultural Engineering and Agronomy graduate students, and a host of others for expanding my view of the world. 
VITA

September 14, 1961 ..... . Born - wilmington, ohio 1987 . . . . . . . . B.S., Purdue University, Lafayette, Indiana

2988 . . . . . . . . Intern, Board on science and Technology for International Development, National Research Council, Washington, D.C.

1987-Present . . . . . . Research Assistant, Department of Agricultural Engineering, ohio state University, Columbus.

FIELDS OF STUDY

Major Field: Soil and Water Engineering 
TABLE OF CONTENTS

ACKNOWLEDGEMENTS . . . . . . . . . . . . . ii VITA ..................... . 1 ... LIST OF TABLES . . . . . . . . . . . . . . . vii IIST OF FIGURES . . . . . . . . . . . . . . ix

I. INTRODUCTION AND OBJECTIVES . . . . . . . . 1

1.1 Introduction .............. 1

1.2 Objectives and scope .......... . 5

1.3 Rationale for Method Selection . . . . 6

II. IITERATURE REVIEW . . . . . . . . . . . 9

2.1 Introduction .............. 9

2.2 Laws of Soil water Movement . . . . . . . 11 2.2.1 Darcy's Law . . . . . . . . . . 12

2.3 Unsaturated Flow . . . . . . . . . . 15 2.3.1 Richards Equation . . . . . . . 16 2.3.2 Green-Ampt Equation . . . . . . 17

2.4 Saturated Flow ............. 19

2.5 Determination of Hydraulic conductivity . . 21 2.5.1 Factors That Affect Hydraulic Conductivity . . . . . . . . . . 21

2.6 Determining Unsaturated Hydraulic conductivity . . . . . . . . . . 26 
2.7 Determining Saturated Hydraulic

Conductivity . . . . . . . . . . 27

2.7.1 Laboratory Methods . . . . . . . 28

2.7.2 Field Techniques - Above the Water Table . . . . . . . . . 29

2.7.3 Field Techniques - Below the Water Table ............. 32

2.8 Flow to Drains . . . . . . . . . . 34

2.9 Studies - Measuring $K$ for Drainage Purposes 35

2.9.1 Selecting a Method . . . . . . . 36

2.9.2 Auger Hole Method . . . . . . . 37

2.9.3 Soil Core Method ... . . . . . 39

2.9 .4 Other Methods .......... 40

2.9.5 Comparison of Methods ....... 43

2.9.6 Determining Hydraulic Conductivity

for DRAIMMOD .......... 46

III. TKEORETICAL BACKGROUND ............. 48

3.1 Guelph Permeameter . . . . . . . . 48

3.1 .1 Theory . . . . . . . . . . . . 48

3.2 Velocity Permeameter . . . . . . . 52

3.2.1 Theory . . . . . . . . . . 53

3.3 Pumping Test Method . . . . . . . . 56

3.3.1 Theory when Well Reaches

Impermeable Layer . . . . . . 59

3.3.2 Theory when Well Does Not Reach

Impermeable Layer . . . . . . 61

IV. EXPERIMENTAL DESIGN AND PROCEDURE . . . . . . 65

4.1 Site Description ........... 65

4.2 Experimental Design ........... 66

4.3 Experimental Procedure ......... 71

4.3.1 Guelph Permeameter........ 71

4.3.2 Velocity Permeameter ....... 74

4.3.3 Pumping Test Method ....... 79 
v. RESULTS AND DISCUSSION . . . . . . . . . 85

5.1 Results . . . . . . . . . . . . . 85

5.1.1 Pumping Test Method . . . . . . 86

5.1.2 Velocity Permeameter Method . . . . 87

5.1.3 Guelph Permeameter Method . . . . 87

5.2 Comparison of Results . . . . . . . . . . 91

5.3 Discussion . . . . . . . . . . . . . . 99

5.3.1 Pumping Test Method . . . . . . 99

5.3 .2 Velocity Permeameter . . . . . . 11?

5.3.3 Guelph Permeameter . . . . . . . 122

5.4 General Discussion .. . . . . . . . 128

vI, SUMMARY AND CONCLUSIONS . . . . . . . . . 139

IIST OF REFERENCES . . . . . . . . . . . . . . . 144 


\section{IIST OF TABLES}

TABLE

PAEE

1. Summary of tests conducted at each research

location .................. 70

2. Pumping test method data . . . . . . . . " 86

3. Velocity permeameter method data - Ravenra silt loam ................. . . 88

4. Velocity permeameter method data - Hoytville silty clay loam . . . . . . . . . . . 89

5. Guelph permeameter method data . . . . . . . 90

6. Summary of saturated hydraulic conductivity data - Ravenna silt loam . . . . . . . . . 92

7. Summary of saturated hydraulic conductivity data - Hoytville silty clay loam . . . . . . . 93

8. Statistical comparison of saturated hyaraulic conductivity data - Ravenna silt loam . . . . 95

9. Statistical comparison of saturated hydraulic conductivity data - Hoytville silty clay jloam . 96

10. Iist of properly functioning observation wells for pumping tests .... . . . . . . . . . 102

11. Observation wells used in pumping test method calculations .. . . . . . . . . . . . 103

12. Estimated saturated hydraulic conductivity values for Hoytville silty clay loam using different sets of observation wells . . . . . 105

13. Estimated saturated hydraulic conductivity values for Hoytville silty clay loam using observation wells in different directions 
14. Comparison of scturated hydraulic conductivity values determined by fully and partially penetrating well calculations using pumping test data for Hoytville silty clay îam ... . 109

15. Profile saturated hydraulic conductivity values for Hoytville silty clay loam . . . . 109

16. Saturated hydraulic conductivity estimates based on four different interpretations of velocity permeameter test data . . . . . 115

17. The number of samples required for various degrees of precision at the $95 \%$ confidence level for saturated hydraulic conductivity of the $\mathrm{A}, \mathrm{Btg}$, and $\mathrm{Bg}$ horizons of Portsmouth sandy loam .............. 137

18. Advantages and disadvantages of field methods for determining saturated hydraulic conductivity ................ 143 


\section{IIST OF FIGURES}

FIGURES

PACE

1. Diagram illustrating apparatus used by Darcy to establish his law.. . . . . . . . . . . 13

2. Geometry and symbols for Green-Ampt infiltration model . . . . . . . . . . . . . 18

3. Schematic of the Guelph permeaneter . . . . . . 49

4. Steady-state flow out of a well situated above the water table . . . . . . . . . . 51

5. Schematic of velocity permeameter . . . . . . . 54

6. Pumping test method - well reaches impermeable layer . . . . . . . . . . . . . . . 58

7. Pumping test method - well does not reach impermeable layer . . . . . . . . . . . . 58

8. Determination of $\theta$, angle of water table slope at nearer observation well . . . . . . . . . 63

9. Plan view of test locations for Ravenna silt loam, subirrigation/drainage experiment, Shafter Farm, wooster

10. Plan view of test locations for Hoytville silty clay loam, subirrigation/drainage experiment, OARDC, Fremont . . . . . . . . . . . . . .

11. The Guelph permeameter . . . . . . . . . 72

12. The velocity permeameter . . . . . . . . 77

13. Plan view of pumping test set-up . . . . . . . . 82

14. Pumping test time-drawdown plot . . . . . . 108 
15. Series of apparon: saturated hydraulic conductivity determinations for two different

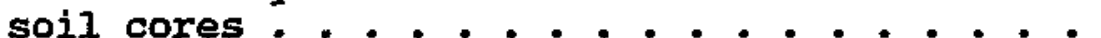

16. Graphic representation of four methods for interpreting velocity permeameter data Hoytville silty clay loam

17. Cyclic progression of apparent saturated hydraulic conductivity values determined by the velocity permeameter mothod ...... 220

18. Cyclic decrease in Guelph permeameter outflow over several time periods ......... 125 
CHAPTER I

INTRODUCTION AND OBJECTIVES

\subsection{Introduction}

The hydraulic conductivity $(K)$ of a soil is the most important soil property affecting the design of water-table management systems (Doty et al., 1986). Hydraulic conductivity values are required for nost models that describe infiltration and water movement through the soil profile. They also are used to determine drain size and spacing, and to design irrigation systems.

Hydraulic conductivity is the ability of a porous medium to transmit water under the influence of a pressure gradient (Hillel, 1982). It is a function of soil moisture conditions and soil suction. If all the soil pores are filled with water, the soil is said to be saturated and the whole pore space is able to conduct water (Childs, 1969). In saturated conditions, soil water moves predominantly under the influence of gravity and the ratio between soil water flow and the pressure gradient is the saturated hydraulic conductivity. In unsaturated soil, the pressure gradient depends on the amount of soil moisture, with soil suction becoming more important as soil moisture decreases. Unsaturated hydraulic 
conductivity is difficult to quantify because it depends on the potential gradient at any point in the system which in turn depends on the moisture content.

For most applications, the region below the water table is taken to be saturated. In reality, complete saturation rarely exists, even several meters below the water table. The term "field saturated hydraulic conductivity" was coined to describe the "saturated" hydraulic conductivity of a porous medium with entrapped air. The field saturated hydraulic conductivity changes as the amount of entrapped air changes and can be a factor of two or more below the actual saturated hyaraulic conductivity (Reynolds and Elrick, 1985).

Various techniques have been developed to determine saturated and unsaturated hydraulic conductivity. Methods used to measure saturated hydraulic conductivity include the auger hole, piezometer, double tube, shallow-well pump-in, air-entry permeameter, and laboratory core methods (Bouwer and Jackson, 1974). The two-plate method and the long-column method are the most common laboratory techniques used to determine unsaturated hydraulic conductivity. In addition, several empirical techniques have been developed to estimate hydraulic conductivity from related soil properties (O'Neal, 1952; Bouma et al., 1979; Rawls et al., 1982; puckett et al., 1985; Baumer et al., 1987).

Selecting an appropriate method for estimating hydraulic conductivity involves a number of trade-offs, including: 
(a) the variability of point samples in heterogeneous soils versus the time, labor, and cost of more extensive sampling methods;

(b) using a technique that measures infiltration versus waiting for a usable water table situation; and

(c) testing at convenience versus conducting tests with optimum initial field conditions.

other factors to be considered before selecting a technique include soil texture, structure, shrink-swell characteristic, layering, anisotropy, macropores, cracks, and coarse fragments.

Choosing a method for measuring hydraulic conductivity should be based on the application of the data (Skaggs, 1976). Hydraulic conductivity values determined in this study will be used as an input parameter to a drainage design model such as DRAINMOD (Skaggs, 1979a). DRAINMOD is a mathematical model developed to simulate the performance of drainage and related water table management systems. DRAINMOD requires two hydraulic conductivity inputs: (1) the saturated lateral hydraulic conductivity for a drain spacing component; and (2) the vertical field saturated hydraulic conductivity for an infiltration component (Fredericks, 1986).

Model outputs are very sensitive to hydraulic conductivity values. On the basis of a sensitivity analysis, hydraulic conductivity ranked next to potential ET as having the greatest effect on computed results (Fredericks, 1986). 
To simulate drainage conditions accurately with DRAINMOD, it is important to establish appropriate methods to determine hydraulic conductivity.

The most accurate method to determine hydraulic conductivity values for drainage design would be to install a drain and calculate the hydraulic conductivity from outflow volume and water-table drawdown data (Skaggs, 1976). This method, however, is not economically feasible, and defeats the purpose of drainage design models.

The pumping test method, based on Guyon's method of wells and piezometers (Lesaffre, 1987a), determines the hydraulic conductivity from the water table drawdown in response to pumping. A situation is created where the water table recedes in a manner similar to drawdown from drainage. Therefore, the pumping test method may be the most accurate method for determining hydraulic conductivity for drainage design that does not require installation of a drain. However, the pumping test method has limitations, most notably time and labor requirements and the need for a shallow water table.

Recently, two quick and simple techniques, the Guelph and velocity permeameters, were developed for determining the field saturated hydraulic conductivity above the water table. If either of these methods is proven to be an adequate substitute for more extensive methods, estimating hydraulic conductivity values for the DRAINMOD model will be greatly facilitated. 


\section{2 objectives and Scope}

The main objective of this study was to compare three "new" methods for determining saturated hydraulic conductivity in the field. The Guelph permeameter, velocity permeameter, and pumping test method were compared for cost, ease of use, time requirements, and most importantly, the range of hydraulic conductivity values determined by each method for the test soils.

An important consideration in choosing test sites was the need to describe the hydraulic conductivity of subirrigation research plots at ohio Agricultural Research and Development Center (OARDC) branches at Wooster and Fremont. Saturated hydraulic conductivity values would add to the data base of soil physical properties required for future projects at these sites.

Another goal of this study was to compare three field techniques for determining saturated hydraulic conductivity as an input for the DRAIMMOD water management simulation model. The research objectives can be stated as follows:

1. To compare three field techniques for determining saturated hydraulic conductivity.

2. To determine the hydraulic conductivity for two soils in ohio.

3. To determine the feasibility of using these techniques to estimate the hydraulic conductivity inputs for DRAIMMOD. 
The first objective was the main focus of this study, and the majority of this work addresses that aspect. In the process of answering objective 1 , a descriptive set of hydraulic conductivity values was collected for both research sites, thus accomplishing objective 2 .

The third objective was not met due to a lack of appropriate input data for the DRAINMOD model, and other circumstances. It had been planned that the hydraulic conductivity values determined by field methods would be compared to values "backed out" of the DRAIMMOD model from measurements of water-table drawdown and drainage outflow. Test runs of the DRAINMOD model would be used to determine the feasibility of using the pumping test method, the Guelph permeameter, the velocity permeameter, or a combination of the techniques to determine appropriate hydraulic conductivity values as inputs to DRAIMMOD. However, digitizing problems and a lack of resources prevented drainage information from being available in a timely fashion to be incorporated as part of the research study presented in this report.

\subsection{Rationale for Method Selection}

The three methods for measuring saturated hydraulic conductivity compared in this study were selected because of applicability and availability. The pumping test method was selected because it is based on a falling water table and, therefore, is probably the best alternative method to 
measuring drain outflow. In addition, the pumping test method is the most common method used for determining hydraulic conductivity for drainage design in France (Lesaffre, 1987b). However, this method requires a shallow water table, and is time consuming and labor intensive.

Alternative methods which required less time and labor, and could be performed above the water table, were sought. The velocity and Guelph permeameter methods were selected. Both are reported to be quick and easy to use. Both have been applied to arainage research and to the design of drainage systems. Neither method requires a shallow water table.

In addition, the velocity permeameter was selected because: the equipment was available (property of USDA-ARS Soil Drainage Research Unit in Columbus, Ohio); it can be used to measure horizontal and vertical hydraulic conductivity; and it can be used to measure the hydraulic conductivity of discrete layers. The Guelph permeameter was selected because it can be used to measure the hydraulic conductivity of discrete layers, and can be operated while other field work is being conducted. A Guelph permeameter was recently purchased by the soil and water group of the Agricultural Engineering Department.

A focus of this group is water-table systems research and how the management of these systems influences productivity and water quality. The identification of techniques which provide accurate estimates of hydraulic conductivity in a 
reasonable time, at a reasonable cost, is vital to the success of their research. 
CHAPTER II

LITERATURE REVIEW

\subsection{Introduction}

The objective of drainage in agriculture is to create between the soil surface and the water table a partially saturated zone of optimum quality and quantity for exploitation by plants and for the management of the soil and crops by the farmer (Raats and Gardner, 1974). Efficient drainage system design depends largely on an understanding of water movement and retention in the saturated and unsaturated zones of a given soil. The literature that describes water movement through soils is extensive. The purpose here is not to cover the topic completely, but to highlight aspects of water movement through soil that pertain to design of drainage and other water table management systems. These aspects then become the principles on which hydraulic conductivity determinations are based. More complete treatments of soil water processes are found in Childs (1969), Luthin (1957), and van Schilfgaarde (1974a).

This review begins with the basic physical principles which drive soil water flow. Darcy's law related these principles to saturated flow in a sand column. Darcy's (1856) 
work was the basis for much of the work that followed. In 1911, Green and Ampt developed an infiltration model which is still widely used. Twenty years later, Richards (1931) developed a physically-based equation for unsaturated flow. Introducing conservation of mass to Darcy's law led to the Laplace equation for saturated flow (Childs, 1969).

Reeve and Luthin (1957) stated that basic principles governing the flow of fluids in porous media are well defined and generally understood. The principle problem from an engineering viewpoint is applying the basic theory to evaluate fluid-flow properties of field soils for practical application in the design of drainage systems.

The focus of this report is the comparison of recently developed methods for measuring saturated hydraulic conductivity for drainage design purposes. It is important here to build a framework for why these new techniques were developed by looking at the other methods that have traditionally been used to measure hydraulic conductivity. The review of established methods for determining hydraulic conductivity begins with an overview of techniques for measuring unsaturated hydraulic conductivity and follows with a description of techniques for measuring saturated hydraulic conductivity. Finally, studies that have considered the determination of hydraulic conductivity for drainage design are reviewed. 


\subsection{Laws of soil water Movement}

The rate of flow of water in a soil is determined by two factors, the force acting on each element of water volume and the resistance to flow from the soil matrix (Childs, 1969). The force acting on the water is a combination of gravitational force and the force due to a difference in hydrostatic pressures at different points in the system. Because forces rarely act in the same direction, it is necessary to choose an arbitrary datum and describe the forces in terms of potential difference. Hydrostatic forces are commonly referenced to atmospheric pressure. Gravitational potential is generally measured from the point (usually the soil surface or water table) where hydrostatic forces equal atmospheric pressure.

The potential, $\phi$, at any point in the system can be defined as:

$$
\phi=h+z
$$

where $z$ is the height above the datum and $h$ is the pressure head (measured with a manometer) at that point. If potential is determined at a sufficient number of points in the soil water system, a contour map of the potential distribution can be constructed. The direction of water flow in the system will be from areas of high potential to areas of lower potential. The magnitude of the potential gradient can be 
determined anywhere in the system by observing the difference in potential between two points and dividing this difference by the distance separating the points.

\subsubsection{Darcy's Law}

Darcy's experiment described the movement of water through a saturated sand column in response to the potential difference between the ends of the column (Darcy, 1856). Darcy showed that the rate of water flow was proportional to this potential gradient (Childs, 1969). Under saturated conditions (Figure 1), the volume flow rate, $Q$, is:

$$
Q=K A \frac{H_{a}-H_{B}}{L}
$$

where $\mathrm{H}_{\mathrm{a}}$ is the hydraulic head at the upper end of the column, $H_{b}$ is the hydraulic head at the lower end of the column, $L$ is the length of the column, $A$ is the cross-sectional area of the column, and $\mathrm{K}$ is a characteristic of the porous medium in the column (Childs, 1969).

The constant of proportionality, $K$, between the flow and the potential gradient is called the hydraulic conductivity. This $k$ has also been referred to as "permeability," "transmissivity," ${ }^{1}$ and "transmission constant" (Reeve and

1 The transmissivity term referred to by Reeve and Luthin (1957) is used in several infiltration equations to describe the hydraulic conductivity of the soil surface layer and should not be confused with the transmissivity term used by hydrogeologist:; to describe the hydraulic conductivity of an aquifer multiplied by its thickness. 


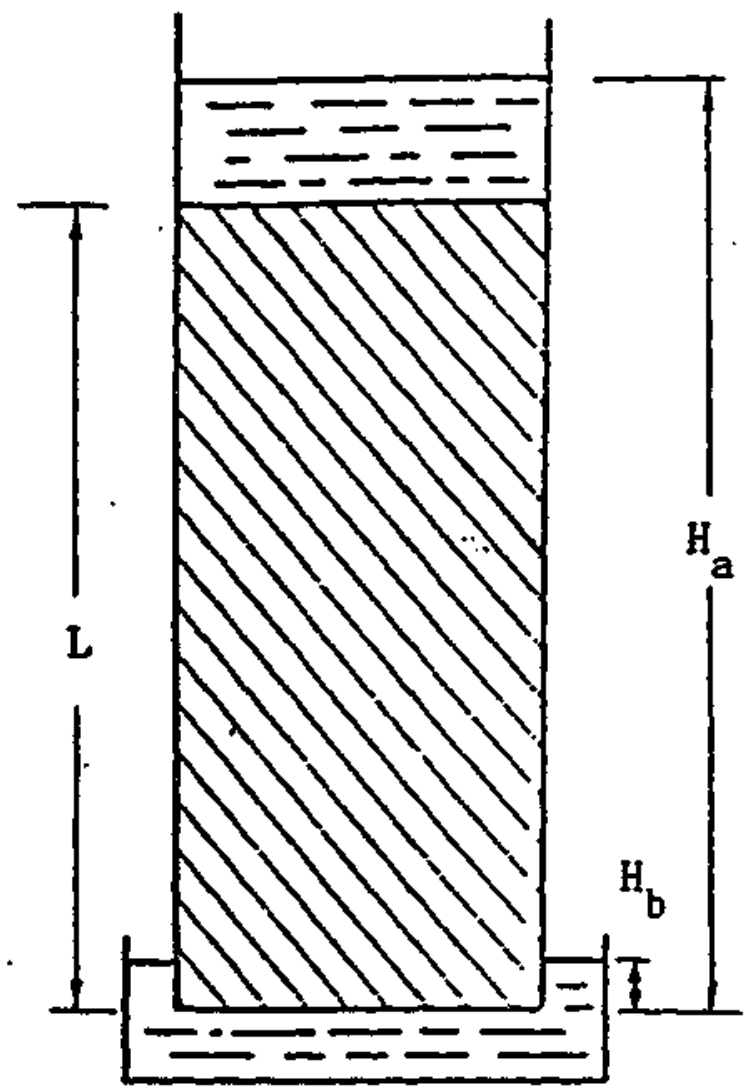

Figure 1. Diagram illustrating apparatus used by Darcy to establish his law (Childs, 1969). 
Luthin, 1957). The units of hyaraulic conductivity are length per unit time. Thus, hydraulic conductivity has the same dimensions as velocity.

Darcy's theory is based on water flowing vertically through a saturated sand column at a constant velocity. The Darcy velocity, also called the average or effective velocity, is the hypothetical velocity of water if it flowed unobstructed through an area approximately equal to the average pore space. Thus, Darcy's law is based on a macroscopic evaluation of soil properties.

Nothing can be precisely known about the actual microscopic velocity of the water particles through the tortuous pore space of soil (Childs, 1969). Water moving through soil follows flow paths that conform to individual pore and particle arrangements. In spite of the complexity of the microscopic flow regime, the effective discharge or macroscopic flow can be adequately described by Darcy's law (Reeve and Luthin, 2957).

To describe saturated flow in any direction, instead of just in a vertical column, the definition of potential, $\phi$, from Equation 2.1 is used. The velocity of flow is in the direction opposite to that in which the hydraulic head is increasing. Equation 2.2 then becomes:

vector $\mathrm{v}=-\mathrm{K} \operatorname{grad} \phi$ 
with velocity components (Childs, 1969):

$$
\begin{aligned}
& v_{x}=-K \frac{\partial \phi}{\partial x}=-K \frac{\partial H}{\partial x} \\
& v_{y}=-K \frac{\partial \phi}{\partial y}=-K \frac{\partial H}{\partial y} \\
& v_{z}=-K \frac{\partial \phi}{\partial z}=-K \frac{\partial H}{\partial z}
\end{aligned}
$$

where $\mathrm{H}$ is the hydraulic head. This is the most general statement of Darcy's law for isotropic porous materials (Childs, 1969).

\subsection{Unsaturated Flow}

Hydraulic conductivity is sharply reduced in the first stages of ursaturation (Childs, 1957). As moisture content decreases, the number of pores filled with air increases and these pores are no longer effective channels for water flow. Large pores, or macropores, will desaturate first. Gravity flow predominantly occurs in these macropores and flow due to soil suction predominantly occurs in smaller pores, or micrcpores. As the degree of unsaturation increases, so will the relative infiuence of soil suction.

Saturated flow assumes that all pores are filled with water ard flowing with liquid. This simplifying assumption does not hold for unsaturated conditions and mathematical descriptions of unsaturated flow are approximations based on marginally valid assumptions. Many attempts have been made to characterize unsaturated flow. These include works by 
Green and Ampt (1911), Richards (1931), Philip (1957a), van Schilfgaarde (1957), Childs (1957, 1969), Bouwer (1969), Watson (1974), Hillel (1982), skaggs and Khaleel (1982), Rawls et al. (1982), Knight (1983), and Baumer et al. (1987). Richards equation and the Green-Ampt equation are included here because they are two of the more important unsaturated flow models with physical meaning and have been applied in drainage design models.

\subsubsection{Richards Equation}

For unsaturated flow, $q$, in the downward (z) direction Darcy's law may be written as:

$$
\mathrm{q}=\mathrm{K}(\boldsymbol{\theta}) \frac{\mathrm{dh}}{\mathrm{dz}}
$$

where the hydraulic conductivity, $\mathrm{K}$, is a function of water content, $\theta$ (Skaggs and Khaleel, 1982). The hydraulic conductivity decreases rapidly as water content decreases.

The principle of conservation of mass for flow in the $z$ direction can be written as:

$$
\frac{d \theta}{d t}-\frac{d q}{d z}
$$

where $q$ is the flux in the $z$ direction, $t$ is time, and $\theta$ is the volumetric soil water content. 
Richards equation was developed by combining equations 2.5 and 2.6 and can be written as:

$$
\frac{\partial \theta}{\partial t}=\frac{\partial}{\partial z}\left[D(\theta) \frac{\partial \theta}{\partial z}\right]-\frac{\partial K}{\partial z}
$$

where $D(\theta)=K(h) d h / d \theta$ is the soil water diffusivity. For most soils, $D(\theta)$ and $K(\theta)$ vary markedly with water content or pressure head. Skaggs and Khaleel (1982) stated that the pronounced nonlinearity of these parameters is the prime source of difficulty in solving Richards equation subject to boundary conditions pertinent to infiltration. When saturated conditions are reached, Richards equation reduces to the Laplace equation for saturated flow.

\subsubsection{Green-Ampt Equation}

Infiltration is the rate of water entry into a soil, generally through downward flow through all or part of the soil surface (Hillel, 1982). The Green-Ampt equation was one of the earliest models developed to describe infiltration into a porous medium (Green and Ampt, 1911). The equation is still widely used, and is the infiltration equation used in DRAINMOD, The following overview is taken from childs (1969).

Green and Ampt assumed that in the infiltration process the advancing water front is a well-defined surface (Figure 2) at which the matric (suction) pressure, $h_{f}$ is a constant characteristic of the soil. This front separates the 


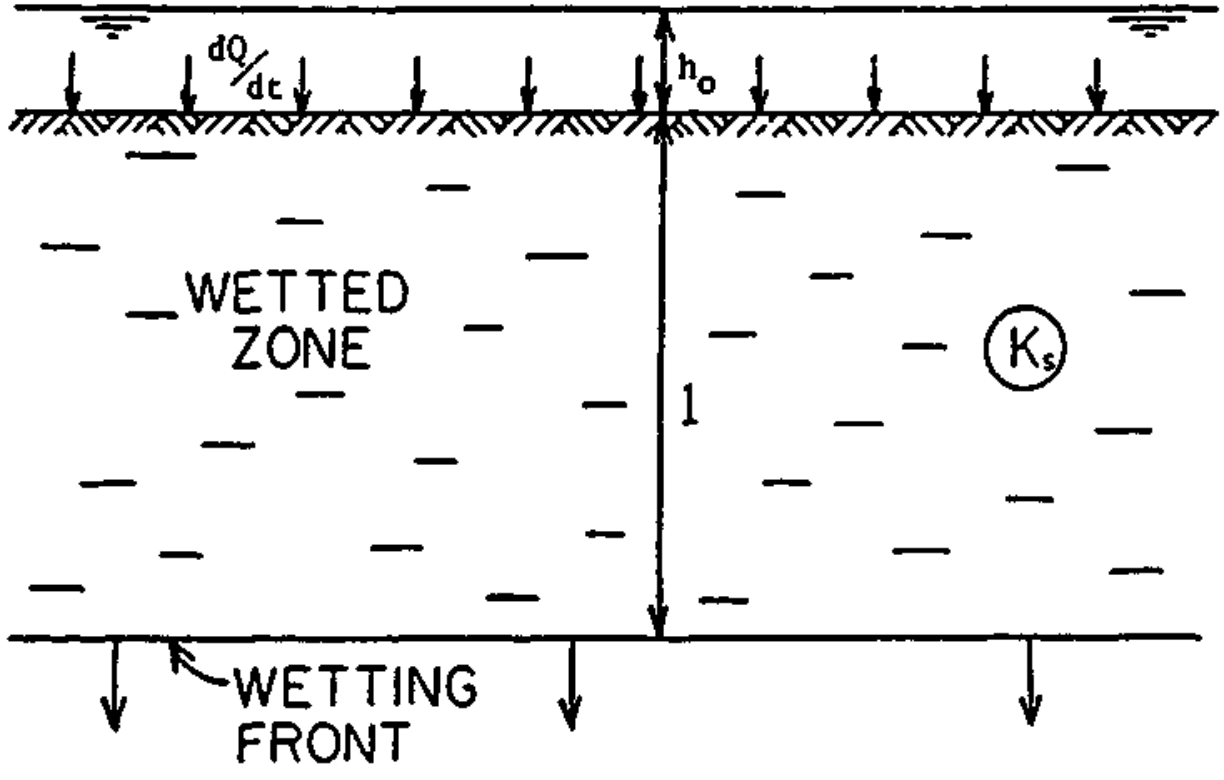

Figure 2. Geometry and symbols for Green-Ampt infiltration model (Bouwer, 1978). 
saturated zone (with uniform hydraulic conductivity, $\mathrm{K}_{\mathrm{s}}$ ) behind the front from the uniformly unsaturated zone ahead of the front which has not yet been affected. This assumes a step-shaped soil moisture characteristic curve dropping from saturation to a constant degree of unsaturation at the airentry pressure, $h_{f}$. Only a granular body of uniform particle and pore sizes would come close to satisfying this condition.

Defining 1 as the depth to which the water front has penetrated at time $t$, and assuming that $h_{0}$ is the hydrostatic pressure of standing water at the soil surface, the Green-Ampt infiltration rate, dQ/dt, can be derived from Darcy's Iaw as:

$$
\frac{d Q}{d t}=K_{s} \frac{h_{0}+1-h_{c}}{1}
$$

When 1 is small (infiltration just beginning) do/dt is large. As 1 increases, dQ/dt will approach the vertical saturated hydraulic conductivity of the soil profile, $\mathrm{K}_{s}$.

The Green-Ampt model, Richard's equation and other methods for determining infiltration are covered in more detail by skaggs and Khaleel (1982).

\subsection{Saturated Flow}

In real-world situations, soil water flow follows tortuous paths. Application of Darcy's law is not practical for most applications, and provides no information on the distributicn of head loss in the system (Amerman and Naney, 
1982). Childs (1969) and others combined Darcy's law with an equation of continuity and developed the Laplace equation for saturated flow:

$$
\frac{\partial^{2} \mathrm{H}}{\partial \mathrm{x}^{2}}+\frac{\partial^{2} \mathrm{H}}{\partial \mathrm{y}^{2}}+\frac{\partial^{2} \mathrm{H}}{\partial \mathrm{z}^{2}}=0
$$

where $H$ is the total hydraulic head. Laplace's equation is a linear, elliptical partial differential equation. Boundary conditions must be specified for complete description of a given problem (Amerman and Naney, 1982).

Amerman and Naney (1982) reported no general solution for the Laplace equation. However, Childs (1969) presented four methods of approximating solutions, namely: (1) conjugate equations; (2) conformal mapping; (3) electrical or other analogues; and (4) numerical iteration. Klute et al. (1965) presented analytical mathematics as another approach.

The two-dimensional flow system associated with drains can be analyzed using any of the above techniques if the geometry is kept simple and simplifying assumptions applied. In general, as the geometry becomes more complicated and anisotropy is considered, the use of Laplace's equation becomes more difficult. Numerical techniques (finite difference and finite element) are now being used to approximate Laplace's equation for extremely complex flow situations (Amerman and Naney, 1982). 


\subsection{Determination of Hydraulic Conductivity}

The hydraulic conductivity of a soil can be determined in-situ or on samples removed to the laboratory, by directly measuring fluid flow through the porous medium. Determination comes from a knowledge of the hydraulic head distribution, boundary conditions, and macroscopic flow velocity (Reeve and Luthin, 1957). The rate of flow is usually determined from a measurement at an inflow or outflow surface and is regarded as distributed over the whole of the surface (Childs, 1969). This ignores the internal structure of the conducting body and treats it as a uniform medium, solid and pore space alike, with a smoothed potential distribution (Childs, 1969).

The hydraulic conductivity of a soil is a difficult property to measure. Because information on other soil properties is often simpler to determine, methods have been developed to estimate hydraulic conductivity from related soil properties, such as soil texture, porosity, and bulk density. Among the studies that address estimation of hydraulic conductivity from related properties are 0 'Neal $(1949 ; 1952)$, Uhland and O'Neal (1951), Hirschi and Moore (1980), Rawls et al. (1982), McKeague et al. (1982), Puckett et al. (1985), Wang et al. (1985), Bouma (1986), and Baumer et al. (1987).

2.5.1 Factors That Affect Hydraulic Conductivity When selecting a method for determining hydraulic conductivity, it is important to consider the factors which 
will affect the hydraulic conductivity and the measurement technique. Properties that affect a soils hydraulic conductivity include temperature, degree of saturation, soil structure, texture, pore size distribution, size and distribution of cracks and macropores, type and percentage of clay, compaction, organic matter content, and salt concentration (Reeve and Luthin, 1957).

The method used for measuring saturated hydraulic conductivity depends on the presence or absence of a water table. Measurements of hydraulic conductivity above the water table are calculated from the rate of infiltration into unsaturated soil. The initial moisture content of the unsaturated zone will affect the rate of infiltration and the speed with which saturation is approached. Philip (1957b) described the effect of moisture content on hydraulic conductivity and hydraulic diffusivity. He differentiated between "short time" infiltration when moisture gradients are the dominant influences and "long time" infiltration when gravity forces take over.

The hydraulic conductivity value determined by techniques based on flow into unsaturated soil is called the "field saturated hydraulic conductivity" and is a function of the amount of air trapped during infiltration. Entrapped air can significantly reduce the measured hydraulic conductivity by blocking water flow with gas-filled pores (Reeve and Iuthin, 1957). The hydraulic conductivity below the water table is 
somewhat less than a saturated value and can be called the "apparent saturated hydraulic conductivity" (skaggs and Khaleel, 1982). Decomposition of organic matter by microorganisms and displacement of soil particles are other causes of blocked pores, and thus reduced hydraulic conductivity (Reeve and Luthin, 1957).

The hydraulic conductivity of a soil is not a constant, but changes in response to interactions between the water and the soil (Reeve and Luthin, 1957). The extent of the fluctuations in hydraulic conductivity depend largely on the mineralogical composition of the soil and the quality of the water. Soils which contain a swelling clay such as montmorillonite will experience a major change in hydraulic conductivity depending on the stage of wetting or drying.

Cropping and cultural practices affect infiltration and hyoraulic conductivity (Uhland and O'Neal, 1951). Deeprooting crops such as clover and alfalfa enhance the hydraulic conductivity of lower soil horizons. Timing and type of tillage can have a profound effect on infiltration and hydraulic conductivity of the surface layer. Tilling the soil when it is too wet may cause soil compaction which may have a lasting detrimental effect on soil hydraulic conductivity. In an infiltration study, Shirmohammadi and Skaggs (1985) showed that the hydraulic conductivity, or "transmissivity", of the plow layer is affected considerably by rainfall, cultivation, and root development. 
Moore et al. (1986) studied preferential flow and hydraulic conductivity of forest soils and found a sharp reduction in the saturated hydraulic conductivity below $30 \mathrm{~cm}$. They attributed the high conductivity of near-surface soils to preferential flow. They also noted a marked decrease in macroporosity and thus the hydraulic conductivity of the surface layer as logging traffic increased. Reeve and Luthin (1957) described the influence of cracks and macropores on the transmission of water in soil and the difficulty of interpreting laboratory measured hydraulic conductivity values where large pores are prevalent. Uhland and O'Neal (1951) pointed out that high percolation rates are commonly the result of wormholes or cracks in the soil.

Peters et al. (1982) reviewed studies of the decrease in hydraulic conductivity associated with soil compaction. Ravina and Magier (1984) investigated the effects of coarsefragment content on hydraulic conductivity. In compacted soils, as coarse fragment content increased so did the saturated hydraulic conductivity.

Hydraulic conductivity of soils is affected by temperature (Bouwer, 1978). The effect of temperature on hydraulic conductivity is due to the effect of temperature on the viscosity of soil water. Viscosity varies inversely with temperature. A lower viscosity allows water to pass through the soil more easily, and thus, is reflected by an increase in hydraulic conductivity. Values of hydraulic conductivity 
are often expressed as an equivalent hydraulic conductivity at 20 degrees Celsius, defined as:

$$
K_{20}=K_{t} \frac{\mu_{t}}{\mu_{20}}
$$

where $k_{t}$ is the hydraulic conductivity value determined at temperature, $t, \mu_{\mathrm{t}}$ is the absolute viscosity of water at temperature, $t$, and $\mu_{20}$ is the absolute viscosity of water at 20 degrees celsius.

Hopmans and Dane (1985) discussed the effect of temperature-dependent hydraulic properties on hydraulic conductivity and found the largest effect to be pressure related. They concluded that laboratory determinations of hydraulic conductivity values should be conducted under temperature conditions similar to field conditions.

Bouwer (1978) differentiated between hydraulic conductivity (K) and intrinsic permeability (K). Hydraulic conductivity is a property of both the fluid and conducting medium. Intrinsic permeability, however, only is a property of the medium, independent of the density and viscosity of the fluid. The relationship between intrinsic permeability and hydraulic conductivity is:

$$
k-\frac{K_{\mu}}{\rho g}
$$

where $\mu$ is the absolute viscosity of the fluid, $\rho$ is the 
density of the fluid, and $g$ is acceleration due to gravity. I.ttrinsic permeability is seldom used to describe soil-water hydrology. It is more commonly applied in the petroleum and natural gas industries (Bouwer, 1978).

Hydraulic conductivity is affected by electrolyte concentration and composition of soil water (Reeve and Luthin, 1957). McNeal (1974) provided an extensive overview of the effects of salts and salinity on soil hydraulic conductivity (permeability). Sodium, in particular, disperses soil minerals and organic matter resulting in aggregate breakdown and surface crusting, which reduces hydraulic conductivity.

\subsection{Determining Unsaturated Hyaraulic conductivity}

The unsaturated hydraulic conductivity must be known to model water content distributions above the water table. Investigators have long realized the importance of flow in the unsaturated zone, but it was Richards (1931) who first discussed Darcy's law in relation to unsaturated flow. His work led to the development of a "two-plate" method for measuring unsaturated hydraulic conductivity. Childs (1945) followed with a study of water flow in the capillary fringe during drainage which led to the "long-column" method for determining unsaturated hydraulic conductivity.

Most steady-state flow methods for measuring unsaturated hydraulic conductivity are variations of the two-plate and long-column methods (Bouwer and Jackson, 1974). Transient 
flow methods for measuring unsaturated hydraulic conductivity that have been developed include the pressure-plate outflow method of Gardner (1956), the horizontal advance of the wetting front method of Bruce and klute (1956), and the instantaneous profile method of Watson (1966). In addition, several methods have been developed to calculate unsaturated hydraulic conductivity based on the soil-water characteristic (Bouwer and Jackson, 1974). Schuh and Bauder (1986) presented a method for estimating the slope of the unsaturated hydraulic conductivity value-soil suction curve from soil mineralogical data and other physical properties of the soil. Bouwer and Jackson (1974) detailed these methods for determining unsaturated hydraulic conductivity.

\subsection{Determining Saturated Hydraulic Conductivity}

Saturated hydraulic conductivity can be found directly by measuring water movement through a soil sample, or indirectly, by estimating from associated soil properties. Methods that measure saturated hydraulic conductivity directly can be divided into two categories: (1) laboratory techniques, and (2) field techniques. Field techniques can be further divided into methods that require a shallow water table and those that do not. Klute and Dirksen (1986) stated that choosing a method for determining hydraulic conductivity depends on such factors as (1) available equipment; (2) nature of the soil; (3) kind of samples available; (4) the skills and 
knowledge of the experimenter; (5) the soil-water suction range to be covered; and (6) purpose for which the measurements are being made.

The descriptions of the following methods for measuring saturated hydraulic conductivity were developed from ASAE (1962), Kirkham (1965), Bouwer and Jackson (1974), Bouma et al. (1982), Amoozegar and Warrick (1986), and Klute and Dirksen (1986).

\subsubsection{Laboratory Methods}

The core sample method determines saturated hydraulic conductivity on samples removed to the laboratory by either a constant head or falling head test. Core samples are taken in the field and are kept from drying. The samples are saturated from the bottom to prevent air entrapnent.

For the constant head test, special apparatuses have been designed to supply water to the bottom of the core samples at constant hydraulic head. The volume of outflow is measured with time. The hydraulic conductivity is found by rewriting Darcy's law as:

$$
\mathrm{K}=\frac{\mathrm{QL}}{\mathrm{Ah}}
$$

where $Q$ is the rate of outflow, $L$ is the length of the core sample, $A$ is core cross-sectional area, and $h$ is the depth of the constant head applied. 
In the falling head test, used with soils of low permeability, the hydraulic conductivity is determined from the rate of change of velocity of a falling water column. A manometer (cross-sectional area a) is placed on top of the sample core (cross-sectional area A) and filled with water. The hydraulic conductivity is determined as:

$$
K=\frac{a L}{A\left(t_{2}-t_{1}\right)} \ln \left(\frac{h_{1}}{h_{2}}\right)
$$

where $L$ is the length of the soil core, $h_{1}$ is the height of the water column at time $t_{1}$, and $h_{2}$ is the height of the water column at time $t_{2}$.

The laboratory core technique is relatively cheap, does not require a water table, and enables sampling for layers or anisotropy. However, this technique is limited by soil disturbances during handling, small sample size, and loss of head at the water/soil interface. Hydraulic conductivity values resulting from this method are typically much lower than those calculated from field measurements and there is often a large variability between samples.

\subsubsection{Field Techniques - Above the water Table}

When using techniques for determining saturated hydraulic conductivity above the water table, the hydraulic conductivity calculations are based on infiltration into unsaturated soil. Even under the best of circumstances some air is entrapped 
during infiltration and the soil does not become fully saturated. These methods give a value for the field saturated hydraulic conductivity which may be significantly different between different methods, sites, and initial moisture conditions.

The percolation test (ASAE, 1962) is the simplest test to conduct. A hole is dug to the desired depth, water is ponded in the bottom of the hole to saturate the soil, and the vertical velocity of water entering the soil is measured. This technique relates well to subsurface seepage.

The shallow well pump-in method (winger, 1960), otherwise known as the dry auger hole method or well permeameter method, measures the rate of flow of water from a (cased or uncased) auger hole when a constant height of water is maintained in the hole. A float valve is usually used to maintain the water level with a large water tank providing the water supply. Hydraulic conductivity values are calculated using the steady state outflow rate and a shape factor determined from nomographs or equations. The position of the water table or impermeable layer below the bottom of the well must be known. This technique is easy to use but is limited by the time requirements needed to reach steady state and to replicate measurements.

In the column method (ASAE, 1962), a large column of soil is carved out in-situ at the required depth and the column is encased in gypsum and removed from the pit. A ring 
infiltrometer is placed on top of the column and the steady infiltration rate is measured using a Mariotte device that maintains a shallow head on the exposed surface. The encased column is, in essence, a very large soil core. This method is relatively cheap and the sample size is larger than other soil core techniques. Carving instead of coring the sample causes less disturbance.

The cylinder permeameter method (winger, 1960) is similar to the ring infiltrometer method for determining infiltration. A large hole is prepared to the appropriate depth. A metal sleeve (smaller in diameter than the hole) is installed in the center of the hole. The same water level is maintained inside and outside the sleeve. The saturated hydraulic conductivity is taken to be the rate of infiltration when soil suction at the bottom of the ring equals zero (saturated condition). This method can measure vertical conductivity of layered soils. However, this method typically produces lower than actual saturated hydraulic conductivity values due to head loss across the soil-water interface. It is simple in theory, but is usually used for one-dimensional analysis, even though flow is three dimensional.

The double tube method (Bouwer, 1964) is similar to the cylinder permeameter. Two concentric tubes are placed in the soil to a given depth and water flow is manipulated to move from the inner to outer tube at a high and changing rate of hydraulic head. Hydraulic conductivity values are then 
determined from tables and graphs. Because the method is based on the flow component from the outside to the inside cylinder, effects of surface sealing and intake rates are reduced. Air entrapment and anisotropy are major sources of errox. The values measured are a combination of vertical and horizontal hydraulic conductivities.

The infiltration gradient technique (Bouwer, 1964) is also similar to cylinder permeameter, but uses small fast reacting piezometers to determine hydraulic gradient below the bottom of the auger hole. The conductivity is determined by dividing the hydraulic gradient by the infiltration rate.

In the air-entry permeameter (Bouwer, 1966), a small covered cylinder is driven into ground. Water is applied to the cylinder until all air is driven out. A large constant head is kept in a reservoir at the top of the cylinder until saturation is reached at the bottom of the cylinder. The water level is then allowed to fall and the conductivity is calculated from falling head equations. The air-entry permeameter measures field saturated hydraulic conductivity in the vertical direction.

\subsubsection{Field techniques - Below the Water Table}

The auger hole method (van Beers, 1970) is the most Fidely used method for determining hydraulic conductivity of soils in the field. A hole is augered to the desired depth below the water table and water is allowed to rise until 
equilibrium is reached. The hole is then pumped or bailed and the rate of rise of the water level in the hole is measured. The saturated hydraulic conductivity is calculated as:

$$
K=\frac{\pi \mathrm{R}^{2}}{\mathrm{Sh}} \frac{\mathrm{dh}}{\mathrm{d} t}
$$

where $R$ is the radius of the auger hole, $S$ is a function of hole geometry found from nomographs, $h$ is the depth of water in the auger hole, and $\mathrm{dh} / \mathrm{dt}$ is the rise in the water level over time increment dt.

The auger hole method is simple in conception and practice, is quick and cheap, and measures a large sample area compared to other techniques. However, extensive variability in repeated measurements is caused by soil heterogeneity, depth of auger hole, water table depth, and depth of water removed from auger hole. This technique is not good in layered soils and is unreliable in some cases due to macropores or side-wall failure.

The piezometer and tube methods are variations of the auger hole method (Kirkham, 1946). These methods give a better description of stratified soils than the auger hole method. However, the techniques are subject to errors near impermeable layers and stony soils will damage the equipment. Another way of measuring hydraulic conductivity is the two well technique (Childs, 1952), and the more complex multiple well (Smiles and Youngs, 1963) and four well 
techniques (Kirkham, 1954). In the two well technique, two auger holes of equal dimensions are installed about one meter apart. Water is pumped at a constant rate from one hole to the other until the difference between the water levels in the two wells becomes constant. The horizontal saturated hydraulic conductivity is determined from the steady-state flow and head difference in the two wells. The multiple and four well techniques are improvements on the two well technique. The multiple well technique is used to sample a larger area. In the four well technique, two extra wells are used to monitor the head level between the two outside wells.

\subsection{Flow to prains}

Drainage design still relies heavily on local experience, but the development of DRAIMMOD and other water table management system models has removed some of the barriers to more thorough design. To facilitate drainage design, certain simplifying assumptions need to be made. In its simplest form, the drainage flow system has been reduced to a steadystate, horizontal flow system where drain spacing is based on rate of water removal at a specified maximum water table height (Bouwer, 1978). However, if the impermeable layer is more than a small distance below the drains, the vertical flow components are too large to ignore. When the impermeable layer is at yreater depths, the upper flow system will be more active resulting in an effective transmissivity (the hydraulic 
conductivity of an aquifer multiplied by the depth from water table to impermeable layer) which is less than the actual transmissivity (Bouwer, 1978).

To address this inequity, Hooghoudt (1940) applied radial-flow theory and images to evaluate effective depths to the impermeable layer. The resulting equation uses effective depth, which is less than the actual depth to the impermeable layer, to determine drain spacing. Assuming horizontal flow, Hooghoudt's equation can be written as:

$$
v=\frac{4 \mathrm{Km}\left(2 \mathrm{D}_{\mathrm{e}}+\mathrm{m}\right)}{\mathrm{L}^{2}}
$$

where $\mathrm{v}$ is the drainage rate, $\mathrm{K}$ is the hydraulic conductivity, $D_{\theta}$ is the effective depth of the impermeable layer below the arain center, $m$ is the height of the water table above drain centers midway between drains, and $I$ is the distance between drains. The Hooghoudt equation is used in DRAIMMOD to determine drain spacing.

\subsection{Studies - Measuring $K$ for Drainage purposes}

This section begins with criteria used in selecting an appropriate method for determining saturated hydraulic conductivity. The two most commonly used methods are the auger hole method and the soil core method. Studies focusing on these methods are reviewed, followed by a review of other methods. Several studies that compared methods are then 
summarized. This section closes with selecting a method for DRAINMOD.

\subsubsection{Selecting a Method}

The method for measuring hydraulic conductivity should be selected so that the soil region and flow direction used in the hydraulic conductivity measurement adequately represent the soil and flow airection in the actual arainage system (Bouwer and Jackson, 1974). Merva et al. (1987) suggested that hydraulic conductivity values used for drainage design should not be an average for the soil profile to the tile depth, but should be the maximum value in the ricinity of the tile.

Soil morphological data should be used to determine optimal sample sizes and measurement techniques (Bouma, 1986). Amoozegar and warrick (1986) report that the presence of macropores can lead to unrealistic values of conductivity in the field. A few large pores allow water to move at rates faster than saturated hydraulic conductivity of the surrounding soil body. To obtain an unbiased estimate of the soil hydraulic conductivity, the sampling volume should contain a proportional amount of macropores compared to the soil body being tested.

Doty et al. (1986) suggested that, for water table management design, at least one hydraulic conductivity determination be conducted for each two hectares. They 
presented a procedure based on the uniformity of these initial readings to determine if additional readings are required. The field under question is then subdivided into design units with similar hydraulic conductivities. Hydraulic conductivity values selected for design purposes should be the geometric mean of all the hydraulic conductivity values of one design unit. If time requirements do not allow measurement of hydraulic conductivity, the hydraulic conductivity can be estimated from the soils on the site.

\subsubsection{Auger Hole Method}

The auger-hole method is the simplest method for determining the hydraulic conductivity of soil in the presence of a water table (USDA-SCS, 1973; Bouwer and Jackson, 1974; Doty et al., 1986). It is also one of the most reliable methoils. Reeve (1982) suggested that field auger-hole determinations are the next best method to determining hydraulic conductivity from subsurface drainage information. Kirkham (1965) presented a comparison of exact and approximate solutions for the auger hole method. He concluded that approximate formulas are adequate for field work, but that for precise work an exact solution should be used.

Rogers et al. (1987a) reported variation in auger hole values due to factors such as depth of auger hole, depth of the water table, and depth of the water pumped from the hole. In soils with low hydraulic conductivity, large percentage 
errors can result if the true water-table level is not established for determinations with the auger-hole method (Kirkham, 1965). Rogers and carter (1987) used a finite element model to determine what depth of hole and depth of water table should be used for auger-hole measurements of saturated hydraulic conductivity when the hydraulic conductivity varies with depth. They recommended that preliminaxy borings be taken to characterize features of the soil profile. Frora the soil profile description, a design drain depth would be estimated. Auger-hole tests should then be conducted at $0.3 \mathrm{~m}$ above and $0.3 \mathrm{~m}$ below the estimated design drain depth, as well as at the estimated depth. Drainage depth could then be taken as depth to the most permeable layer.

Auger-hole formulas do not hold if much soil sloughs off auger hole walls (Kirkham, 1965). Reeve (1982) reported that the texture of the soil and its susceptibility to smearing determines if additional steps need to be taken to improve the accuracy of the auger hole method.

Carter et al. (1984) presented a method for improving the quality of hydraulic conductivity measurements from the auger hole method by using an electronic sensor to determine the water level in the auger hole.

Auger-hole tests do not determine hydraulic conductivity of the surface, or plow layer. If any indication is given that this layer is less permeable than the subsoil, then 
alternative techniques should be employed to determine the hydraulic conductivity of this layer (Kirkham, 1965).

\subsubsection{Soil core Method}

zobeck et al. (1985) measured saturated hydraulic conductivity of two different soils using samples with three different cross-sectional areas. They found the vertical saturated hydraulic conductivity and variability between samples of one soil which was characterized by a high number of macropores (35 macropores $/ \mathrm{m}^{2}$ ) to be significantly higher than the other soil which had no macropores. In the soil with macropores, the vertical hydraulic conductivity was ten times greater than horizontal hydraulic conductivity. Variability between samples decreased as the cross-sectional area increased.

Smaller cores yield higher values for saturated hydraulic conductivity than larger cores due to "unrepresentative macropore-continuity patterns" in the smaller samples (Bouma, 1986). The size of sample necessary to obtain representative measurements, or critical sample size, shoidd be developed based on soil morphology.

In determining saturated hydraulic conductivity values for subirrigation experiments, wells and skaggs (1976) saturated soil cores with a normal subirrigation process to include the effects of entrapped air. The values determined were lower than values that would have been obtained had the 
soil cores been saturated under suction to remove all of the air. They found significant variability within close field proximity for two different soils.

Leeds-Harrison et al. (1986) found that the apparent saturated hydraulic conductivity values of a swelling clay soil determined by the core method changed dramatically with the amount of time the soil sample had been saturated. Hydraulic conductivity values determined on cracked and dry soil cores were an order of magnitude higher than values determined after the same cores had been wetted for 30 days. They attributed the difference to the time required for moisture to infiltrate the clay peds which then swell cracks closed.

Rogers et al. (1987a) reported that hydraulic conductivity values obtained on soil cores pressed into the soil were twice those for cores hammered into the soil. Hammering distorted the samples such that the pore size distribution was changed. They suggest that the velocity permeameter will encounter the same problems as the core method.

\subsubsection{Other Methods}

Stibbe et al. (1970) described a methos for evaluating vertical saturated hydraulic conductivity in the field using large soil monoliths. They varied the rate of saturation and found that by slowly saturating the monoliths they could 
effectively push all air out of the monolith. Increasing the rate of saturation produced varied levels of entrapped air and "field saturated" hydraulic conductivities reduced by onethird to one-half. The large cross-sectional area of the field monoliths should give vertical saturated hydraulic conductivity values that are directly applicable to infiltration and other vertical flow situations. They also found a favorable comparison between values determined by monoliths and those determined from drain outflows, and suggested that the monoliths would provide good estimates of hydraulic conductivity for drainage research at their study site.

Rogers et al. (1987b) used the velocity permeameter to determine the hydraulic conductivity of structured clay soils. They concluded that the velocity permeameter is not suitable for measuring hydraulic conductivity on structured clay soils for the same reasons that laboratory cores of the same soil are unsuitable. They suggested, however, that the velocity permeameter could be a useful tool on other less-structured soils and that the velocity permeameter also can be used to calculate the sorptivity and Green-Ampt wetting front pressure with a small additional amount of work.

Kanwar et al. (1987) compared hydraulic conductivity values determined by the velocity permeameter and the Guelph permeameter for a uniform loam soil under no-till and conventional tillage conditions. They found the horizontal 
values determined by the velocity permeaneter to be significantly higher than the vertical values. They suggest that this is due to the presence of soil horizons and horizontal macropores. The data obtained by the Guelph permeameter were found to lie between the vertical and horizontal values determined by the velocity permeameter. values determined by the Guelph permeameter were not significantly different than horizontal velocity permeameter values. They also conducted hydraulic conductivity determinations on laboratory cores from the same site and found the values determined by the core method to be much larger than by the other methods.

Rogers et al. (1987a) stated that the hydraulic sonductivity values determined by the Guelph permeameter will tend to reflect the larger component, whether vertical or horizontal. Guelph permeameter measurements will take much longer than other techniques on soil with low hydraulic conductivities. They obtained "many" negative values of hydraulic conductivity when using the Guelph permeameter on layered soils. They then suggested that this brings the validity of other Guelph permeameter values into question.

The most effective way to measure hydraulic conductivity for drainage design would be to install a drain and calculate the hydraulic conductivity from water table drawdown and drain discharge (Bouwer and Jackson, 1974). Skaggs (1976) presented a method to determine the hydraulic conductivity-drainable 
porosity ratio, $k / f$, from water table duawdown or vater table rise measurements near a single drain or between parallel arains. The limitation of this method is that one or mo ie subsurface drain must be in place in the field. Youngs (1976) describes an approach where drainage flow is used to measure hydraulic conductivity variation with depth and to design a drainage plan for a predicted stress period of rainfall. He suggests that water-table recession alone in an area drained by ditches may provide sufficient information to design a drainage system on a rational physical basis.

\subsubsection{Comparison of Methods}

Hoffman and Schwab (1964) suggested that hydraulic conductivity evaluations from core samples and auger holes are less reliable for predicting drain spacing than evaluations from drain outflow measurements. They cited inability of the core sample and auger-hole methods in adequately accounting for the effect of cracks in the soil due to small sampling aisea. Several techniques, such as the laboratory core method and auger-hole method, developed for sandy soils, may not be applicable to structured clay soils (Bouma, 1986). Merva et al. (1987) found lateral hydraulic conductivity values determined by the velocity permeameter just below tile depth to be 3 times greater than values determined for the soil profile above the tile depth by the auger hole method. 
ASAE (1962) reviewed various methods for measuring saturated hydraulic conductivity. They concluded that methods that use water flowing into a hole from surrounding soil are preferable to methods where water flows out of the hole. The reason provided was that the latter provide lower values probably from clogging of pores. They also reported that the variability of measurements varies roughly inversely with sample size, and, thus, they present in order of preference auger hole, piezometer, well-point, tube, and core methods. Bouwer and Jackson (1974) stated that the below-the-watertable methods are all of comparable accuracy.

Rogers et al. (1985) compared four techniques for determining hydraulic conductivity for a silt loam soil with a subsurface fragipan. They conducted tests with the laboratory core, auger hole, and double tube methods and also calculated hydraulic conductivity from water table drawdown. They found that the four methods of determining hydraulic conductivity they studied gave similar values of hydraulic conductivity. The double-tube and laboratory core methods displayed large variation in hydraulic conductivity values. They attributed this to the relatively small sample size of the two techniques. Both techniques allow determination of hydraulic conductivity values for individual layers. They suggested that this may be useful in understanding and quantifying the soil-moisture flow system. The auger hole method gave little information about individual layers and 
the values obtained were also quite variable. They concluded that the choice of method to be used will depend on the soil conditions at the time measurements are desired and on the planned use of the data. Several core measurements can be made in the same amount of time needed for a single measurement with the auger hole method and the core may provide other useful information about the soil.

The degree of anisotropy should be a major consideration when selecting soil hydraulic conductivity values (Rogers et al., 1987a). By modeling flow, it was shown that large increases in vertical hydraulic conductivity cause relatively small increases in flow to an auger hole, whereas an increase in the horizontal hydraulic conductivity proluces a proportional increase in flow to an auger hole. This would also hold true for flow to a subsurface drain. Small core or velocity permeameter readings in the vertical direction are valuable in describing vertical infiltration or upward movement of water. However, horizontal core or velocity permeameter readings in the horizontal direction are probably inadequate for drainage design. Water management system designers might need to use two different sets of hydraulic conductivity data in a design model such as DRAINMOD.

Bouwer and Jackson (1974) presented various techniques for measuring anisotropy in soil hydraulic conductivity. To determine anisotropy between horizontal and vertical directions they suggested combining a method that measures 
predominantly vertical flow, such as the tube method, with a method that measures predominantly horizontal flow, such as the two-well method. To determine if soil is isotropic in a lateral plane, horizontal hydraulic conductivity measurements with two two-well methods can be conducted perpendicular to one another.

\subsubsection{Determining Hydraulic Conductivity for DRAINMOD}

The DRAINMOD water table management system model uses the Green-Ampt equation to determine infiltration rate and the Hooghoudt equation to determine drain spacing (Skaggs, 1979a). Both of these equations require an input value for hydraulic conductivity. Because the Green-Ampt model describes vertical infiltration into the soil and the Hooghoudt equation assumes horizontal flow near the drains, two different values for hydraulic conductivity need to be determined to represent the appropriate flow system for each equation.

Fredericks (1986) suggested the use of the auger hole method to determine the lateral saturated hydraulic conductivity for the Hooghoudt component of DRAINMOD. A method that determines saturated hydraulic conductivity from vertical infiltration such as the air-entry permeameter would probably be most appropriate for determining the Green-Ampt hydraulic conductivity parameter (Skaggs and Khaleel, 1982). Shirmohammadi and skaggs (1985) showed that the hydraulic conductivity of the plow layer is affected considerably by 
rainfall, cultivation, and root development. They concluded that models that predict infiltration should use appropriate values of hydraulic conductivity determined under equivalent conditions. 
CHAPTER III

THEORETICAL BACKGROUND

This section describes the basic mathematical principles used to calculate hydraulic conductivity by the three methods compared in this study.

\subsection{Guelph Permeameter}

The Guelph permeameter (GP) is a variation of the shallow well pump-in method. The Guelph permeameter uses an in-iole Mariotte bottle to maintain a constant water level in a shallow auger hole to measure the field saturated hydraulic conductivity (Figure 3 ).

\subsubsection{Theory}

The theoretical analysis for the Guelph permeameter presented below comes from Reynolds et al. (1983) and Reynolds and Elrick (1985). The Guelph permeameter theory is based on flow out of a shallow well constructed with an auger.

The flow from a shaliow well can be described in terms of pressure and gravitational fluxes along the wall and base of the well. Water lilow out of the well can be broken down into three components: (1) radial pressure flux $\left(v_{x p}\right)$ through 


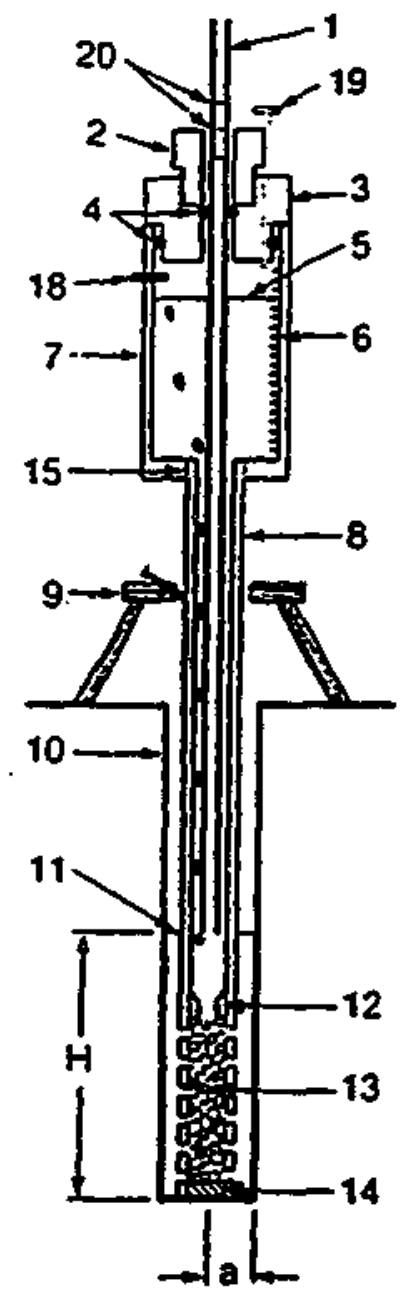

1. air-inlet tube (threaded at base)

2. threaded collat

3. removable cap

4. sliding air-tight seals

5. liquid surface in reservoir

6. measuring scale

7. reservoir tube

8. outlet tube

9. tripod assembly

10. well

11. steady liquid level in well

12. outlet port (threaded)

13. perméameter tip

14. rubber stopper

15. threaded coupling

18. pressure transducer (optional)

19. release valve

20. calibration lines

Figure 3. Schematic of the Guelph permeameter (Reynolds and Elrick, 1986). 
the waIl; (2) vertical pressure flux $\left(v_{\mathrm{zp}}\right)$ through the base; and (3) gravitational flux $\left(v_{3}\right)$ through the base. If flow is assumed to be steady-state in a homogeneous, isotropic, rigid porous medium with a semi-infinite, field saturated flow domain, then the fluxes can be expressed as the Darcy relationships:

$$
\begin{aligned}
& \hat{v}_{x p}=-\left.K_{f s} \frac{\partial \psi_{p}}{\partial x}\right|_{z=s} \hat{z} \\
& \hat{v}_{z p}=-\left.K_{f s} \frac{\partial \psi_{p}}{\partial z}\right|_{z=0} \hat{k} \\
& \bar{v}_{g}=-\left.K_{f s} \frac{\partial \psi_{z}}{\partial z}\right|_{z=0} \hat{k}
\end{aligned}
$$

where $r$ and $z$ are defined in Figure $4, \hat{x}$ and $\hat{k}$ are unit vectors in the positive $r$ and $z$ directions respectively, $\psi_{p}$ is the pore water pressure head, and $\psi_{2}$ is the elevation head relative to the base of the well. The radial pressure gradient is taken at the wall $(r=a)$ and the vertical gradients taken at the base of the well $(z=0)$.

The total flow, $Q$, can tinen be described as:

$$
Q=f_{A_{p}} \bar{v}_{x p} d \bar{A}_{A q}+\int_{A_{b}} \bar{v}_{z p} \mathrm{~d} \bar{A}_{b}+\int_{A_{b}} \bar{v}_{g} \mathrm{~d} \bar{A}_{b}
$$

where $d A_{n}$ and $d A_{b}$ represent the appropriate differential areas of the well wall and base: 


\section{ground surface}

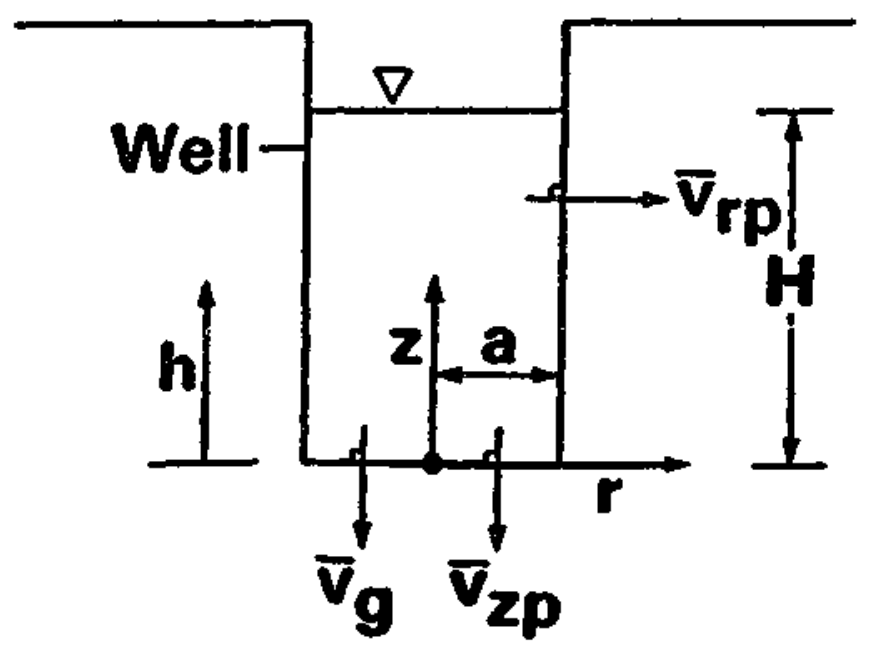

Figure 4. Steady-state flow out of a well situated above the water table (Reynolds et al., 1983). 


$$
\begin{aligned}
& d \bar{A}_{w}=2 \pi a d z(\hat{L}) \\
& d \bar{A}_{b}=2 \pi r d r(-\hat{k})
\end{aligned}
$$

where a is the radius of the well.

By substituting Equations $3.1,3.2,3.3,3.5$, and 3.6 and simplifying, Equation 3.4 becomes:

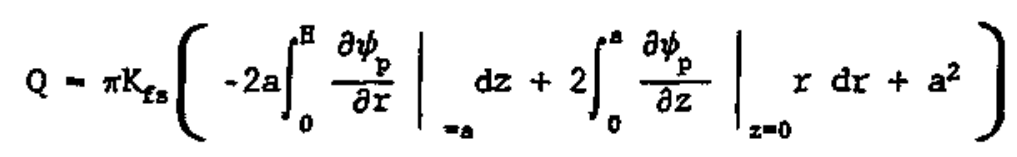

where $\mathrm{H}$ is the constant height of water in the well.

Equation 3.7 can be rewritten as:

$$
Q=\frac{2 \pi H^{2}}{C} K_{f s}+\pi a^{2} K_{f s}+\frac{2 \pi H}{C} \phi_{m s}
$$

where $\phi_{\mathrm{m}}$ is the matric flux potential, and $c$ is a shape factor. The shape factor $c$ is determined from nomographs using the ratio $\mathrm{H} / \mathrm{a}$ and soil type. To determine $\mathrm{K}_{\mathrm{fs}}$, the flow rate (Q) is measured for 2 different depths and the field saturated hydraulic conductivity and matrix flux potential are found by solving simultaneous equations.

\subsection{Velocity Permeameter}

The velocity permeameter (VP) developed and described by Merva $(1979,1987)$ is an improved version of the falling head permeameter (Todd, 1959). The velocity permeameter estimates the field saturated hydraulic conductivity of a core driven 
into the soil in either the vertical or horizontal direction. A schematic diagram of the velocity permeameter is presented in Figure 5. The following theoretical development comes from Merva (1979, 1987).

\subsubsection{Theory}

Darcy's law (Equation 2.2) can be rewritten as:

$$
v_{s}=-K_{s} \frac{h}{s}
$$

where $v_{s}$ is the flux (or velocity) of water passing through the medium in the $s$ direction, $h$ is the head of water causing flow, $s$ is the distance through which the head is dissipated, and $\mathrm{K}$ is the saturated hydraulic conductivity measured in the airection of flow.

When differentiated with respect to head, h, Equation 3.9 becomes:

$$
\frac{\partial v}{\partial h}=-\frac{k_{s}}{s}
$$

By rearranging Equation 3.10:

$$
-\mathrm{K}_{\mathrm{s}}=s \frac{\partial \mathrm{v}}{\partial \mathrm{h}}
$$

it can be seen that the saturated hydraulic conductivity is equal to the rate of change of flux with respect to head multiplied by the distance through which the head is dissipated. 


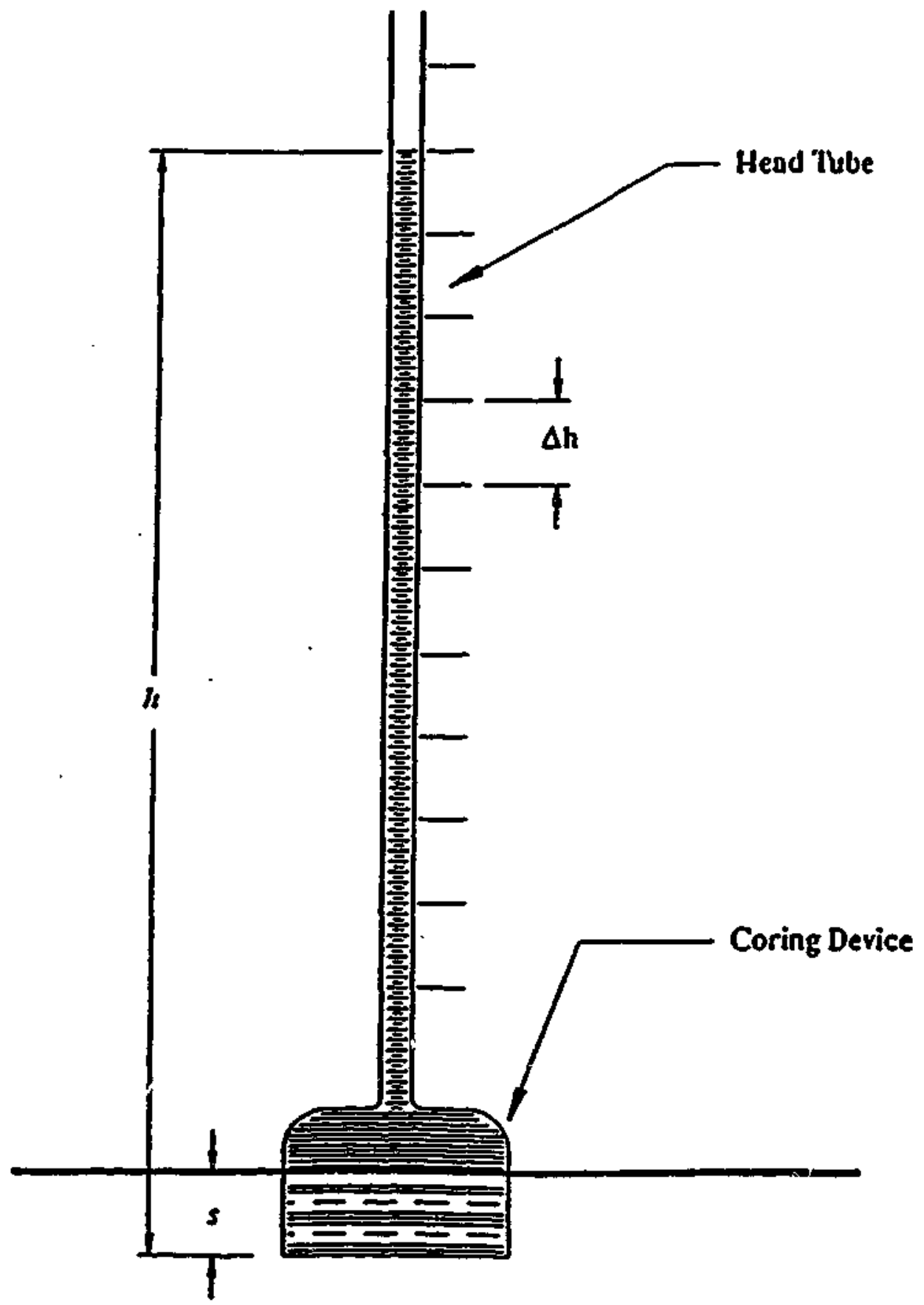

Figure 5. Schematic of velocity permeameter (Merva, 1987). 
The velocity permeameter consists of a manometer (head tube) connected to a soil core in such a way that the rate of fall in the head tube can be calculated as water passes through a known depth of soil in the core. By choosing different combinations of interchangeable head tubes and soil cores, the velocity of water falling in the head tube can be brought within a range which can be measured for a series of consecutive fixed increments measured on the head tube scaie. The slope $\partial \mathrm{v} / \partial \mathrm{h}$ is then found from the change in velocity for successive head increments.

As the water column falls through a head increment, $\Delta h$, in time increment, $\Delta t$, the velocity can be written as:

$$
v-\frac{\Delta h}{\Delta t}
$$

The rate of change of velocity with head is:

$$
\frac{\Delta v}{\Delta h}=\frac{v_{2}-v_{1}}{\Delta h}=\frac{\frac{\Delta h}{\Delta t_{2}}-\frac{\Delta h}{\Delta t_{1}}}{\Delta h}=\frac{1}{\Delta t_{2}}-\frac{1}{\Delta t_{1}}
$$

provided the head increment is held constant.

Using Equation 3.13 , the Iinear least squares curve is found for a sequence of $\Delta v / \Delta h$ readings to estimate the slope $\partial \mathrm{v} / \partial \mathrm{h}$. A copyrighted computer program has been written, to calculate the apparent saturated hydraulic conductivity as the measurements are taken, for field use with a hand-held HP-41 calculator with a time module. By depressing a key on the calculator, the operator stores the times when the water 
column passes each head increment $(\Delta h)$. From a sequence of times $(1 / \Delta t)$, the calculator computes the slope $\partial v / \partial \mathrm{h}$ using a linear least square curve fitting technique.

Also developed into the computer program is a coefficient of determination, $R^{2}$, developed from the least squares determination, which describes the goodness of fit. Merva (1979) suggested that a low $\mathrm{R}^{2}$ does not necessarily mean an incorrect value, but that the data points $1 / \Delta t$ exhibited scatter during the curve fitting procedure.

To determine a single "best" value, a series of hydraulic conductivity determinations are made on the same core. Merva (1987) observed that the appazent hydraulic conductivity values decrease initially until they level out and then increase slightly before continuing to decrease. The "best" value of hydraulic conductivity is determined to be the lowest apparent hydraulic conductivity recorded before the slight increase. This is thought to be the point at which the soil core becomes completely saturated, just before the wetting front moves out of the soil core. Persons interested in obtaining a copy of the computer program should contact Dr. Merva directly at Department of Agricultural Engineering, Michigan State University.

\subsection{Pumping Test Method}

The pumping test method (PTM) is based on the method of "wells and piezometers" developed by Guyon (1964) and 
described by Lesaffre (1987a). This field technique, for measuring saturated hydraulic conductivity where a shallow water table exists, is based on equations similar to those used for drainage design and modeling, and, therefore, may be the most appropriate method available for determining saturated hydraulic conductivity for drainage design. Another advantage to the pumping test method is that the radius of influence, which is several meters large, gives a more "field effective" value.

The pumping test method is a water table drawdown method. A centrally located well (Figure 6) is pumped down to a shallow impermeable layer, if present, and the shape of the cone - * depression is monitored in a series of observation wells. From the drawdown and the rate, of water being pumped, an "equivalent horizontal" hydraulic conductivity can be calculated.

The test can be carried oui: even if no shallow impermeable layer is present (Figure 7). In this case, it is assumed that the soil is homogeneous and that the equivalent horizontal saturated hydraulic conductivity above the bottom of the well is equal to the average hydraulic conductivity below the well.

In addition, the pumping test method allows the operator to determine the drainable porosity-the ratio of the volume of water pumped to the volume of soil drained--which is another important parameter used to describe the soil profile 


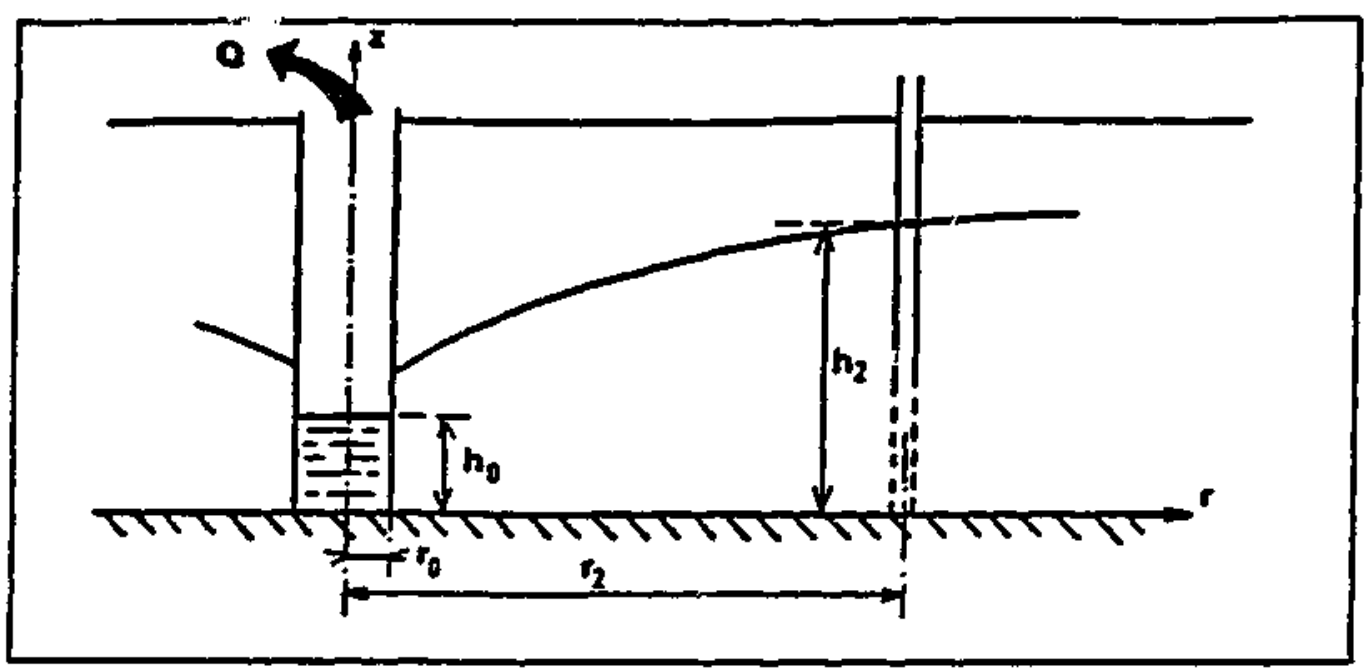

Figure 6. Pumping test method - well reaches impermeable layer (Lesaffre, 1987a).

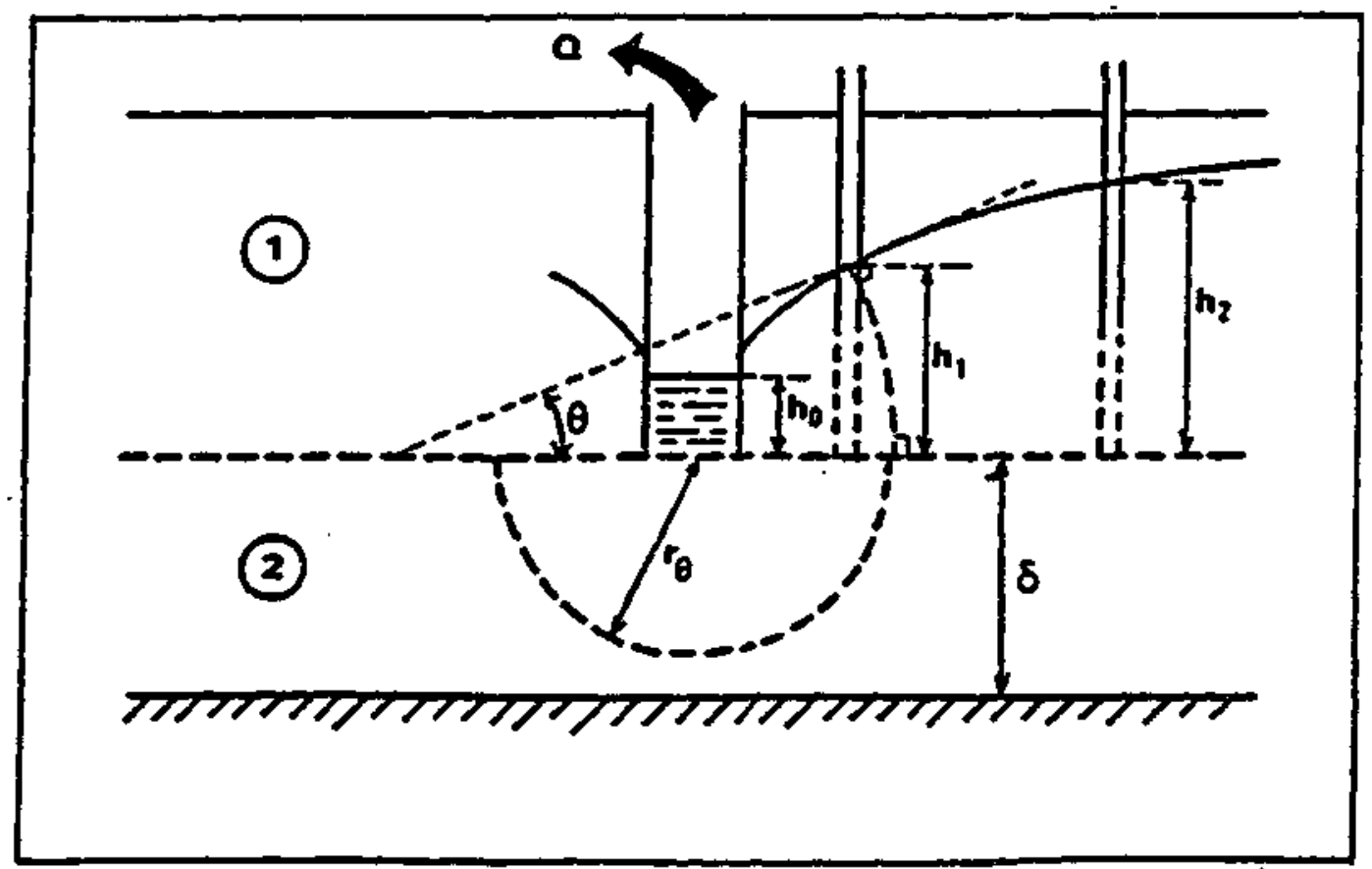

Figure 7. Pumping test method - well does not reach impermeable layer (Iesaffre, 1987a). 
for drainage design. By drawing down the water level in the pumped well in steps, the drainable porosity can be calculated from the volume of water pumped and the water table drawdown during the early dewatering stage.

\subsubsection{Theory When Well Reaches Impermeable Layer}

The theory for determining saturated hydraulic conductivity by the pumping test method is developed from Lesaffre (1987a) unless noted otherwise.

Pumping test theory assumes radial symmetry around the well axis. Determination of saturated hydraulic conductivity begins when steady-state drawdown is reached. The radial component of the saturated flow per unit width through any vertical section, $q(r)$, can be derived from Darcy's law:

$$
q(r)=-\int_{0}^{h(r)} K(z) \frac{\partial \psi(r, z)}{\partial r} d z
$$

where $r$ is the radial coordinate from the well axis, $z$ is the elevation above the impermeable layer, $\psi(r, z)$ is the hydraulic head above the imperiteable layer, $h(r)$ is the water-table height above the impermeable layer, and $K(z)$ is the horizontal component of the depth-dependent hydraulic conductivity.

Using the unit-discharge potential function $F(r)$ :

$$
q(r)=-\frac{d F(r)}{d r}
$$


Equation 3.14 is transformed to:

$$
F(r)=\int_{0}^{h} K(z)(\psi-z) d z
$$

At this point it becomes necessary to use Dupuit's assumption. Dupuit assumed the flow of water to be essentially horizontal everywhere (Childs, 1969). From the orthogonal relation of streamlines to equipotentials, it follows that the equipotentials must be approximately vertical. At the intersection of an equipotential with the water table, the hydrostatic pressure is zero and the potential is just the height, $h(r)$, of the water table above the impermeable layer at that point (Childs, 1969). Dupuit's assumption is sufficiently accurate for distances from the pumping well greater than 1.5 times the depth of the flow domain (Beax and verruijt, 1987), but becomes less valid closex to the pumping well. Substituting $h(r)$ for $\psi(r, z)$ in Equation 3.16 yields:

$$
F(r)=K(h) \frac{h^{2}}{2}
$$

where:

$$
K(h)=\frac{2}{h^{2}} \int_{0}^{h} K(z)(h-z) d z
$$

The parameter $\mathrm{K}(\mathrm{h})$ is the "equivalent horizontal hydraulic conductivity" and is equal to the hydraulic conductivity for homogeneous and isotropic soils. 
The total flow rate through any vertical cylindrical section is equal to the discharge, $Q$, pumped out of the well:

$$
Q=-2 \pi r q(r)
$$

Substituting the expression for $F(r)$ in Equation 3.17 into Zquation 3.15, combining Equations 3.15 and 3.19 , and integrating yields:

$$
\frac{Q}{\pi} \ln \left(\frac{r_{2}}{r_{0}}\right)-h_{2}^{2} K\left(h_{2}\right)-h_{0}^{2} k\left(h_{0}\right)
$$

where $h_{0}$ is the height of water in the pumped well, $h_{2}$ is the height of water in the farthest observation well (well 2), and $r_{2}$ is the distance from the center of the pumped well to observation well 2.

If the soil is homogeneous, Equation 3.20 is used to determine the average saturated hydraulic conductivity. If not, the pumping test is conducted such that the water height inside the pumped well is negligible $\left(h_{0}=0\right)$ and Equation 3.20 becomes:

$$
\mathrm{K}\left(\mathrm{h}_{2}\right)-\frac{\mathrm{Q}}{\pi \mathrm{h}_{2}^{2}} \ln \left(\frac{\mathrm{r}_{2}}{\mathrm{r}_{0}}\right)
$$

3.3.2 Theory when Well Does Not Reach Impermeable Layer When the pumped well does not reach an impermeable layer (Figure 7), the pumped discharge is considered to be the sum 
of two terms, the contributions to flow from above the bottom of the well (zone 1) and below the bottom of the well (zone 2). The soil is assumed to be homogeneous, that is, the equivalent horizontal hydraulic conductivity of zone 1 is assumed equal to the average hydraulic conductivity of zone 2 .

The following equations are taken from Lesaffre (1987a) without the benefit of the theoretical development (Guyon, 1976). The hydraulic conductivity is developed from analytical solutions using $\theta$, the angle of the water table slope in the nearest piezometer. The quantity $A$ is calculated as:

$$
A-\frac{h_{2}^{2}-h_{0}^{2}}{h_{1}^{2} \ln \left(\frac{r_{2}}{r_{0}}\right)}
$$

where $h_{0}, h_{1}$, and $h_{2}$ are water heights above the well bottom in the pumped well, the nearest piezometer, and the farthest piezometer respectively. The angle of the water table slope, $\theta$, is determined from the equation:

$$
A=1-\theta \cot \theta+\frac{r_{1}}{h_{1}} \theta
$$

where $r_{1}$ is the distance from the center of the pumped well to the nearest piezometer. 
If $A\left(h_{1}{ }^{2} / r_{2}{ }^{2}\right)<0.5, \theta$ can be approximated (in radians) as:

$$
\theta-\frac{A h_{2}}{r_{1}}\left(1-\frac{A h_{1}^{2}}{3 r_{1}^{2}}+\frac{2 A^{2} h_{1}^{4}}{9 r_{1}^{4}}\right)
$$

Otherwise, an implicit solution to Equation 3.23 must be found. To accomplish this, the lengths $A\left(h_{1} / x_{1}\right)$ and $A$ are respectively placed along the horizontal and vertical axes of a graph to establish endpoints $M$ and $N$ (Figure 8 ). The curve 1 - $\theta \cot \theta$ is plotted (in radians) and the intersection between this curve and line MN gives $\theta$.

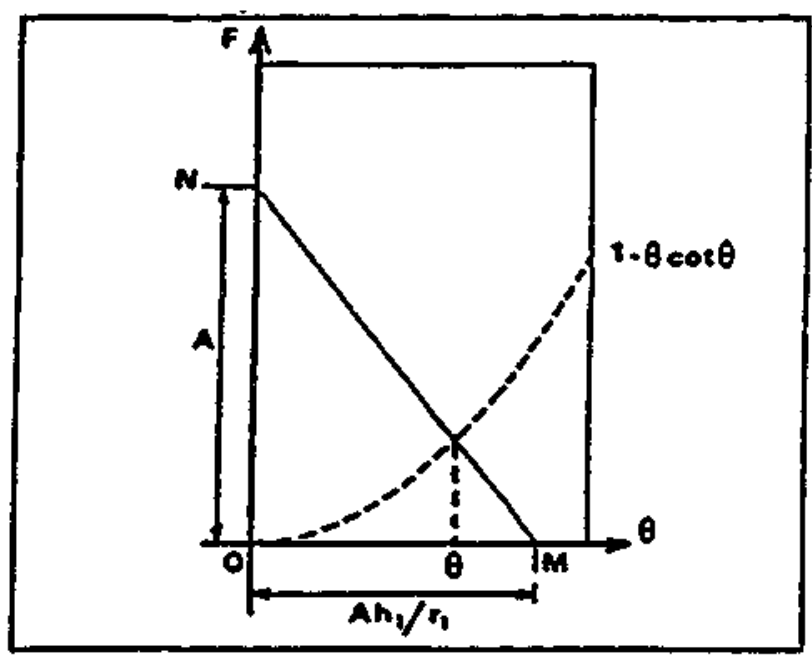

Figure 8. Determination of $\theta$, angle of water table slope at nearer observation well (Lesaffre, 1987a). 
The radius of the spherical potential line through which the contribution of zone 2 flows is calculated from:

$$
r_{\theta}=r_{1}+h_{1} \tan \frac{\theta}{2}
$$

Different calculations are made if the impermeable layer lies within or outside of this radius. If the depth to the impermeable layer, $\delta$, is greater than $r_{\theta}$, then the quantity $B$ is equal to:

$$
\text { B }-2 \mathrm{ah}_{1}^{2}+2 \mathrm{x}_{\theta}^{2} \sin \theta
$$

If on the other hand the depth to the impermeable layer is less than $\mathbf{r}_{\theta}$, B can be determined by:

$$
B=\frac{h_{2}^{2}-h_{0}^{2}}{\ln \left(\frac{x_{2}}{x_{0}}\right)}\left[1+\frac{\delta}{h_{2}}\left(1-\frac{\delta^{4}}{6 r_{2}^{4}}\right)\right]
$$

The saturated hydraulic conductivity is then calculated as:

$$
K=\frac{Q}{\pi B}
$$


CHAPTER IV

EXPERIMIENTAL DESIGN AND PROCEDURE

\subsection{Site Description}

The three techniques previously described were tested at two locations: 3) subirrigation/controlled drainage research plots, Shafter Farm, OARDC, Wooster, on Ravenna silt loam during the summer of 1988, and 2) subirrigation/controlled drainage plots, Vegetable crops Research Branch, OARDC, Fremont, on Hoytville silty clay loam during the spring of 1989 .

Ravenna silt loam is a fine, mixed, mesic Aeric Fragiaqualf formed in the glacial till that characterizes northeastern ohio. The soils range in slope from 0 to 6 percent (test plot is 2 percent) with a subsoil fragipan starting at 35 - $75 \mathrm{~cm}$. Ravenna soils are somewhat poorly drained, marked by seasonal wetness and low permeability. A combination of surface and subsurface drainage is recommended for these soils (USDA-SCS, 1984).

The Hoytville silty clay loam soil found at the Veget:able Crops Branch near Fremont is a variant of the Hoytville series with a higher sand content. Hoytville soils are fine, illitic, mesic Mollic Ochraqualfs. These soils range in slope 
from 0 to 2 percent (test plot is 1 percent) and are high in organic matter. Because of high clay content, these very poorly drained soils have a high shrink-swell potential and low permeability, and are subject to compaction and clodding. They are characterized by seasonal wetness and ponding and require a combination of surface and subsurface drainage for crop production (USDA-SCS, 1987).

\subsection{Experimental Design}

Bouwer and Jackson (1974) suggested that the number of measurements to be taken for characterizing the saturated hydraulic conductivity of a given field depends on the variability of the soil, the desired accuracy, the availability of funds and manpower, and the cost of the measurements in relation to the cost of the drainage system. For drainage design purposes, Doty et al. (1986) recommended one determination for each 2 ha of field area. Both research plots used in this study were less than one-half ha. Because the plots were small, the number of measurements was chosen to give a zufficient number of replicates for comparison purposes. Five or six determinations for each technique are necessary for statistical analysis of a fairly homogeneous research plot (oral communication, ohio state statistics consulting service).

Soil survey maps showed that the research plots were confined to one soil series. In addition, the management 
practices were consistent throughout the field. The assumption was made that, because of the natural heterogeneity of both soils, measurements conducted at one site $(30 \mathrm{~cm}$ apart) would have the same variability as measurements conducted throughout the field (30 m apart). Three test locations were chosen randomly in each research plot (Figures 9 and 10). Backfill trenches over subsurface drains were avoided.

For the purpose of drainage design, the saturated hydraulic conductivity of each distinct soil layer should be determined (skaggs, 1979a). Both the Ravenna and Hoytville soils are common agricultural soils, and as such, have a plow layer in the top $30 \mathrm{~cm}$ of the soil profile. Below the plow layer, both soils have a fairly uniform subsoil that extends below the typical subsurface drainage depth. Therefore, tests should be conducted to characterize the plow layer and the subsoil.

The velocity and Guelph permeameters can measure the hydraulic conductivity of discrete layers. Therefore, tests of both permeameters were conducted in the plow layer at a depth of $20 \mathrm{~cm}$ below the ground surface, and in the subsoil at 2 different depths $(40 \mathrm{~cm}$ and $60 \mathrm{~cm})$. The pumping test method does not provide an estimate of hydraulic conductivity For discrete layers, but provides an estimate of hydraulic conductivity for the soil profile below the water table. A summary of tests conducted is presented in Table 1. 


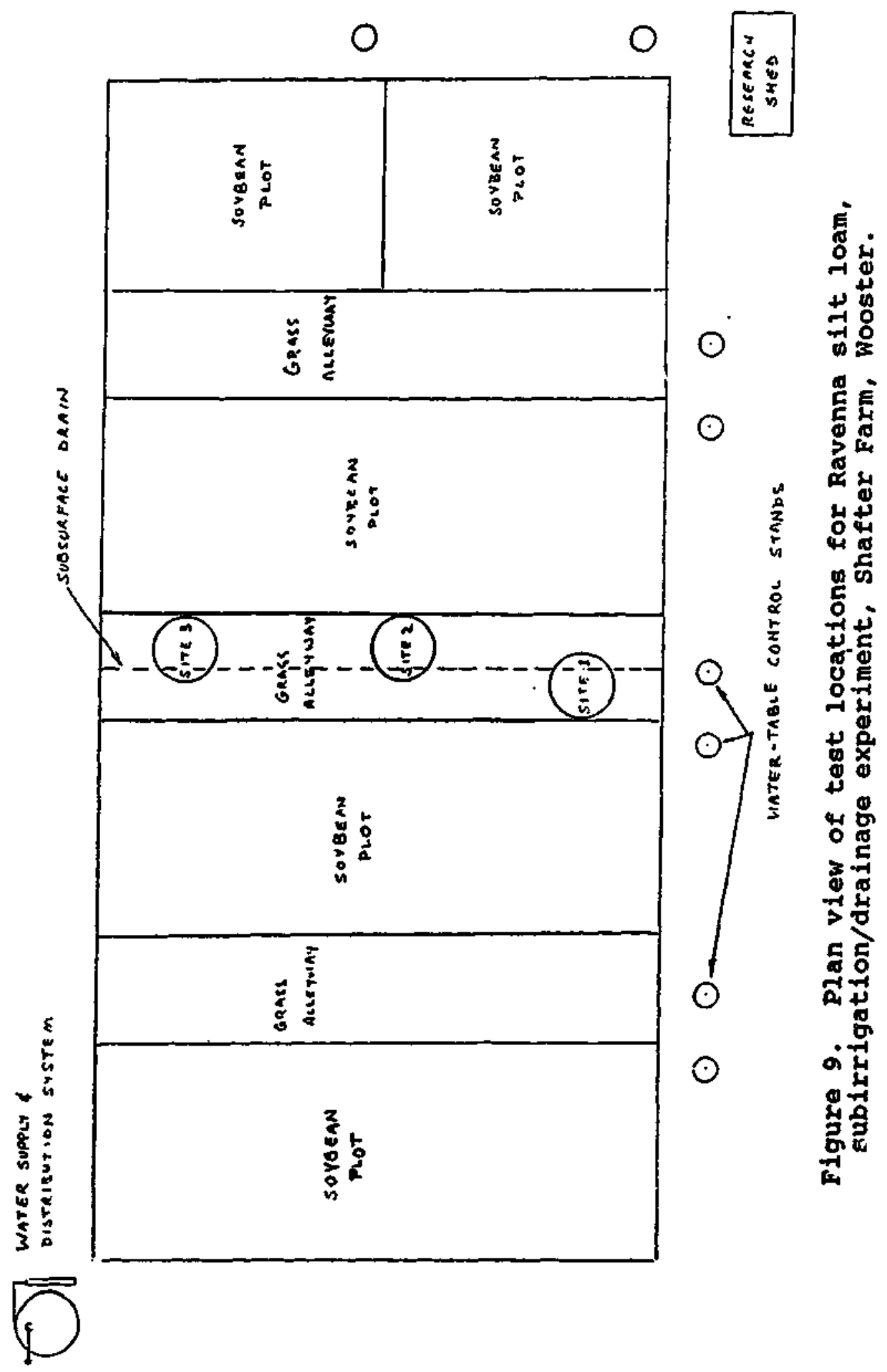




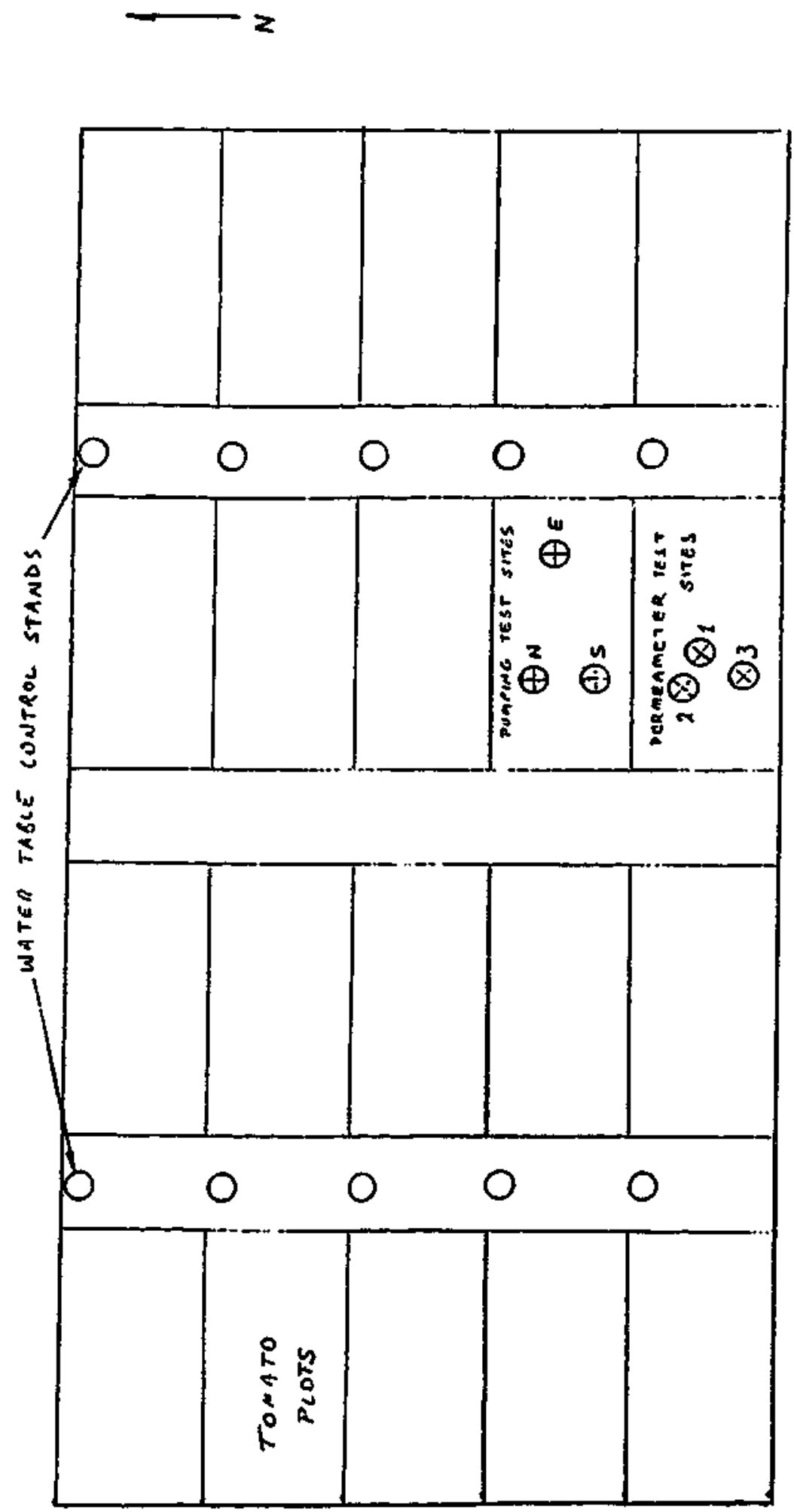


Table 1. Summary of tests conducted at each research location.

\begin{tabular}{|c|c|c|c|c|}
\hline Method & $\#$ & Depth (cm) & sites & Total \\
\hline Pumping Test & 2 & Profile & 3 & 6 \\
\hline $\begin{array}{l}\text { Velocity Permeameter } \\
\text { (vertical) }\end{array}$ & $\begin{array}{l}3 \\
3 \\
3\end{array}$ & $\begin{array}{l}20 \\
40 \\
60\end{array}$ & $\begin{array}{l}3 \\
3 \\
3\end{array}$ & $\begin{array}{r}9 \\
9 \\
\frac{9}{27}\end{array}$ \\
\hline (horizontal) & $\begin{array}{l}2 \\
2 \\
2\end{array}$ & $\begin{array}{l}20 \\
40 \\
60\end{array}$ & $\begin{array}{l}3 \\
3 \\
3\end{array}$ & $\begin{array}{r}6 \\
6 \\
\frac{6}{18}\end{array}$ \\
\hline Guelph Permeameter & $\begin{array}{l}2 \\
2 \\
2\end{array}$ & $\begin{array}{l}20 \\
40 \\
60\end{array}$ & $\begin{array}{l}3 \\
3 \\
3\end{array}$ & $\begin{array}{r}\epsilon \\
6 \\
6 \\
18\end{array}$ \\
\hline \multicolumn{5}{|c|}{$\begin{array}{l}\text { \#- Number of measurements at each site } \\
\text { Depth - Depth below soil surface } \\
\text { Sites - Number of locations in field } \\
\text { Total - Total number of measurements taken }\end{array}$} \\
\hline
\end{tabular}




\subsection{Experimental Procedure}

\subsubsection{Guelph Permeameter}

The procedure followed for determining hydraulic conductivity by the Guelph permeameter method was taken from "2800KI Operating Instructions" included with the Guelph permeameter kit purchased from the SoilMoisture Equipment corporation (Soilmoisture, 1986). Before the site was prepared, the permeameter itself was assembled according to the manual. Before and during site preparation, the soil and site were inspected and a description of the site recorded. Guelph permeameter measurements were conducted at depths of $20 \mathrm{~cm}, 40 \mathrm{~cm}$, and $60 \mathrm{~cm}$ at 3 different sites within each research plot.

Once a site was chosen, the well bore-hole was prepared with the $6 \mathrm{~cm}$ diameter soil auger included in the kit. The hole was augered to 10-15 cm above the test depth. A "sizing auger", also included in the kit, was then used to excavate the final 10-15 $\mathrm{cm}$ while shaping the borehole into a uniform cylindrical geometry. A well preparation brush, with a diameter slightly greater than $6 \mathrm{~cm}$, was then lowered to the bottom of the hole and pulled up (once only) to scour the sides of the well hole and reduce the smear layer caused by augering.

Following hole preparation, the permeameter was placed in the hole (Figure 11). For measurements at 20 and $40 \mathrm{~cm}$, the permeameter was supported by the tripod that comes with 


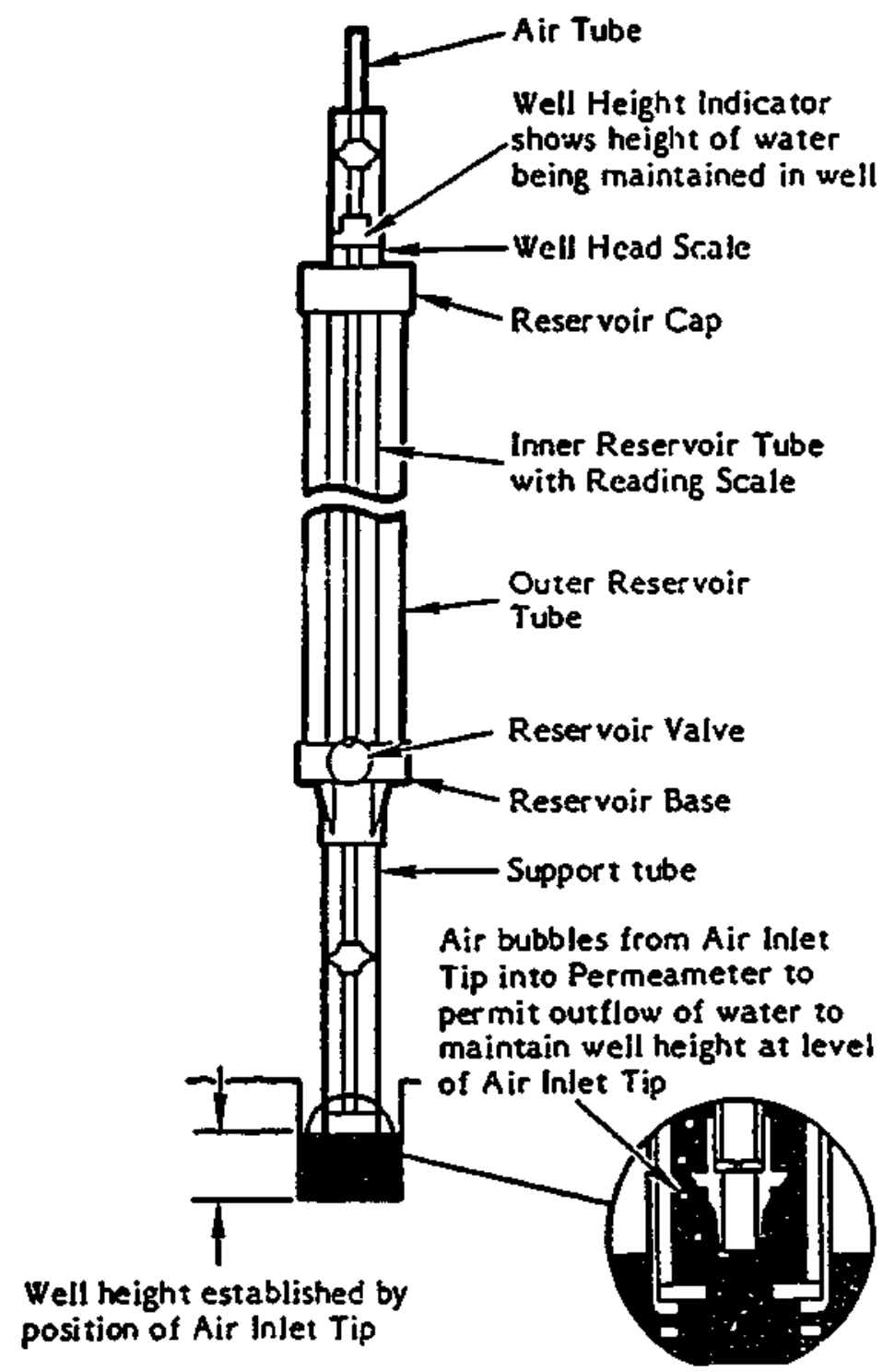

Figure 11. The Guelph permeameter (SoilMoisture, 1986). 
the kit. Pea gravel $(0.5-1.0 \mathrm{~cm}$ diameter $)$ then was placed around the permeameter outlet to a depth of $20 \mathrm{~cm}$ from the bottom of the hole. The pea gravel was used to reduce the size of bubbles moving through the air inlet (providing a more uniform drop in the water level in the permeameter reservoir) and to reduce cavitation of the well hole.

After the permeameter was in place, the reservoir was filled completely with water using the portable water tank that comes with the kit. Guelph permeameter procedures state that pressure effects can be minimized by maintaining a partial vacuum in the air space above the water in the reservoir. This should not be a problem if the reservoir is completely filled at the beginning of the test (which was the procedure followed here) or if the vacuum pump included in the kit is used.

The initial in-hole water level, $\mathrm{H}_{1}$, was then established. The rate of outflow was recorded over a convenient time increment depending on how fast the water was moving into the soil. Once steady state outflow had been reached (i.e. the same outflow rate for 3 successive time periods), the head level was raised for the second reading $\left(\mathrm{H}_{2}\right)$. The outflow rate for $\mathrm{H}_{2}$ was recorded once a new steadystate outflow rate was reached.

Water levels of $\mathrm{H}_{1}=5 \mathrm{~cm}$ and $\mathrm{H}_{2}=10 \mathrm{~cm}$ were used for all measurements on the Ravenna soil. On the heavy clay Hoytville soil, 5 and $10 \mathrm{~cm}$ water levels were used in the plow 
layer, while 10 and $20 \mathrm{~cm}$ water levels were issed for deeper measurements.

Guelph permeameter tests were conducted under a dining canopy, or a specially designed sun shade, to reduce the influence of direct sunlight and temperature fluctuations.

\subsubsection{Velocity Permeameter}

The procedure for taking hyaraulic conductivity measurements with the velocity permeameter vas developed from Merva (1979, 1987). Installation and operation of the velocity permeameter computer program using a HP-4l calculator was carried out according to program instructions obtained directly from Dr. Merva (written communication, 1988). Practical knowledge in the use of the velocity permeameter was provided by Dr. Norman Fausey and John Maul of the USDA-ARS Soil Drainage Research Unit at columbus.

The measurements were conducted at 3 different sites within each research plot. All measurements for one location were taken in one $50 \mathrm{~cm} \times 100 \mathrm{~cm}$ sampling pit. In each sampling pit, measurements were taken at depths of $20 \mathrm{~cm}, 40$ $\mathrm{cm}$, and $60 \mathrm{~cm}$. The pit was initially prepared for tests at the $20 \mathrm{~cm}$ depth. Once measurements were completed for the 20 cm depth, the procedure was repeated at $40 \mathrm{~cm}$ and $60 \mathrm{~cm}$.

At each depth, vertical measurements were taken on 3 different cores and horizontal measurements on 2 different cores, for a total of 15 measurements in one sampling pit. 
The vertical conductivities were taken at the bottom of the pit. The horizontal conductivities were taken in the pit walls.

The pit was initially prepared for vertical measurements. Using a spade, the pit was dug to a depth $5 \mathrm{~cm}$ less than the test depth (eg. $15 \mathrm{~cm}$ for tests at $20 \mathrm{~cm}$ depth), making sure to minimize disturbance of the sample area. A garden hoe was then used to create a level surface in the bottom of the pit at $2 \mathrm{~cm}$ above the test depth $(\mathrm{eg} .18 \mathrm{~cm}$ depth for $20 \mathrm{~cm}$ tests) .

Next, the $7.6 \mathrm{~cm}$ diameter soil core was pressed into the pit bottom with a drop hammer to a depth of $2 \mathrm{~cm}$, so that the bottom of the soil core was located at the test depth. The soil core was then wiggled and broken off to create a rough, unsmeared surface at the test depth. The soil was removed from the soil core, and the core replaced on the same site where it had been removed.

The length of the soil sample in the soil core was required in order to calculate the hydraulic conductivity. Before insertion, an initial height from the top of the core to the sample surface was taken. The core was then driven into the soil approximately an additional $5 \mathrm{~cm}$ with the drop hammer. The height to the top of the core was measured again and the difference between the first reading and the second reading recorded as the core length. 
After the soil core was in place, the head tube manometer was attached (Figure 12). The coring tube comes fitted with a quick release coupler to facilitate attachment. A pressurized source of water (a portable sprayer) was then used to fill the coring tube with water through a special water inlet valve similar to the water inlet of an air-entry permeameter. The time when water was first applied to the soil sample was recorded. When water entered the bottom of the head tube, the water level was raised slowly to force out entrapped air. After the air was removed, the water valve was closed and the water column allowed to fall in a trial run.

At this point, a judgement was made on whether the head tube was the appropriate size, or needed to be replaced by a smaller or larger tube based on the rate of fall. If the fall was too fast for the timing button on the calculator to be pressed every $10 \mathrm{~cm}$ or less of fall, then a larger tube was attached to slow the rate of fall. If on the other hand the rate of fall was so slow that the timer could be pressed repeatediy during a 1 or $2 \mathrm{~cm}$ drop, a smaller head tube was attached which increased the rate of fall. Trial runs were continued until the appropriate size head tube was found.

once the appropriate set-up was in place, the site information was entered into the calculator computer program. This information consisted of site number, direction (vertical or horizontal), core length, coring tube size (small, medium, or large - corresponding to the diameters of available coring 


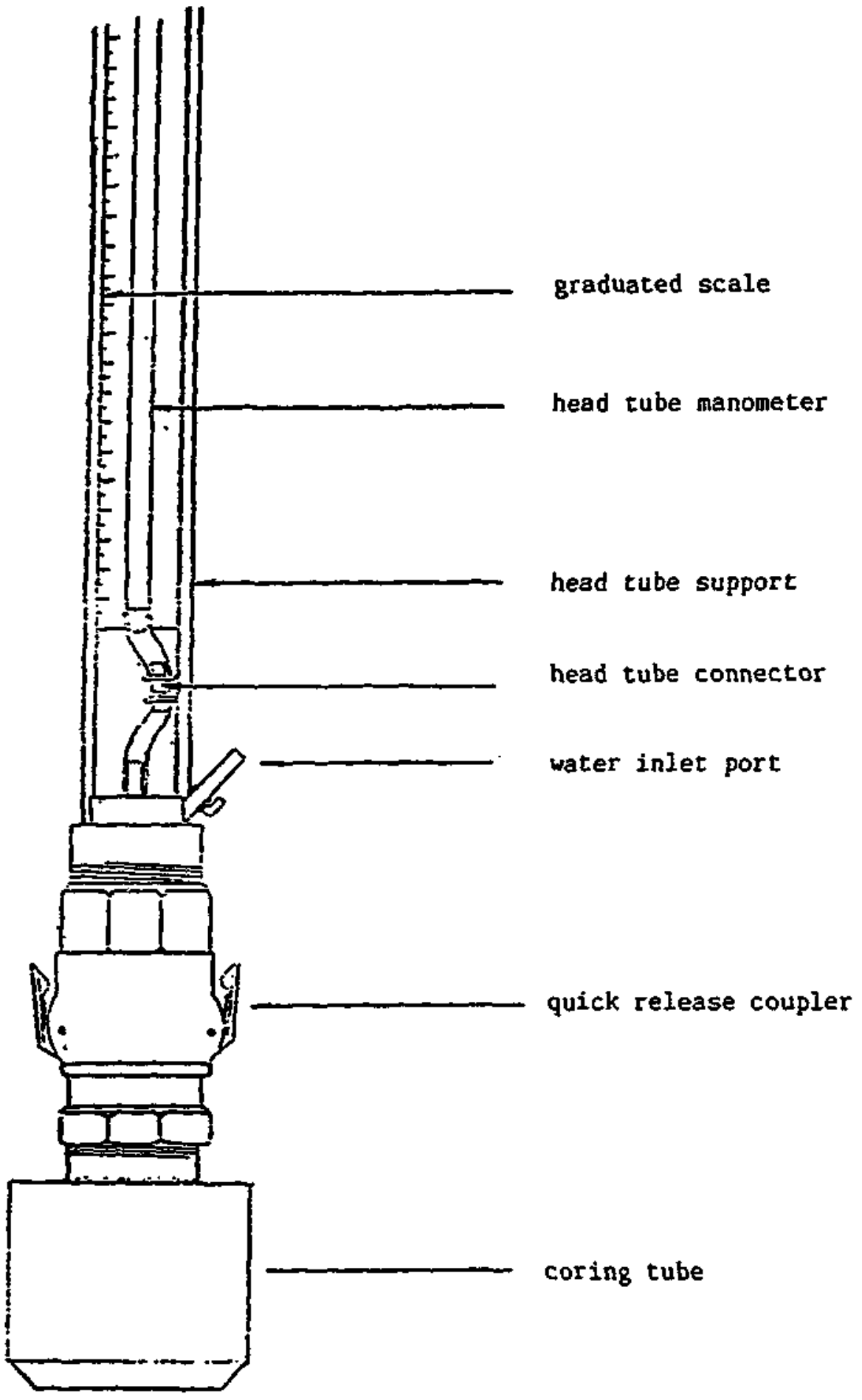

Figure 12. The velocity permeameter. 
tubes already stored in the program), and head tube size (small, medium, or large - also corresponding to the diameters of available head tubes already stored in the program).

A single measurement was then taken by raising the water to the top of the head tube and closing the water inlet valve so the water in the head tube fell as water was forced through the soil sample. An appropriate head increment (usually between $2.5 \mathrm{~cm}$ and $10 \mathrm{~cm}$ ) was determined from the final trial run. The program was started as the water passed some point near the top of the head tube. The timer button was then depressed as the water passed the chosen increment, and depressed each time the water level passed an additional increment for at least 5 increments. After the last time increment was entered, the caiculator computed an apparent hydraulic conductivity value and $R^{2}$ value.

A series of measurements were taken by refilling the head tube and repeating the procedure. Repeated readings were taken on the same soil core until the apparent hydraulic conductivity reached some asymptotic value. The velocity permeameter method usually yielded a final value within 15-20 minutes with a maximum of about 30 minutes.

Horizontal measurements were taken following completion of the vertical measurements. The pit was dug about $10 \mathrm{~cm}$ below the desired depth (eg. $30 \mathrm{~cm}$ for $20 \mathrm{~cm}$ depth measurements). Horizontal measurements were taken such that the middle of the soil core was at the test depth. Again, the 
core was pressed about $2 \mathrm{~cm}$ into the wall and wiggled to remove the smeared pit wall. Once the soil was removed from the core, the core was replaced from where it was removed and was pushed into the pit wall using a screw press braced against the far side of the pit. The depth that the sample was pressed into the pit wall was measured to determine the core length. The rest of the horizontal test was completed following the same procedure as for the vertical test.

\subsubsection{Pumping Test Method}

The tests and calculations were carried out according to "average hydraulic conductivity when the well does not reach the barrier", as described by Lesaffre (1987a) . The procedure for the pumping test method as described by Lesaffre is not very specific and left many aspects open to interpretation. Where deviations were made, their justification is presented.

Preparation included making, wrapping, installing, and developing the pumping well and observation wells. The wells were fashioned from schedule 40 pvc tubing. One deviation from the procedure described by Lesaffre (1987a) was the use of observation wells, slotted the entire length below the surface, instead of piezometers. Observation wells were used to provide an estimate of the saturated hydraulic conductivity for the soil profile from the bottom of the plow layer to a depth of $1.2 \mathrm{~m}$. 
The distance from the ground surface to the impermeable layer at Wooster was approximately $10 \mathrm{~m}$ and at Fremont $2.3 \mathrm{~m}$. Installation of wells to these depths was not feasible with the equipment available, so partially penetrating wells were installed. In addition, fully penetrating wells slotted along their entire length would produce results which reflected the influence of hydraulic conductivity values at or near the impermeable layers. For drainage design, the hydraulic conductivity of the soil profile to a depth of $1.2 \mathrm{~m}$ is most important. Therefore, fully penetrating wells might not give the most accurate estimate of hydraulic conductivity that regulates flow to subsurface drains.

The observation wells were made of $1.88 \mathrm{~cm}(0.75$ inch) inside diameter PVC tubing. This pipe was chosen because the smaller the well diameter, the quicker they would respond to changes in the water table, and $1.88 \mathrm{~cm}$ was the smallest diameter pipe that would still accommodate a blow tube (for measuring water table depth). The tubing for the pumping well was chosen to be $5 \mathrm{~cm}$ (ID), because that was the maximum tube size that would fit in a hole prepared with the largest available auger $(7 \mathrm{~cm}$ diameter). All wells were cut to a length of $150 \mathrm{~cm}$.

Holes were drilled in all of the pipes to allow water entry (or exit). In the observation wells, $0.5 \mathrm{~cm}$ diameter holes were drilled $2.5 \mathrm{~cm}$ apart in four lengthwise rows along the bottom $120 \mathrm{~cm}$ of the pipe. For the pumping well tube, 
$1.25 \mathrm{~cm}$ diameter holes were drilled every $2.5 \mathrm{~cm}$ apart in four lengthwise rows along the bottom $100 \mathrm{~cm}$ of the pipe.

Completed pipes were then wrapped once with Typar landscape fabric as a filter to reduce sediment movement into and out of the wells. It is recommended that observation wells have a casing to block sediment from moving in and out of the well. Because a cased well was too expensive for our budget, an alternative method for keeping sediment out of the wells was needed. Typar was chosen after discussion with drainage professionals at ADS (Advanced Drainage Systems) who use Typar as a sediment filter around subsurface drains.

The layout used for the wells is presented in Figure 13. Once the pumping well was installed, observation wells were installed at $0.5,1.0,2.0$, and $3.0 \mathrm{~m}$ from the pumping well in four directions 90 degrees apart (to check for anisotropy). on the Hoytville soil, additional wells were installed at 0.25 and $0.75 \mathrm{~m}$ from the pumping well at 45 degree angles (between the cther lines of wells) to describe water table drawdown near the pumping well in greater detail. The observation wells were installed in holes prepared with a $2.5 \mathrm{~cm}$ diameter auger and then surrounded by a sand filter. The $5 \mathrm{~cm}$ pumping well tube was placed in a hole prepared by a $7 \mathrm{~cm}$ diameter auger and packed with a sand filter. All wells were installed to a depth of $120 \mathrm{~cm}$. The elevations of the tops of all the observation wells and the pumping well were found with respect 


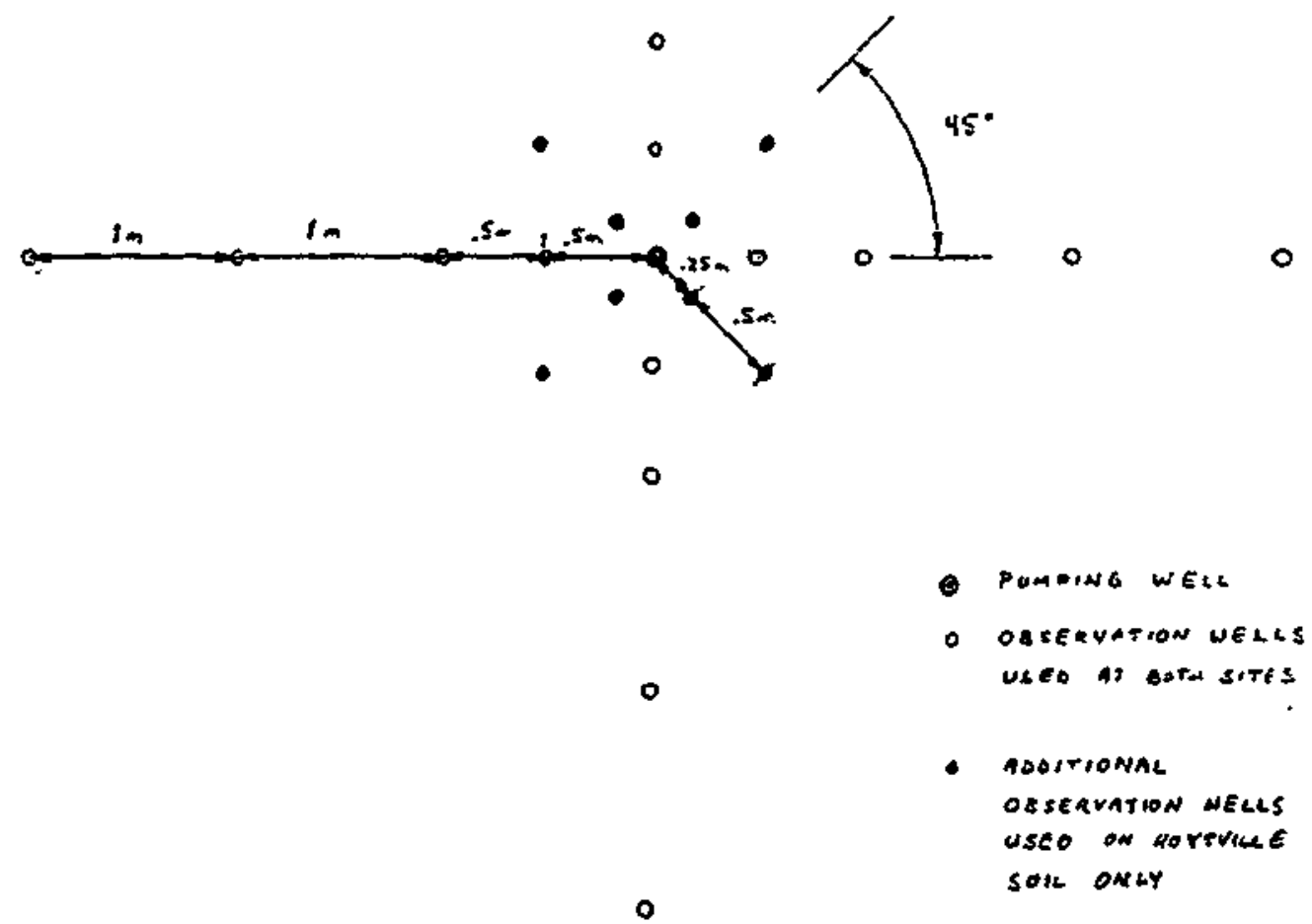

Figure 13. Plan view of pumping test set-up. 
to the ground surface at the pumping well in order to calculate drawdowns from a common groundwater surface.

Surge blocks to develop the wells were manufactured by Department of Agricultural Engineering shop personnel. Pointed blocks of $1.75 \mathrm{~cm}$ and $4.5 \mathrm{~cm}$ diameters were made from heavy steel rod to develop the observation wells and the pumping well, respectively. A rope was attached to the nonpointed end to recover the surge blocks. After the wells were installed, they were developed with the surge blocks by dropping the block into the water, allowing it to sink all the way to the bottom of the well and rapidly pulling the block back to the surface. This process was repeated ten times for each well.

The pumping test required a pump and power source, as well as a way to measure the outflow and purping rate. The pumps that were used were peristaltic pumps (MasterFlex Model 7953) with a maximum pumping rate of $0.31 / \mathrm{min}$. Power for the pumps was provided by an on-site power supply at each research site. Outflow was measured with 2 liter graduated plastic cylinders and elapsed time was kept with a stopwatch.

Using the pumping test method, two repetitions of the steady-state test for hydraulic conductivity were taken at each of three different sites within the research plot. Before pumping began, water table readings were taken in all wells with a blow tube. For hydraulic conductivity determinations, the water level in the central well was pumped 
down as near to the bottom of the well as possible. Water table readings were taken every 30 minutes to determine drawdown in all the observation wells. Pumping was continued until the water levels in the observation wells were stable over a period of twu hours, implying steady-state conditions. The volume of water pumped during each 30-minute period also was measured to determine outflow rate. once the water table stabilized, the steady-state outflow rate was determined as the rate that did not change through successive 30-minute periods.

Because of concern that the homemade well tube used in the pumping test method might affect flow into the well or the level of water in the well, this method was repeated at one site after the pumping well tube had been removed. 


\section{CHAPTER V \\ RESULTS AND DISCUSSION}

In this section, the saturated hydraulic conductivity data developed from field measurements using the pumping test method, the velocity permeameter, and the Guelph permeameter are presented. To meet the first objective of this study, the data for the different techniques are compared. Observations developed from field experience, including problems encountered in conducting tests, are presented in a discussion of the methods. This section concludes with a general discussion on measuring saturated hydraulic conductivity for drainage purposes, with an emphasis on the methods presented in this study.

\subsection{Results}

Calculations of hydraulic conductivity were carried out to several significant figures. However, because of the uncertainties associated with saturated hydraulic conductivity determinations, the data may not be meaningful past one, possibly two, significant digits. The hydraulic conductivity values are presented to two significant digits. 
5.1.1 Pumping Test Kethod

pumping test method data are presented in Table 2 . The research design called for two repetitions at three differcnt locations for each soil. The data for one pumping test on the Hoytville soil were omitted because of well failure. Because this set-up failed, additional tests were conducted on the other two installations to bring the total number of tests on the Hoytville soil to seven.

Table 2. Pumping test method data.

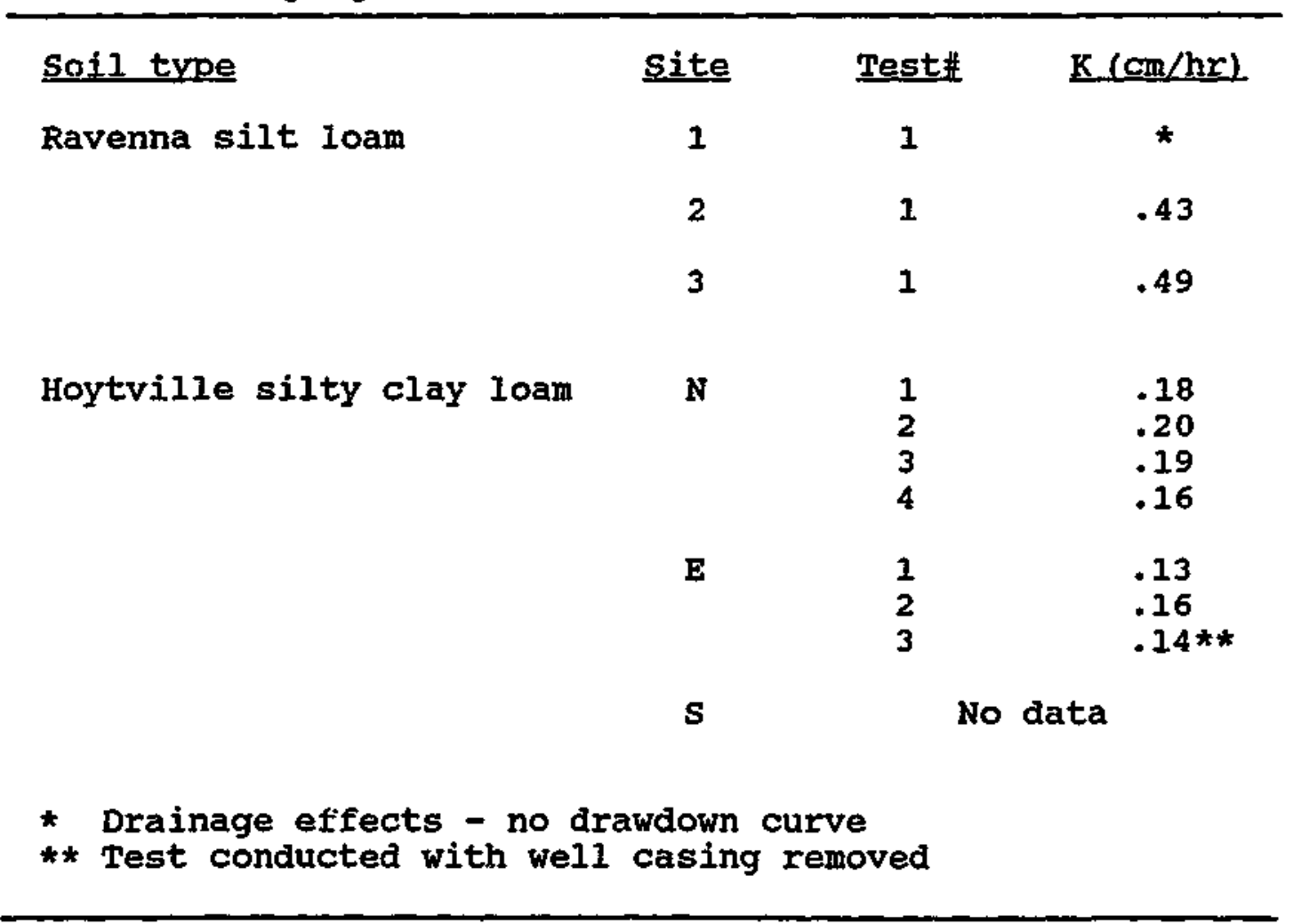


Only three of six measurements were completed on the Ravenna soil (one at each of three different locations in the field) due to time constraints. of the three tests completed, two provided a steady-state drawdown curve. Data for the other test were omitted because the pumping well was installed too near a subsurface drain (see *, Table 2). Water was pumped from the drain rather than from the water table around the well and steady state drawdown was never attained. This problem was only discovered after the tests were completed.

\subsubsection{Velocity Permeameter Method}

Velocity permeameter method data for the Ravenna soil and the Hoytville soil are presented in Tables 3 and 4 , respectively. Each value represents the geometric mean of the three lowest apparent saturated hydraulic conductivity determinations for each soil core. The reason for this method of estimation is explained in section 5.3.2. Several values of hydraulic conductivity determined by the velocity permeameter are not included in the statistical analysis because of problems that also are addressed in section 5.3.2. These values are denoted by $*, * *$, and $* * *$ in Tables 3 and 4 .

\subsubsection{Guelph Permeameter Method}

Guelph permeameter data for both locations are presented in Table 5. The one negative value obtained from measurements 
Table 3. Velocity permeameter method data - Ravenna silt loam.

Direction \& Depth (cm)

Vertical

20

$$
\begin{aligned}
& 1 \\
& 2 \\
& 3
\end{aligned}
$$

40

$$
\begin{aligned}
& 1 \\
& 2 \\
& 3
\end{aligned}
$$$$
3
$$

60

1
2
3

Horizontal

20

$$
\begin{aligned}
& 1 \\
& 2 \\
& 3
\end{aligned}
$$

40

60

$$
\begin{aligned}
& 1 \\
& 2 \\
& 3
\end{aligned}
$$

1

2

3

$$
\begin{aligned}
& 2.5 \\
& 4.5 *
\end{aligned}
$$$$
\text { 17. } 0 \text { * }
$$

0.057

2.7

1.7

0.041

1.3

0.36
2.1

17. 0 *

24 . 0 *

1.8

2.0

2.3

0.46

0.75

1.1
1.6

3.5

17.0 *

0.40

1.4

1.0

0.095

0.42

2.2

\section{3}


Table 4. Velocity permeameter method data - Hoytville silty clay loam.

Depth (cm)

Vertical

20

40

60

$$
\begin{aligned}
& 1 \\
& 2 \\
& 3
\end{aligned}
$$

1.2

2.4

0.38

0.067

$27.0 *$

26.0*

0.77
$5.7 *$
0.96

0.49

0.30

1.7
0.067
$15.0 *$ ***
0.19
0.10
$2.6 * t *$
$29.0 *$

0.020

1.4

6.4

0.042

$23.0 *$

0.36

0.097

$3.6 * * *$

1.7

Horizontal

20

$\begin{array}{lll}1 & 0.39 & 4.9 * \\ 2 & 0.030 * * & 0.30 \\ 3 & 0.054 & 0.10\end{array}$

40

$\begin{array}{lll}1 & 0.10 & 0.082 \\ 2 & 0.027 & 0.65 \\ 3 & 0.39 & 0.20\end{array}$

60

$\begin{array}{lll}1 & 3.5 * & 0.034 \\ 2 & 0.84 & 0.33 \\ 3 & 2.3 & 2.5\end{array}$

* pore connected to surface

** unsteady rate of fall

*** subsurface drain effects 
Table 5. Guelph permeameter method data.

\begin{tabular}{|c|c|c|c|c|}
\hline soil type & Depth (cm) & Site & Test\# & $\mathrm{R}(\mathrm{cm} / \mathrm{hr})$ \\
\hline \multirow[t]{3}{*}{ Ravenna silt loam } & 20 & $\begin{array}{l}\dot{1} \\
2 \\
3\end{array}$ & $\begin{array}{l}1 \\
2 \\
1 \\
2 \\
1 \\
2\end{array}$ & $\begin{array}{l}0.25 \\
\text { No data } \\
1.9 \\
0.048 \\
0.20 \\
0.56\end{array}$ \\
\hline & 40 & $\begin{array}{l}1 \\
2 \\
3\end{array}$ & $\begin{array}{l}1 \\
2 \\
1 \\
2 \\
1 \\
2\end{array}$ & $\begin{array}{l}0.0098 \\
\text { No data } \\
0.36 \\
0.011 \\
0.43 \\
0.014\end{array}$ \\
\hline & 60 & $\begin{array}{l}1 \\
2 \\
3\end{array}$ & $\begin{array}{l}1 \\
2 \\
1 \\
2 \\
1 \\
2\end{array}$ & $\begin{array}{l}0.084 \\
-0.021 * \\
0.15 \\
\text { No data } \\
0.0032 \\
0.055\end{array}$ \\
\hline \multirow[t]{3}{*}{$\begin{array}{l}\text { Hoytville silty } \\
\text { clay loam }\end{array}$} & 20 & $\begin{array}{l}1 \\
2 \\
3\end{array}$ & $\begin{array}{l}1 \\
1 \\
1\end{array}$ & $\begin{array}{l}0.12 \\
0.68 \\
0.0086\end{array}$ \\
\hline & 40 & $\begin{array}{l}1 \\
2 \\
3\end{array}$ & $\begin{array}{l}1 \\
1 \\
1\end{array}$ & $\begin{array}{l}0.0030 \\
0.0025 \\
\text { No data }\end{array}$ \\
\hline & 60 & $\begin{array}{l}1 \\
2 \\
3\end{array}$ & $\begin{array}{l}1 \\
1 \\
1\end{array}$ & $\begin{array}{l}0.016 \\
0.00076 \\
0.0053\end{array}$ \\
\hline * negative value - & omitted frc & site & average & \\
\hline
\end{tabular}


with the Guelph permeameter (see * in Table 5) was not included in site averages.

\subsection{Comparison of Results}

Saturated hydraulic conductivity data are summarized in Tables 6 and 7. The geometric mean of the saturated hydraulic conductivity data for each method are presented, as well as the range of values and the number of samples. Bouwer and Jackson (1974) presented justification for using the geometric mean of hydraulic conductivity values to represent a site. Values determined by the auger hole method and soil survey estimates from Wayne and Sandusky Counties are included for comparison.

Saturated hydraulic conductivity estimates determined by either permeameter are for a distinct depth below the ground surface. In contrast, hydraulic conductivity estimates by the pumping test method are for the soil profile from a depth of approximately $30 \mathrm{~cm}$ to a depth of 100 to $120 \mathrm{~cm}$. So that they could be compared to the pumping test data, the values determined at depths of 40 and $60 \mathrm{~cm}$ by each permeameter were combined. The geometric mean of these combined values are presented as a profile hydraulic conductivity.

To statistically compare methods, a non-parametric median test was selected to test the hypothesis that the values determined by two or more methods are different. In the median test, the saturated hydraulic conductivity values of 
Table 6. Summary of saturated hydraulic conductivity data Ravenna silt loam.

\begin{tabular}{|c|c|c|c|c|c|}
\hline Depth (CM) & Method & \# & $\frac{\text { Mean } \mathrm{K}}{(\mathrm{cm} / \mathrm{hr})}$ & Range & of $K$ \\
\hline 20 & $\begin{array}{l}\text { GP } \\
\text { VP (V) } \\
\text { VP (H) } \\
\text { VP (ave) } \\
\text { survey }\end{array}$ & $\begin{array}{r}5 \\
4 \\
6 \\
10 \\
-\end{array}$ & $\begin{array}{l}0.30 \\
2.33 \\
0.14 \\
0.43 \\
-.--\end{array}$ & $\begin{array}{l}0.048 \\
1.6 \\
0.060 \\
0.060 \\
1.5\end{array}$ & $\begin{array}{l}-1.9 \\
-3.5 \\
-0.45 \\
-3.5 \\
-5.0\end{array}$ \\
\hline 40 & $\begin{array}{l}\text { GP } \\
\text { VP (V) } \\
\text { VP (H) } \\
\text { VP (ave) }\end{array}$ & $\begin{array}{r}5 \\
9 \\
6 \\
15\end{array}$ & $\begin{array}{l}0.074 \\
1.03 \\
0.28 \\
0.61\end{array}$ & $\begin{array}{l}0.0098 \\
0.057 \\
0.12 \\
0.057\end{array}$ & $\begin{array}{l}3-0.43 \\
-2.7 \\
-0.60 \\
-2.7\end{array}$ \\
\hline 60 & $\begin{array}{l}\text { GP } \\
\text { VP (V) } \\
\text { VP (H) } \\
\text { VP (ave) }\end{array}$ & $\begin{array}{r}4 \\
9 \\
6 \\
15\end{array}$ & $\begin{array}{l}0.055 \\
0.44 \\
0.15 \\
0.29\end{array}$ & $\begin{array}{l}0.0032 \\
0.041 \\
0.048 \\
0.041\end{array}$ & $\begin{array}{l}2-0.23 \\
-2.2 \\
-0.87 \\
-2.2\end{array}$ \\
\hline Profile & $\begin{array}{l}\text { GP } \\
\text { VP(V) } \\
\text { VP(H) } \\
\text { VP(ave) } \\
\text { PTM } \\
\text { Auger } \\
\text { Survey }\end{array}$ & $\begin{array}{r}9 \\
18 \\
12 \\
30 \\
2 \\
6\end{array}$ & $\begin{array}{l}0.065 \\
0.67 \\
0.21 \\
0.42 \\
0.46 \\
0.29 \\
-.-2\end{array}$ & $\begin{array}{l}0.0032 \\
0.041 \\
0.048 \\
0.041 \\
0.43 \\
0.071 \\
0.15\end{array}$ & $\begin{array}{l}-0.016 \\
-2.7 \\
-0.87 \\
-2.7 \\
-0.49 \\
-1.3 \\
-0.5\end{array}$ \\
\hline
\end{tabular}

\# - number of measurements

Mean $\mathrm{K}$ - geometric mean of hydraulic conductivity values

GP - Guelph permeameter

VP(V) - velocity permeameter (vertica1)

VP(H) - velocity permeameter (horizontal)

VP(ave) - velocity permeameter (geometric mean of $\mathrm{V}$ and $\mathrm{H}$ ) PTM - pumping test method

Auger - auger hole method

Survey - Wayne county Soil Survey estimate 
Table 7. Summary of saturated hydraulic conductivity data Hoytville silty clay loam.

\begin{tabular}{|c|c|c|c|c|}
\hline Depth_(cm) & Method & \# & $\frac{\text { Mean K }}{(\mathrm{cm} / \mathrm{hr})}$ & Range of $\mathrm{K}$ \\
\hline 20 & $\begin{array}{l}\text { GP } \\
\text { VP(V) } \\
\text { VP(H) } \\
\text { VP (ave) } \\
\text { Survey }\end{array}$ & $\begin{array}{r}3 \\
7 \\
4 \\
15 \\
-\end{array}$ & $\begin{array}{l}0.090 \\
0.87 \\
0.16 \\
0.44 \\
\end{array}$ & $\begin{array}{l}0.0086-0.68 \\
0.020-26.0 \\
0.054-0.39 \\
0.020-26.0 \\
0.5-5.0\end{array}$ \\
\hline 40 & $\begin{array}{l}\text { GP } \\
\text { VP (V) } \\
\text { VP (H) } \\
\text { VP (ave) }\end{array}$ & $\begin{array}{r}2 \\
7 \\
6 \\
13\end{array}$ & $\begin{array}{l}0.0028 \\
0.43 \\
0.15 \\
0.28\end{array}$ & $\begin{array}{l}0.0025-0.0030 \\
0.042-1.7 \\
0.027=0.65 \\
0.027-1.7\end{array}$ \\
\hline 60 & $\begin{array}{l}\text { GP } \\
\text { VP (V) } \\
\text { VP (H) } \\
\text { VP (ave) }\end{array}$ & $\begin{array}{r}3 \\
5 \\
5 \\
10\end{array}$ & $\begin{array}{l}0.0039 \\
0.41 \\
0.55 \\
0.44\end{array}$ & $\begin{array}{l}0.0010-0.016 \\
0.067-3.6 \\
0.034=2.5 \\
0.034=3.6\end{array}$ \\
\hline Profile & $\begin{array}{l}\text { GP } \\
\text { VP (V) } \\
\text { VP (H) } \\
\text { VP (ave) } \\
\text { PMM } \\
\text { Auger } \\
\text { Survey }\end{array}$ & $\begin{array}{r}5 \\
12 \\
11 \\
23 \\
7 \\
4\end{array}$ & $\begin{array}{l}0.0034 \\
0.42 \\
0.27 \\
0.35 \\
0.16 \\
0.25 \\
-.--\end{array}$ & $\begin{array}{l}0.0010-0.016 \\
0.042-3.6 \\
0.027-2.5 \\
0.027-3.6 \\
0.13-0.20 \\
0.057-1.3 \\
0.5-1.5\end{array}$ \\
\hline
\end{tabular}

\# - number of measurements

Mean $\mathrm{K}$ - geometric mean of hydraulic conductivity values

GP - Guelph permeameter

VP(V) - velocity permeameter (vertical)

VP(H) - velocity permeameter (horizontal)

VP(ave) - velocity permeameter (geometric mean of $\mathrm{V}$ and $\mathrm{H}$ ) PTM - pumping test method

Auger - auger hole method

Survey - Sandusky county soil survey estimate 
the methods being compared are ranked from lowest to highest and the median value is found. Based on the total number of values represented by each method, the number of values expected to fall above the median is specified. The ratio of the number of values that actually fall above the median to the number of values expected to fall above the median is established for each method. A chi-square $\left(x^{2}\right)$ analysis is then conducted on these ratios. The analysis returns a probability that the chi-square value will be exceeded, which can then be interpreted to determine if the techniques are different at a chosen level of confidence.

The results of the statistical analysis are presented in Tables 8 and 9. For this comparison, two techniques were taken to be different if the probability of exceeding the chisquare value was less than 0.10 . This is equivalent to stating that two techniques are different at a 90 percent level of confidence. The higher the probability that the chisquare value is exceeded, the more likely that the values of saturated hydraulic conductivity estimated by different methods are not significantly different. Consultants from the Ohio State University Statistics Consulting Service suggested that the number of saturated hydraulic conductivity values used in the statistical analysis of this study were sufficient to conclude whether two techniques' were significantly different, but were not sufficient to determine conclusively if two techniques were the same. 
Table 8. Statistical comparison of saturated hydraulic conductivity data - Ravenna silt loam.

Depth (cm) Method 1 Method 2 Prob $>x^{2}$ Different

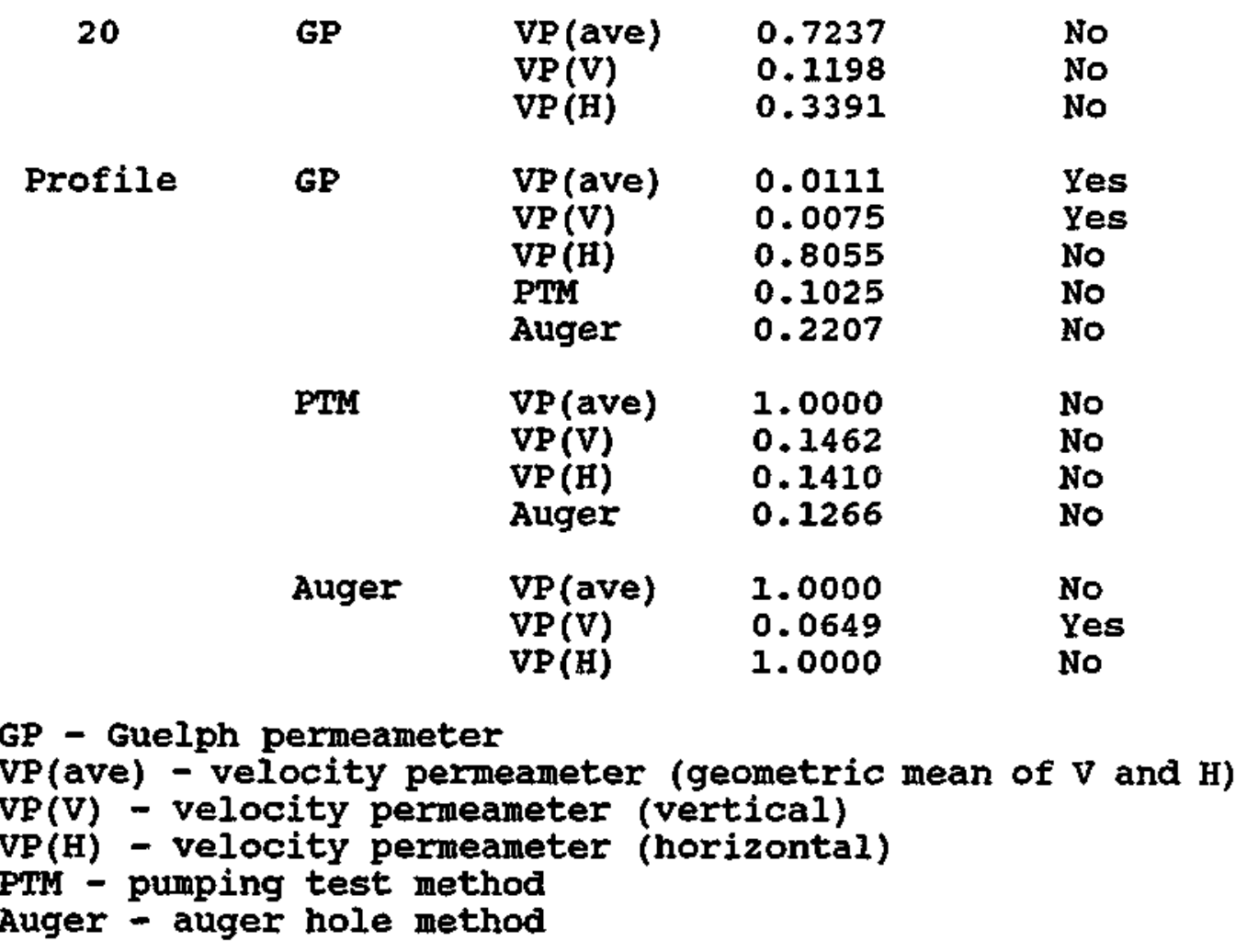


Table 9. Statistical comparison of saturated hydraulic conductivity data - Hoytville silty clay loam.

Depth (cm) Method 1 Method 2 prob $>x^{2}$ Different

20

GP

VP (ave)

$\mathrm{VP}(\mathrm{V})$

$\mathrm{VP}(\mathrm{H})$

0.6171

0.0771

0.6831

No

Yes

No

Profile

GP

VP (ave)

0.0160

0.0162

0.0090

VP (H)

PTM

0.0051

luger

0.0047

Yes

Yes

Yes

Yes

Yes

PIM

VP (ave)

VP (V)

VP (H)

Auger

0.0353

0.0348

0.1587

0.1568

Yes

Yes

No

No

Auger

VP (ave)

0.9418

0.5078

VP (V)

0.8802

No

No

No

GP - Guelph permeameter

VP(ave) - velocity permeameter (geometric mean of $\mathrm{V}$ and $\mathrm{H}$ )

VP(V) - velocity permeameter (vertical)

VP(H) - velocity permeameter (horizontal)

PIM - pumping test method

Auger - auger hole method 
With one exception (pumping test method versus velocity permeameter on the Hoytville soil), values determined by the auger hole, pumping test, and velocity permeameter methods are not statistically different. Profile geometric mean hydraulic conductivity values determined by the pumping test method, velocity permeameter method, and auger hole method all fell between 0.20 and $0.70 \mathrm{~cm} / \mathrm{hr}$ for the Ravenna soil, and between 0.15 and $0.45 \mathrm{~cm} / \mathrm{hr}$ for the Hoytville soil. These values compare favorably to the $0.15-0.5 \mathrm{~cm} / \mathrm{hr}$ soil survey estimate for the Ravenna soil, but fall below the $0.5-1.5 \mathrm{~cm} / \mathrm{hr}$ soil survey estimate for the Hoytville soil.

The statistical analysis showed best agreement between values determined by horizontal velocity permeameter and auger hole measurements. At both locations, profile geometric mean hydraulic conductivities determined by horizontal velocity permeameter tests were very close to values determined by the auger hole method (Ravenna: horizontal velocity permeameter $0.21 \mathrm{~cm} / \mathrm{hr}$, auger hole method - $0.29 \mathrm{~cm} / \mathrm{hr}$; Hoytville: horizontal velocity permeameter $-0.27 \mathrm{~cm} / \mathrm{hr}$, auger hole method $-0.25 \mathrm{~cm} / \mathrm{hr}$ ). This is not surprising, because the auger hole method predominantly measures the horizontal hydraulic conductivity near the auger hole.

For both soils, tire geometric mean hydraulic conductivity based on Guelph permeameter measurements was lower than the values found by all other techniques. Even though the profile geometric mean saturated hydraulic conductivity value 
determined by the Guelph permeameter on the Ravenna soil was not statistically aifferent from the pumping test, auger hole, or horizontal velocity permeameter values, this value was only fifteen to twenty percent of values obtained from the other methods. On the heavy clay Hoytville soil, the profile saturated hydraulic conductivity value determined by the Guelph permeameter method is significantly lower than the values determined by the other methods and soil survey estimates. The profile geometric mean hydraulic conductivity determined by the Guelph permeameter is statistically different from the auger hole, pumping test, and profile velocity permeameter values. Values of saturated hydraulic conductivity for the plow layer determined by Guelph permeameter measurements showed good agreement with velocity permeameter values for the plow layer, and in particular, with horizontal velocity permeameter values.

It is possible, however unlikely, that the low profile saturated hydraulic conductivity values found with the Guelph permeameter represent the ability of the soil to transmit water to subsurface drains. The only way to determine which value is most appropriate would be to compare the results presented here to the hydraulic conductivity calculated from drain outflow measurements. 


\subsection{Discussion}

A discussion of the results for each technique is presented, followed by some general observations on all techniques.

\subsubsection{Pumping Test Method}

The data for one pumping test on the Hoytville soil were omitted because, despite pumping for several hours, the water level in the observation wells did not respond and the maximum volume of water that could be pumped was about $2 \mathrm{cc} / \mathrm{min}$ compared to more than $100 \mathrm{cc} / \mathrm{min}$ at the other two sites. The failure was probably caused by smearing of the sides of the bore hole during well preparation. The well for the failed pumping test was installed in very moist soil above the water table, whereas the other two were installed after the water table was brought near the surface. The piston-like action of the auger in the wells below the water table apparently worked to develop those wells.

variability in results was very low for the pt'jing test method (see Tible 2, p86). Whereas the range of saturated hydraulic conductivity values for the Guelph and velocity perneameters covered several orders of magnitude at both sites, the highest saturated hydraulic conductivity value determined by the pumping test method was 160 percent of the lowest value for the Hoytville soil, and 115 percent for the Ravenna soil. This can be attributed to the volume of soil 
sampled by the method. The pumping test method estimates the saturated hydraulic conductivity of a volume measuring several cubic meters, thus reducing the effects of local heterogeneity (i.e. cracks, macropores, etc.).

Precision of readings from the pumping test method was high. Outflow was measured in a graduated cylinder, to the nearest $10 \mathrm{ml}$ over the course of at least 15 minutes. The error from misreading the volume pumped by $20 \mathrm{ml}$ is a low percentage of flow (2 percent) and can be assumed to be negligible. Another possible source of operator error is the depth to water measured in the observation wells. A blow tube was ursed, which was graduated in centimeters. measurements were read to within $1 \mathrm{~cm}$. Error in reading water levels would have the greatest effect in the farthest piezometers where drawdown is smallest. A 1 cm error in drawdown at an observation well 2 in from the pumping well would result in a maximum error of about 10 percent.

Because of concern that the homemade well tube used in the pumping test method might affect flow into the well or the level of water in the well, this method was repeated at one site after the well tube had been removed (see ** in Table 2). The value of saturated hydraulic conductivity obtained with no well tube $(0.14 \mathrm{~cm} / \mathrm{hr})$ fell between the values determined in tests with the well tube in place $(0.13 \& 0.16 \mathrm{~cm} / \mathrm{hr})$, suggesting that the effect of the well tube may have been negligible. 
Values for individual measurements by the pumping test were to be calculated from the average drawdowns in observation wells at 0.5 and $2.0 \mathrm{~m}$ from the pumping well as recommended by Lesaffre (1987a). However, the water level in several observation wells never changed in response to pumping, presumably because of problems encountered during hole preparation. In addition, several other observation wells stopped working during the course of running tests. still other observation wells began working at some point during tests after initially showing no response to pumping. A list of which observation wells worked for each test is presented in Table 10. Observation wells at 0.5 and $2.0 \mathrm{~m}$ from the pumping well provided usable data at only site $E$ on the Hoytville soil. At other sites, data obtained from functional observation wells was used in calculations. The combinations of observation wells used for saturated hydraulic conductivity calculations at each site are presented in Table 11.

Additionally, in several cases, no saturated hydraulic conductivity value could be estimated for a single direction from the pumping well, because one or more observation wells in that direction failed. Therefore, the saturated hydraulic conductivity values presented in the results section (Table 2) were calculated from the (arithmetic) average drawdown of all working observation wells at the specified distances. 
Table 10. List of properly functioning observation wells for pumping tests.

\begin{tabular}{|c|c|c|c|c|c|}
\hline Soil & site & Test & \multicolumn{3}{|c|}{$\begin{array}{l}\text { Observation wells at (cm) } \\
\underline{25} \underline{50} \quad \underline{75}\end{array}$} \\
\hline \multirow[t]{2}{*}{ Ravenna silt loam } & 1 & $I$ & - & $\mathbf{N}$ & - \\
\hline & 2 & 1 & - & $\mathbf{S}, \mathrm{N}$ & - \\
\hline \multirow[t]{2}{*}{$\begin{array}{l}\text { Hoytville silty } \\
\text { clay loam }\end{array}$} & $\mathbf{N}$ & $\begin{array}{l}1 \\
2 \\
3 \\
4\end{array}$ & $\begin{array}{l}\mathrm{NE}, \mathrm{NW} \\
\mathrm{NE}, \mathrm{NW} \\
\mathrm{NE}, \mathrm{NW} \\
\text {, }\end{array}$ & $\begin{array}{l}- \\
S \\
S \\
s\end{array}$ & $\begin{array}{r}\mathrm{SW}, \mathrm{SE}, \mathrm{NE} \\
\mathrm{SW}, \mathrm{SE}, \mathrm{NE} \\
\mathrm{SW}, \mathrm{SE}, \mathrm{NE} \\
\mathrm{SW}, \mathrm{SE}\end{array}$ \\
\hline & $\mathbf{E}$ & $\begin{array}{l}1 \\
2 \\
3\end{array}$ & $\begin{array}{l}\mathrm{SW}, \mathrm{NE} \\
\mathrm{SW}, \mathrm{NE} \\
\mathrm{SW}, \mathrm{NE}\end{array}$ & $\begin{array}{l}S, N, w, E \\
S, N, w, E \\
S, N, w, E\end{array}$ & $\begin{array}{l}- \\
\text { NW }\end{array}$ \\
\hline soil & Site & Test & $\begin{array}{l}\text { Observ } \\
\underline{100}\end{array}$ & $\begin{array}{c}\text { tion wells } \\
\underline{200}\end{array}$ & at $\begin{array}{r}(\mathrm{cm}) \\
\underline{300}\end{array}$ \\
\hline \multirow[t]{2}{*}{ Ravenna silt loam } & 1 & 1 & $\mathbf{S}, \mathbf{N}, \mathbf{E}$ & $S, N$ & - \\
\hline & 2 & 1 & $\mathbf{S}, \mathbf{N}$ & $\mathbf{N}$ & $\mathbf{S}, \mathrm{N}$ \\
\hline \multirow[t]{2}{*}{$\begin{array}{l}\text { Hoytville silty } \\
\text { clay loam }\end{array}$} & $\mathbf{N}$ & $\begin{array}{l}1 \\
2 \\
3 \\
4\end{array}$ & $\begin{array}{l}S, W, E \\
S, N, E \\
S, N, E \\
S, N, E\end{array}$ & $\begin{array}{l}N, E \\
N, E \\
N, E \\
N, E\end{array}$ & $\begin{array}{l}- \\
- \\
-\end{array}$ \\
\hline & $\mathbf{E}$ & $\begin{array}{l}1 \\
2 \\
3\end{array}$ & $\begin{array}{l}W \\
W \\
W\end{array}$ & $\begin{array}{c}N, W \\
S, N, W \\
S, N\end{array}$ & $\begin{array}{l}- \\
-\end{array}$ \\
\hline
\end{tabular}


Table 11. Observation wells used in pumping test method calculations.

\begin{tabular}{|c|c|c|c|}
\hline soil & site & $\mathrm{B}_{1}(\mathrm{~cm})$ & $\underline{\mathrm{R}}_{2 \mathrm{~m}}(\mathrm{Cm})$ \\
\hline Ravenna silt loam & $\frac{1}{2}$ & $\begin{array}{l}100 \\
100\end{array}$ & $\begin{array}{l}200 \\
300\end{array}$ \\
\hline $\begin{array}{l}\text { Hoytville silty } \\
\text { clay loasn }\end{array}$ & $\begin{array}{l}\mathbf{N} \\
\mathbf{E}\end{array}$ & $\begin{array}{r}100 \\
50\end{array}$ & $\begin{array}{l}200 \\
200\end{array}$ \\
\hline \multicolumn{4}{|c|}{$\begin{array}{l}R_{1} \text { - distance to nearest observation wells } \\
R_{2} \text { - distance to farthest observation wells }\end{array}$} \\
\hline
\end{tabular}


Two questions come to mind when considering this situation: (1) does the distance from the purning well of the two observation wells used for calculations have any bearing on the saturated hydraulic conductivity value obtained; and (2) does the direction of the line of observation wells used have any bearing on the value obtained.

To address the first question, saturated hydraulic conductivity values calculated from pairs of observation wells at 0.25 and $0.75 \mathrm{~m}, 0.5$ and $1.0 \mathrm{~m}, 1.0$ and $2.0 \mathrm{~m}$, and 0.5 and $2.0 \mathrm{~m}$ were compared for two sites on the Hoytville soil (Table 12). The values obtained were similar, except for the 0.5 and $2.0 \mathrm{~m}$ pair which was less than 40 percent higher in all cases. To address the second question, saturated hydraulic conductivity values calculated from lines of observation wells pointing in different directions were compared for two sites on the Hoytville soil (Table 13). The largest variation between directions was found between the observation wells pointing north and those pointing south at site $E$. The saturated hydraulic conductivity value determined by using the north wells was higher, by up to 50 percent, than the value from the south wells in 3 consecutive tests. Other values compared between different directions were much closer (less than 20 percent difference) suggesting that the saturated hydraulic conductivity value was practically the same in all directions. 
Table 12. Estimated saturated hydraulic conductivity values for Hoytville silty clay loam using different sets of observation wells.

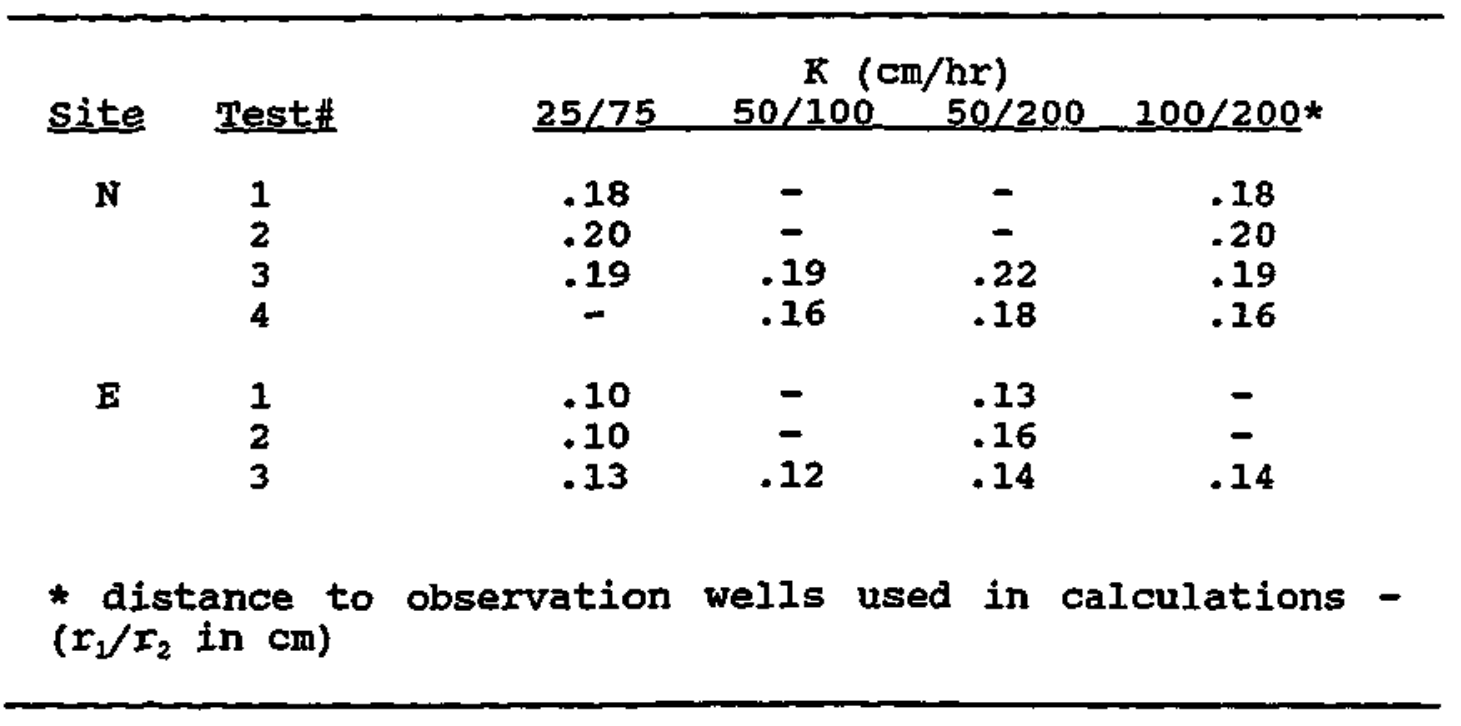


Table 13. Estimated saturated hyöraulic conductivity values for Hoytville silty clay loam using observation wells in different directions.

\begin{tabular}{|c|c|c|c|c|c|}
\hline site & Test\# & Direction & $\mathrm{R}_{3}$ & $\underline{\mathbf{R}}_{2}$ & $\underline{\mathrm{K}}(\mathrm{cm} / \mathrm{hr})$ \\
\hline \multirow[t]{3}{*}{$\mathbf{N}$} & 2 & $\begin{array}{l}\text { N } \\
\text { E } \\
\text { All }\end{array}$ & 100 & 200 & $\begin{array}{l}.15 \\
.17 \\
.16\end{array}$ \\
\hline & 3 & $\begin{array}{l}\mathbf{N} \\
\text { E } \\
\text { All }\end{array}$ & 100 & 200 & $\begin{array}{l}.18 \\
.21 \\
.19\end{array}$ \\
\hline & 4 & $\begin{array}{l}\text { N } \\
\text { E } \\
\text { AlI }\end{array}$ & 100 & 200 & $\begin{array}{l}.19 \\
.21 \\
.20\end{array}$ \\
\hline \multirow[t]{3}{*}{$\mathbf{E}$} & 1 & $\begin{array}{l}N \\
\text { E } \\
\text { S } \\
\text { W } \\
\text { All }\end{array}$ & 50 & 200 & $\begin{array}{l}.14 \\
.14 \\
.13 \\
.10 \\
.13\end{array}$ \\
\hline & 2 & $\begin{array}{l}N \\
\text { S } \\
\text { All }\end{array}$ & 50 & 200 & $\begin{array}{l}.18 \\
.14 \\
.16\end{array}$ \\
\hline & 3 & $\begin{array}{l}\text { N } \\
\text { S } \\
\text { AII }\end{array}$ & 50 & 200 & $\begin{array}{l}.22 \\
.14 \\
.14\end{array}$ \\
\hline
\end{tabular}


Freeze and Cherry (1979) siated that the "nonuniqueness" of the interpretation of pumping test data is a disadvantage of the method. Unless the hydrogeological system is explicitly known, the data may be based on erroneous assumptions. Leaky confined and bounded situations may appear as an unconfined groundwater flow system. Add to that the effects of delayed yield and partial penetration and the system becomes even harder to define. Time-drawdown plots were developed from data from pumping tests at Fremont to check for delayed yield (see example, Figure 14). No significant effect was detected.

Saturated hydraulic conductivity values, using the same water table drawdown data and a fully penetrating well equation (Lesaffre, 1987a), were calculated and compared to the saturated hydraulic conductivity values obtained using the partially penetrating well formula. This comparison was conducted to determine the sensitivity of saturated hydraulic conductivity values to using fully penetrating well calculations in situations where the pumping well does not reach the impermeable layer, because, in many cases, the depth to the impermeable layer is unknown. The values determined from the fully penetrating well calculations were about 200 percent of the values determined from partially penetrating calculations for two locations on the Hoytville soil (Table 14). This is expected because the fully penetrating calculations neglect the flow contribution from below the 


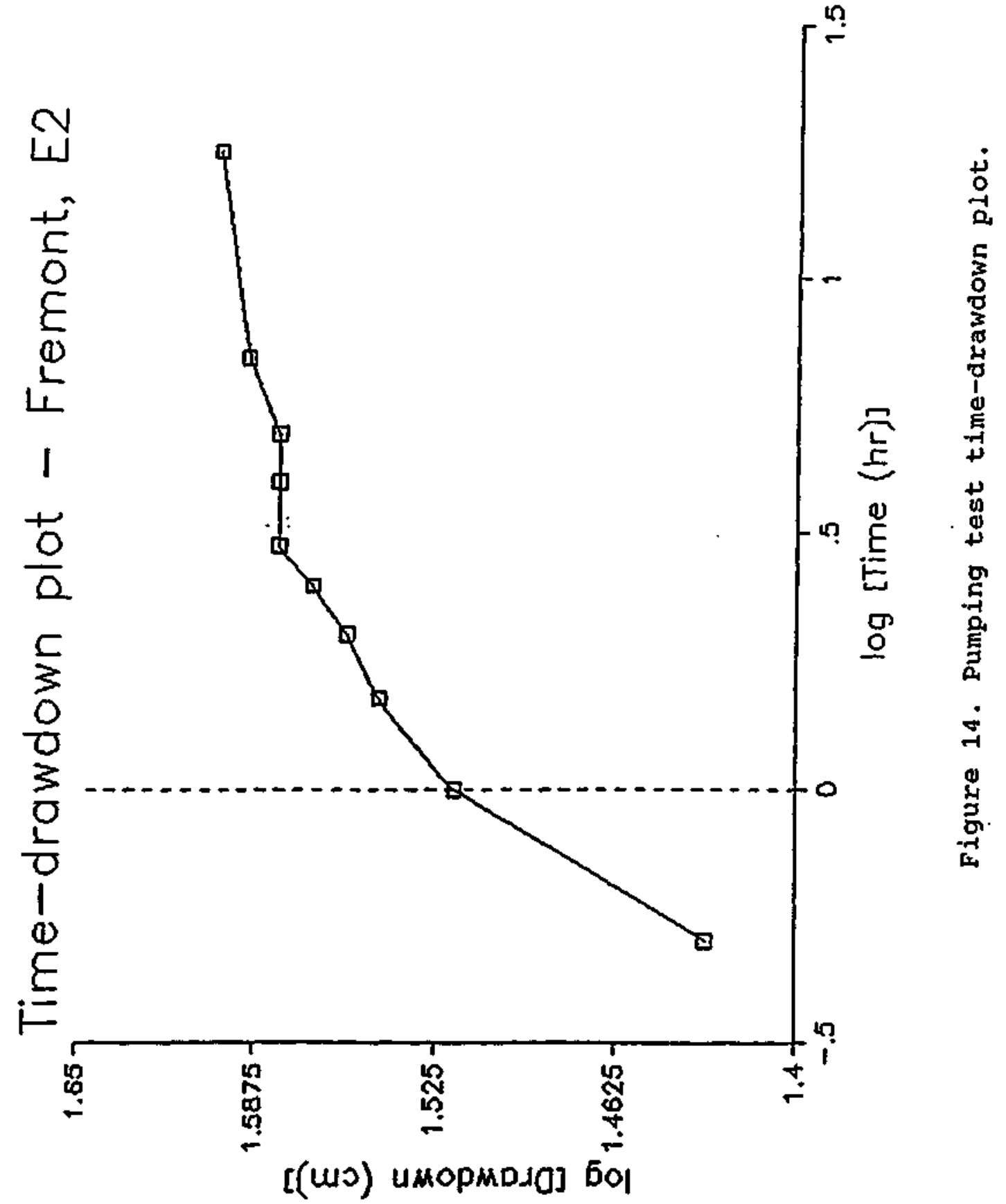


Table 14. Comparison of saturated hydraulic conductivity values determined by fully and partially penetrating well calculations using pumping test data for Hoytville silty clay loam.

\begin{tabular}{|c|c|c|c|c|}
\hline Site & Test\# & $\begin{array}{r}\mathrm{K} \\
\text { Ful11y }\end{array}$ & $\begin{array}{l}\text { (cm/hr) } \\
\text { partially }\end{array}$ & $\underline{\mathrm{K}}_{\mathrm{F}} / \underline{\mathrm{K}}_{\mathrm{P}}$ \\
\hline $\mathbf{N}$ & $\begin{array}{l}1 \\
2 \\
3 \\
4\end{array}$ & $\begin{array}{r}.36 \\
.39 \\
.39 \\
.32\end{array}$ & $\begin{array}{l}.18 \\
.20 \\
.19 \\
.16\end{array}$ & $\begin{array}{l}2.0 \\
2.0 \\
2.1 \\
2.0\end{array}$ \\
\hline $\mathbf{E}$ & $\begin{array}{l}1 \\
2 \\
3\end{array}$ & $\begin{array}{r}.25 \\
.32 \\
.30\end{array}$ & $\begin{array}{r}.13 \\
.16 \\
.14\end{array}$ & $\begin{array}{l}1.9 \\
2.0 \\
2.1\end{array}$ \\
\hline
\end{tabular}

Table 15. Profile saturated hydraulic conductivity values for Hoytville silty clay loam.

\begin{tabular}{ll}
\hline & $\mathrm{K}$ (cm/hr) \\
& \\
Pumping test (fully penetrating) & .32 \\
Pumping test (partially penetrating) & .16 \\
& .0034 \\
Guelph permeameter & .42 \\
Velocity permeameter (vertical) & .27 \\
Velocity permeameter (horizontal) & .35 \\
Velocity permeameter (average) & .25 \\
Auger hole & \\
\hline
\end{tabular}


wells. A 200 percent difference in saturated hydraulic conductivity values falls well within the variability of other methods of determining saturated hydraulic conductivity. The saturated hydraulic conductivity values determined using fully penetrating well calculations are actually closer to the saturated hydraulic conductivity values determined by the auger hole and velocity permeameter methods for the Hoytville soil than values determined by partially penetrating well calculations (Table 15).

In using the pumping test method on the Ravenna soil, an interesting situation was encountered. When the water table was raised with the subirrigation system, the soil profile acted as a semi-confined aquifer. Although observation well data taken throughout the plot described a nearly flat water table located near the surface, searches for the water table with an auger showed a mound of water directly over the drain, and rapid drop-off to water table depths in the range of 50 to $100 \mathrm{~cm}$ below ground surface farther away from the drain. Saturated conditions and some standing water at the surface suggest that subirrigation water was pushed up through well holes, auger holes, and other avenues of preferential flow and then was redistributed through the more permeable plow layer. In this situation the observation wells acted as piezometers, reporting the hydraulic head of the confined aquifer. For confined conditions, a different method for calculation of saturated hydraulic conductivity by the purping 
test method might be needed. The main consideration should be whether the saturated hydraulic conductivity value determined adequately describes the soil profile for use in arainage design.

When the pumping test must be carried out over an extended period, a problem exists in determining how to account for natural water table fluctuations and evapotranspiration. In this study, water table fluctuations were monitored with observation wells outside the area influenced by pumping and the "original" water table level adjusted accordingly. The $1.88 \mathrm{~cm}$ diameter observation wells were installed in $2.5 \mathrm{~cm}$ auger holes and surrounded by a sand filter. Unless the test area is covered, rainfall during the pumping test can seriously affect results because observation wells act as vertical drains and will give false readings of the water table.

The main advantage to using the pumping test is that an "in-situ" value for saturated hydraulic conductivity is obtained from a large, representative sample volume. In addition, the pumping test method provides information on storage properties as well as saturated hydraulic conductivity data to be obtained from a single measurement.

of the three methods presented here, the pumping test method is the most time consuming and labor intensive. Preparation includes making, wrapping, installing, and developing the pumping well and observation wells. The 
technique requires a pump and power source, as well as a way to measure the outflow and pumping rate. Once installed, the technique is relatively easy and several tests can be run on one setup. The procedure described by Lesaffre (1987a) requires at least 4 hours to complete one measurement of drainable porosity and saturated hydraulic conductivity. on heavy clay soils, that time could easily double or treble. The average time to achieve steady-state flow conditions on the Hoytville soil at Fremont was 12 hours.

on soils with low saturated hydraulic conductivity, the pumping test is easy for one person to conduct. As the saturated hydraulic conductivity increases, so does the rate of arawdown, the rate of outflow, and thus, the rate at which readings must be taken to provide a good estimate of the shape of the water table. On highly permeable soils, a minimum of two people would be necessary to keep pace.

The punping test requires a shallow water table, which may never be found on some soils, and only during short periods on other soils. Unless a controlled drainage or subirrigation system is in place, this test will probably be limited to use in soils with a shallow bedrock barrier or with a perched water table in the early spring.

\subsubsection{Velocity Permeameter}

Repeated readings were taken with the velocity permeameter on the same soil core until the apparent hydraulic 
conductivity reached some asymptotic value. Although several tests produced results similar to those described by Merva (1987), where successive readings decrease, level off, increase slightly, then continue to decrease (Figure 15a), most were much harder to interpret (Figure 15b). Several methods were tried to determine an appropriate value of hydraulic conductivity from the set of apparent hydraulic conductivity values collected. These included finding the arithmetic mean of all values, the geometric mean of all values, and the geometric mean of the three lowest values. In addition, each group of three successive apparent hydraulic conductivity readings were lumped together and their geometric mean found to develop a moving (geometric) mean, from which the hydraulic conductivity was taken to be the lowest value of the moving mean.

A comparison of hydraulic conductivity values determined by these different methods is presented in Table 16 . These values were compared graphically (Figures 16a and 16b). It was decided that the geometric mean of the three lowest readings provided the most appropriate value of saturated hydraulic conductivity, because it appeared to fall on or near an asymptotic value. The saturated hydraulic conductivity was determined to be the geometric mean of the three lowest apparent saturated hydraulic conductivity readings for each soil core, after negative values and extraneous values were discarded. 

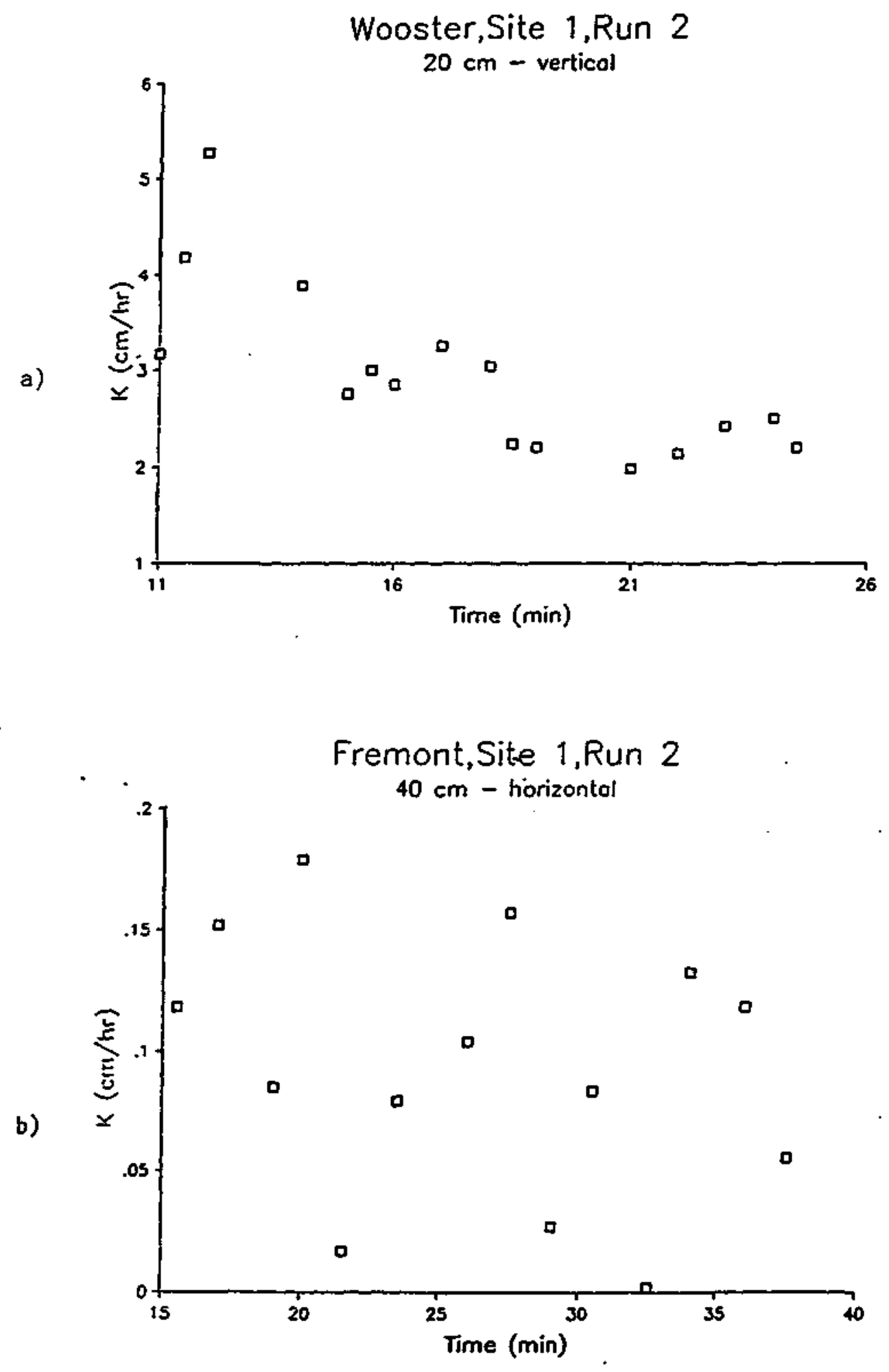

Figure 15. Series of apparent saturated hydraulic conductivity determinations for two different soil cores. 
Table 16. Saturated hydraulic conductivity estimates based on four different interpretations of velocity permeameter test data for $20 \mathrm{~cm}$ depth of Hoytville silty clay loam.

\begin{tabular}{|c|c|c|c|c|c|}
\hline \multirow[b]{2}{*}{ site } & \multirow[b]{2}{*}{ Test\# } & \multicolumn{3}{|c|}{$\mathrm{K}(\mathrm{m} / \mathrm{hr})$} & \multirow[b]{2}{*}{ M-MEAN } \\
\hline & & A-MEAN & G-MEAN & 3-LOW & \\
\hline 1 & $\begin{array}{l}1 \\
2 \\
3\end{array}$ & $\begin{array}{l}2.1 \\
0.15 \\
0.097\end{array}$ & $\begin{array}{l}1.7 \\
0.14 \\
0.069\end{array}$ & $\begin{array}{l}1.2 \\
0.067 \\
0.020\end{array}$ & $\begin{array}{l}0.90 \\
0.13 \\
0.033\end{array}$ \\
\hline 2 & $\begin{array}{l}1 \\
2 \\
3\end{array}$ & $\begin{array}{r}3.6 \\
27.0 \\
1.4\end{array}$ & $\begin{array}{r}3.4 \\
35.0 \\
1.4\end{array}$ & $\begin{array}{r}2.4 \\
27.0 \\
1.4\end{array}$ & $\begin{array}{r}3.0 \\
28.0 \\
1.2\end{array}$ \\
\hline 3 & $\begin{array}{l}1 \\
2 \\
3\end{array}$ & $\begin{array}{c}0.79 \\
32.0 \\
6.7\end{array}$ & $\begin{array}{c}0.71 \\
31.0 \\
6.1\end{array}$ & $\begin{array}{c}0.38 \\
26.0 \\
6.4\end{array}$ & $\begin{array}{c}0.44 \\
26.0 \\
6.5\end{array}$ \\
\hline $\begin{array}{l}\text { A-Mean } \\
\text { G-Mean } \\
\text { 3-Low } \\
\text { M-Mean }\end{array}$ & \multicolumn{5}{|c|}{$\begin{array}{l}\text { - Arithmetic mean of all values } \\
\text { - Geometric mean of all values } \\
\text { - Geometric mean of three lowest values } \\
\text { - Lowest value of moving geometric mean }\end{array}$} \\
\hline
\end{tabular}




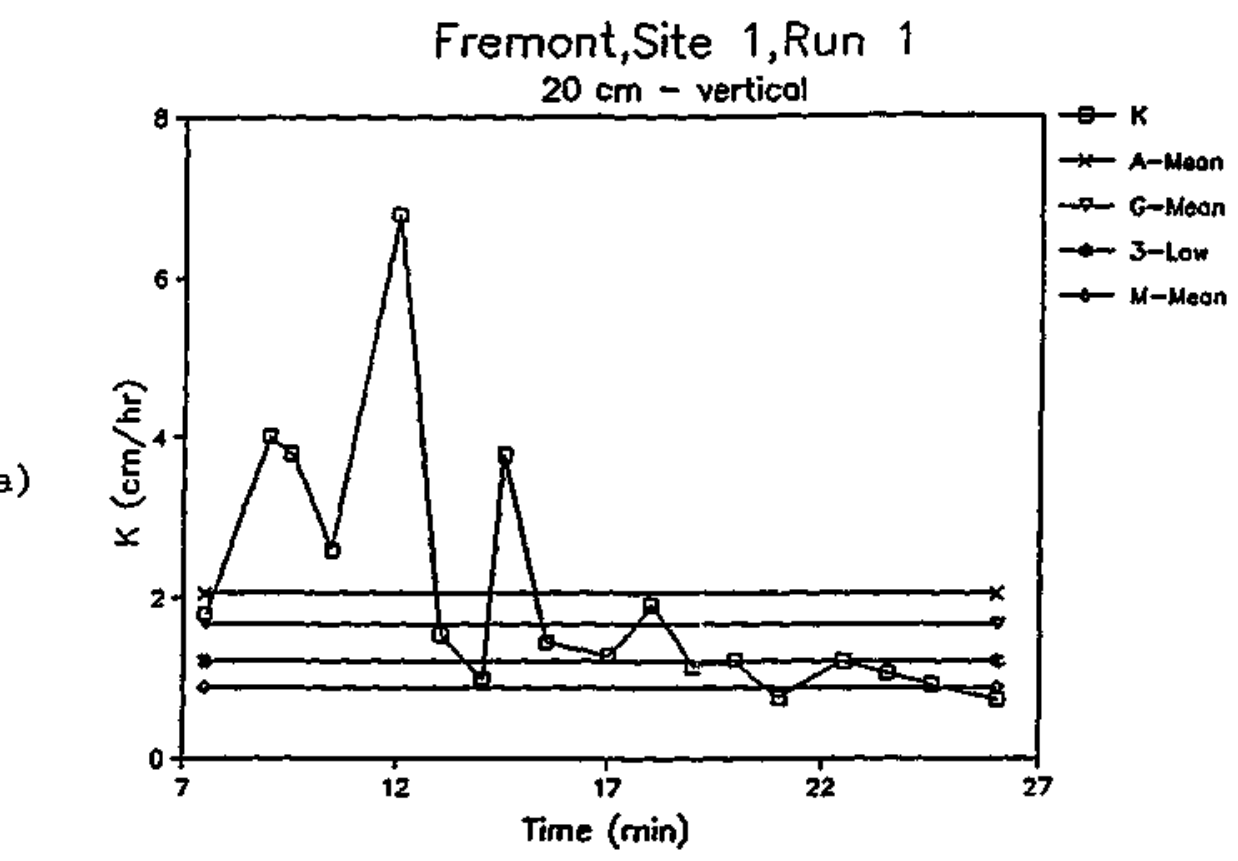

Fremont,Site 1,Run 2

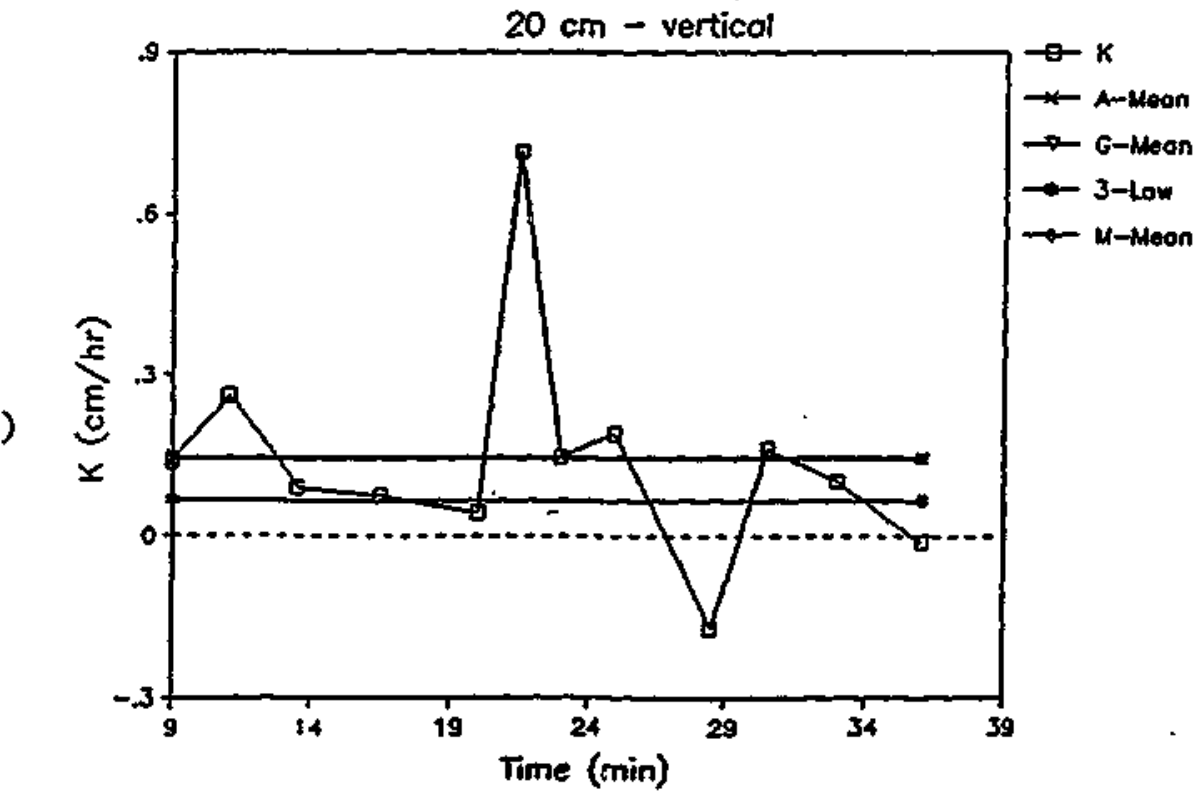

Figure 16. Graphic representation of four methods for interpreting velocity permeameter data. 
on the Hoytville soil, several measurements with the velocity permeameter resulted in water flowing through a macropore or crack directly connected to the surface. These values (denoted by an * in Table 3) were not included in site averages because they were artificially high. on the Ravenna soil, pores connected to the surface at the 40 or $60 \mathrm{~cm}$ depths caused a failure on the first or second pass of the permeameter, while at $20 \mathrm{~cm}$, apparent saturated hydraulic conductivity values would slowly increase until failure after several readings. These values were omitted from site means.

One other value (see **, Table 3) was discarded. Unlike the steady fall of the water column encountered on all other readings, the water columin for this reading repeatedly fell with an unsteady, jerky motion and even stopped completely at one point before continuing to fall.

In preparing one site at Fremont for $60 \mathrm{~cm}$ horizontal readings, an old clay drainage tile was discovered at approximately $75 \mathrm{~cm}$ of depth. This appears to have caused a significant increase in the apparent saturated hydraulic conductivity for the $60 \mathrm{cn}$ vertical measurements at this site (see $* * *$ in Table 3 ). The values for the $60 \mathrm{~cm}$ readings at this site were also discarded.

On both soils, roughly 2 orders of magnitude separate the lowest and highest values for the velocity permeameter. This wide disparity can be partially attributed to the small sample size used by the velocity permeameter. As long as a 
sufficient number of measurements are taken at a site, this level of variability may be acceptable.

In using the velocity permeameter, the operator: presses a calculator button as the water level falls passed a graduation that signifies a head increment. In most cases, the water was falling at approximately $2 \mathrm{~cm} / \mathrm{sec}$ and the button was being pressed every 3 or 4 seconds. At this rate of fall, with a little practice, it was easy to press the button at precisely the time the water level passed the proper graduation. However, at times, because of limitations in head tube size, the water level fell either faster (up to $5 \mathrm{~cm}$ per second) or slower (as slow as $1 \mathrm{~cm}$ in 5 seconds). In both cases, the precision at which the operator pressed the tey was diminished. The precision was especially affected when the fall was very slow. The closeness to the tube and angle at which the water level was viewed affected how the fall was interpreted. Therefore, it might be expected that very high values (greater than $10 \mathrm{~cm} / \mathrm{hr}$ ) or very low values (less than $0.1 \mathrm{~cm} / \mathrm{hr}$ ) would show a higher degree of non-uniformity between successive runs on the same core.

Another source of variability resulted when the water fell slowly. Several times, the rate of fall of water in the head tube was so slow that two, or even three, calculations of the apparent saturated hydraulic conductivity could be conducted without refilling the head tube. The resulting apparent saturated hydraulic conductivity values were 
different if taken in the lower part of the head tube than if they had been taken near the top of the head tube. This phenomenon is illustrated in Figure 17, where more than one measurement was taken during each refilling of the head tube, producing a cycling between successive readings. This suggests that the successive $\mathrm{dv} / \mathrm{dh}$ increments do not fit the linear least square determination very well. In theory, this relationship should hold only when the wetting front is exactly at the bottom of the soil core. To provide consistency in successive apparent saturated hydraulic conductivity measurements using the velocity permeameter, the operator should refill the head tube before each run and begin the calculation when the water level reaches a common starting point.

The geometric mean vertical saturated hydraulic conductivity was higher than the geometric mean horizontal saturated hydraulic conductivity for both soils, 300 percent higher on the Ravenna soil, and 150 percent higher on the Hoytville soil. Greater values of saturated hydraulic conductivity in the vertical direction can be attributed to the principally vertical orientation of macropores and cracks. Dabney and Selim (1987) found a 3 to 1 vertical to horizontal ratio for saturated hydraulic conductivity determined on laboratory cores from an olivier silt loam soil, which is characterized by a fragipan similar to that of the Ravenna silt loam soil. Rogers et al. (1987b) found a 1.5 to 1 


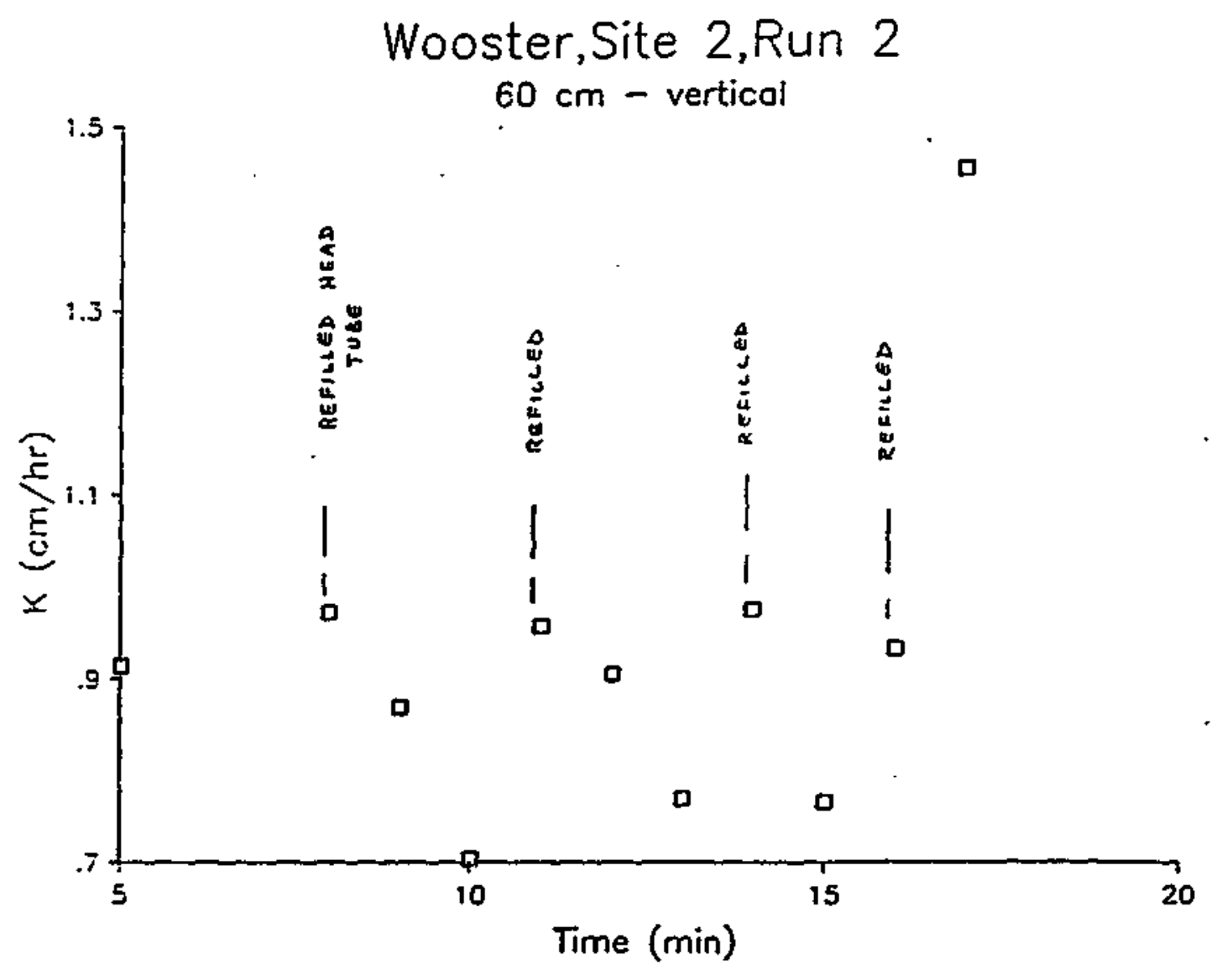

Figure 17. Cyclic progression of apparent saturated hydraulic conductivity values determined by the velocity permeameter method. 
vertical to horizontal ratio for velocity permeameter saturated hydraulic conductivity measurements on a commerce silt loam, with a silty clay loam subsoil similar to that of the Hoytville silty clay loam soil. In a soil with a large number of macropores ( 35 macropores $/ \mathrm{m}^{2}$ ), zobeck et al. (1985) found vertical saturated hydraulic conductivity values were ten times greater than horizontal saturated hydraulic conductivity values. They defined macropores as "pores, significantly larger than those resulting from simple packing of elementary particles."

Field measurements at wooster were carried out during the summer of 1988, when the soil profile was extremely dry. Problems in installing the coring tube of the velocity permeameter in the subsoil fragipan were encountered. The dry conditions caused shattering under the impact of the drophammer, and increased failures in vertical tests. Problems were partially alleviated by soaking the bottom of the pit for a short time to facilitate core entry. Rogers et al. (1987b) expressed concern about distortion of velocity permeameter samples while driving the coring tube. Soil moisture content at the time of sampling is crucial to the success of core sampling. If the soil is too dry, clay soils will shatter, if too wet they will compact and smear.

Rogers and Carter (1984) observed a reduction in saturated hydraulic conductivity values using the laboratory core method when the ends of the soil core were trimmed, so 
soil samples were broken or "minimally trimmed" to prevent smearing of the soil surface and sealing of pores. This provides further justification for Merva's (1987) procedure of breaking the soil surface before fully inserting the sample core.

The velocity permeameter is easy to use and can be operated by one person, but requires entering time increments into the HP calculator immediately following the filling of the head tube (a two-handed process) and is greatly facilitated by a second person. The velocity permeameter requires little water (less than 1 liter per determination for these soils), but requires some site preparation. Before the permeameter is installed, a pit must be dug to the appropriate depth while minimizing soil disturbance. Special care must be taken in preparing the pit for shallow measurements in the horizontal direction. Pit side walls are easily compacted resulting in lower than actual values for horizontal saturated hydraulic conductivity. The proper core and head tube must be chosen for soil conditions (this process becomes easier with a little experience). The velocity permeameter method usually takes about 15-20 minutes with a maximum of about 30 minutes for one determination.

\subsubsection{Guelph Permeameter}

Water levels of 5 and $10 \mathrm{~cm}$ were used for all measurements on the Ravenna soil at wooster. On the heavy 
clay Hoytville soil, 5 and $10 \mathrm{~cm}$ water levels were used in the plow layer, whereas 10 and $20 \mathrm{~cm}$ water levels were used for deeper measurements. Elrick et al. (1987) suggested that using 5 and $10 \mathrm{~cm}$ heads on solls with low permeability may lead to large errors. For this reason, the heads were doubled to 10 and $20 \mathrm{~cm}$ for measurements below the plow layer on the heavy clay Hoytville soil. Values determined by the Guelph permeameter may have been improved by increasing the head levels to 20 and $25 \mathrm{~cm}$ (the maximum levels allowed by the permeameter). Elrick et al. (1987) pointed out, however, that in highly layered or variable soils, higher head levels create additional problems. Rogers et al. (1987a) also reported that layering may be the cause of a large number of negative saturated hydraulic conductivity values obtained from Guelph permeameter tests in the soils of the Lower Mississippi Valley.

One major problem with the Guelph permeameter is weatherrelated. If left in direct sunlight, many small air bubbles form in the reservoir, and the water level rises and falls with the number of bubbles as the sun moves behind clouds or as the temperature changes. This problem was partially corrected by conducting tests under a large dining canopy, but long-term tests were seriously affected by temperature and pressure fluctuations. Guelph permeameter procedures state that pressure effects can be minimized by maintaining a partial vacuum in the air space above the water in the 
reservoir. This should not be a problem if the reservoir is completely filled at the beginning of the test (which was the procedure followed here) or if the vacuum pump included in the kit is used. This procedure apparently is not sufficient as extreme changes in weather (with accompanying change in barometric pressure) resulted in very strange numbers, sometimes appearing as if water was being pumped into the reservoir out of the well. The problem may have been caused by an excessive amount of air dissolved in the water supply. A possible improvement with the current set-up would be to deaerate the water supply before filling the reservoir and to re-establish a vacuum after the water in the reservoir has been exposed to ambient weather conditions for a period of time. A pressure regulator in the upper reservoir would facilitate measurements, especially on less permeable soils.

In several cases, instead of a steady fall of water in the reservoir, the water level would remain the same (or even increase slightly) during one or more time increments only to take a dramatic drop as a large bubble of air worked its way into the air-inlet tube. This effect was partially corrected by filling the well hole around the permeameter with pea gravel. In obtaining several readings at 40 and $60 \mathrm{~cm}$ depths, the steady-state outflow was determined by studying the cyclic drop in water level over several time periods to determine an average value (Figure 18). 
Guelph permeameter outflow

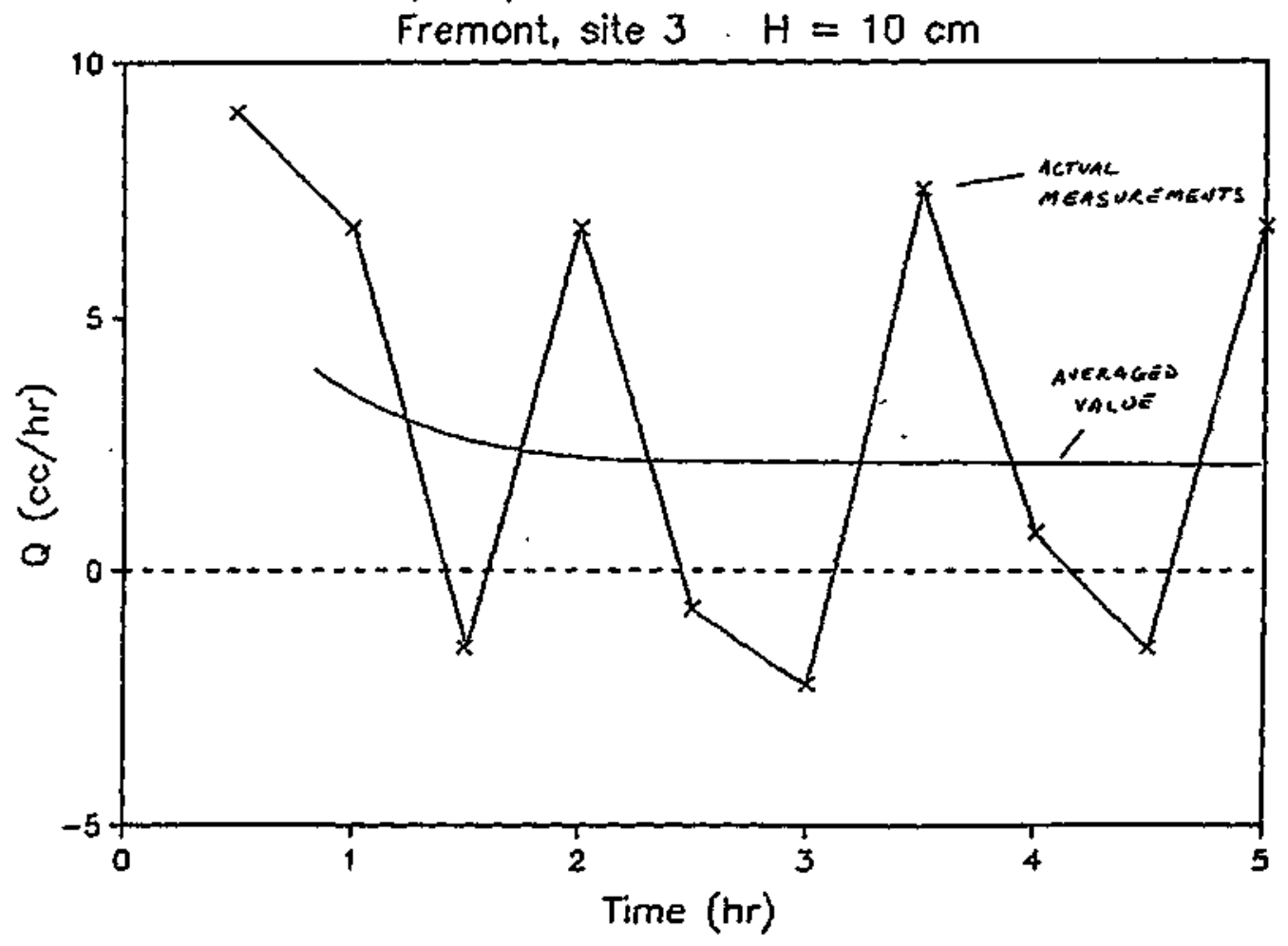

Figure 18. Cyclic decrease in Guelph permeameter outflow over several time periods. 
Another problem, especially on the heavy clay Hoytville soil, was preparation of the well hole. The soil moisture level was near field saturation when Guelph tests were performed on the Hoytville soil. It is probable that the sides of the auger hole were badly smeared by the auger during hole preparation. A hole brush is provided with the Guelph permeameter kit to remove the smear layer. The recommended procedure for using the hole brush, which was the procedure followed here, is to push the brush to the bottom of the hole one time and pull it back out without twisting the brush.

However, in heavy clay soils under high moisture conditions, one pass with the hole brush is insufficient to remove the smear layer. Repeated use or twisting of the brush was not used because the smear layer cannot be removed with the hole brush without significantly affecting the hole in other ways. Elrick et al. (1987) acknowledged this problem and remarked that data taken from test holes with a smear layer will result in low values of saturated hydraulic conductivity, unrepresentative of the soil being tested. A spiked wheel, similar to the one described by Reeve (1982) for use with the auger hole method, might improve hole preparation for saturated hydraulic conductivity measurements with the Guelph permeameter.

Low values of saturated hydraulic conductivity, similar to those found in this study, as well as high variability, were reported for Hoytville and associated Toledo soils 
(average value of about $0.01 \mathrm{~cm} / \mathrm{hr}$ ) by Taylor et al. (1961) from auger hole tests. It is possible that Taylor et al. encountered similar problems in site preparation.

on the Ravenna soil, some collapse of auger-hole sidewalls was experienced (as evidenced by buildup of sediment on the bottom of the permeameter), but this problem was corrected for the most part by the use of pea gravel which added physical support to auger-hole walls and reduced cavitation by air bubbles.

The precision in reading the reservoir scale of the Guelph permeameter was high. The scale was marked off in millimeters. Because the final outflow rate was based on the average fall of water in the reservoir over several consecutive time periods, the level of error in reading the instrument was minimal. setting the air-inlet tube to establish the head level in the well hole presented another possibility for operator error, but discrepancies could easily be kept within $1 \mathrm{~mm}$. A $1 \mathrm{~mm}$ discrepancy in setting or reading the water level would produce a maximum error in calculating hydraulic conductivity of about 1 percent. Certainly, the other problems (see below) with this technique outweighed any problems associated with precision of readings.

The Guelph permeameter is easy to use if controlling the local environment is not a problem. The Guelph permeameter, or even several Guelph permeameters, can easily be installed and operated by one person. One measurement requires less 
than two liters of water. The time to complete one measurement with the Guelph permeameter is advertised at 30 minutes to 2 hours (SoilMoisture, 1986). However, on the heavy clay Hoytville soil, several tests required 6 or more hours at each head level to reach steady state outflow, for a total time needed in excess of 12 hours for a single hydraulic conductivity determination. Once installed, the Guelph permeameter requires little attention, and can be tended while doing other field work.

\subsubsection{General Discussion}

The most important factor in selecting a method for determining saturated hydraulic conductivity of a soil or site is the end application of the data. In this case, the focus is on drainage design and modeling. The researcher or practitioner must choose a "field effective" hydraulic conductivity value for arainage design or modeling. Should this value be the saturated hydraulic conductivity of the most permeable layer, the least permeable layer, or some value obtained by integrating different layers or directions? It is difficult to assess which one of these methods gives the best value of saturated hydraulic conductivity for drainage of a particular soil without installing a drainage system.

Because flow to drains predominantly is lateral, drainage rates depend mostly on horizontal saturated hydraulic conductivity. An effective horizontal saturated hydraulic 
conductivity value should be used in drain spacing equations (Skaggs, 1979b). In homogeneous, isotropic soils, the saturated hydraulic conductivity is the same in the horizontal and vertical directions, and techniques that measure the saturated hydraulic conductivity in ej.ther direction should give consistent values. Because this situation is rarely encountered in any soil, it is important to select a method which calculates saturated hydraulic conductivity from flow in the horizontal direction (Skaggs, 1979b).

Skaggs (1976) stated that determining saturated hydraulic conductivity and drainable porosity values for drainage design would best be served by a technique that is based on water table drawdown. Installing a drainage system and calculating an effective horizontal saturated hydraulic conductivity from drain outflow and drawdown measurements would give the best description of lateral flow to arains. However, this method is extremely costly and time consuming, and in essence, defeats the purpose of the drainage design procedure. The pumping test method, the only other currently available method for estimating saturated hydraulic conductivity from drawdown data, is as near to simulating drainage as can be achieved without actually installing a drainage system.

The Guelph permeameter measures a combination of vertical and horizontal saturated hydraulic conductivity, with the value reflecting the predominant direction of water flow. This technique could possibly give a good estimate of 
horizontal saturated hydraulic conductivity if horizontal flow predominates. However, unless additional tests are performed on the soil to determine the principle direction of flow, the operator cannot be sure whether the value is an effective horizontal saturated hydraulic conductivity.

Velocity permeameter tests can be conducted on soil cores installed in either the vertical or horizontal direction. Vertical measurements will not give good estimates of the lateral saturated hydraulic conductivity needed for drain spacing equations. Horizontal velocity permeameter measurements, on the other hand, could possibly give good estimates provided that the cross-sectional area inside the soil core is representative of any cross-sectional area of the lateral flow system. However, it might be extremely difficult to obtain a representative soil volume because of problems inherent in soil core techniques, namely effects of local heterogeneity, and soil disturbance during installation. These points will be discussed in more detail later. In general, velocity permeameter measurements in the horizontal direction offer questionable saturated hydraulic conductivity values to describe an extensive lateral flow system.

The saturated hydraulic conductivity values collected from these two research sites eventually may be used as an input to the DRAIMMOD model (skaggs, 1979a). DRAINMOD uses the Hooghoudt equation to determine drain spacings. Short of installing a drain, the method that would provide the best 
value of the effective horizontal saturated hydraulic conductivity for this equation would be the pumping test method. Freeze and Cherry (1979) stated that the biggest practical disadvantage to using pumping test methods is the expense. They suggested that in many cases other less involved methods, such as the piezometer method, can provide adequate data.

In fact, when a water table is present, the auger hole method is recommended for finding the saturated hydraulic conductivity input to Hooghoudt's equation in DRAINMOD (Fredericks, 1986). Like the pumping test method, the auger hole method predominantly measures horizontal flow. Previously obtained auger hole data on both soils showed good agreement with the pumping test data of this study.

If a water table is present at some time during the year when measurements can be taken, a technique that measures the saturated hydraulic conductivity below the water table such as the pumping test or auger hole methods, should be selected. This will ensure that the saturated hydraulic conductivity is measured under conditions that approach complete saturation. However, if no water table is present when tests are conducted, a method for measuring saturated hydraulic conductivity in unsaturated soil must be used.

These methods measure the rate of infiltration into soils at less than complete saturation, or "field saturation", and by their very nature are not good simulations of the drainage 
process. However, for certain applications such as input parameter to the Green-Ampt equation, a field saturated hydraulic conductivity value determined from infiltration into unsaturated soil may be most appropriate. The Green-Ampt equation is the infiltration model used in DRAINMOD and requires an input of saturated hydraulic conductivity separate from the input used in the drain spacing equation.

skaggs and Khaleel (1982) recommended that, for infiltration equations, $+1 \mathrm{ch}$ as the Green-Ampt equation, the saturated hydraulic conductivity be determined by the airentry permeameter. The velocity permeameter is similar to the air-entry permeameter, in that it is based on infiltration into an unsaturated soil core until some field saturated hydraulic conductivity value is found. If the air-entry permeameter is indeed the best method for determining the saturated hydraulic conductivity for infiltration equations, then the velocity permeameter should be a more than adequate alternative which is quicker and easier to use.

The pumping test method estimates only a soil profile value of horizontal saturated hydraulic conductivity. When using an extensive drawdown method, such as the pumping test method, however, the effects of profile heterogeneities, nonuniformities, and anisotropy are lumped such that they are properly represented in drain spacing equations (Skaggs, 1979b). Errors made in estimating the effects of soil layering and depth to impermeable layer are also incorporated 
into estimated saturated hydraulic conductivity values and result in smaller errors in predicted drain spacings.

When using point measurements to determine a field effective value of saturated hydraulic conductivity for drainage design, it becomes increasingly important to detect variations in saturated hydraulic conductivity between layers and directions. Guelph permeameter and velocity permeameter measurements can be established in individual soil layers. similarly, a series of auger hole method or piezometer method tests can be used to determine the saturated hydraulic conductivity of individual layers.

The Guelph permeameter cannot be used to detect soil anisotropy, the value determined being a combination of horizontal and vertical saturated hydraulic conductivity. The velocity permeameter can be used to detect anisotropy between vertical and horizontal saturated hydraulic conductivity.

By using the pumping test and installing observation wells in all directions around the pumping well, the horizontal saturated hydraulic conductivity can be estimated for different directions. The velocity perzeameter, though the horizontal core can be installed in any direction, would probably not be able to detect subtle differences in saturated hydraulic conductivity between different directions in a horizontal plane. The Guelph permeameter and other auger hole methods cannot be applied to determining saturated hydraulic conductivity in different directions. 
Bouwer and Jackson (1974) state that soil variability is a far greater source of inaccuracy for evaluating "the" saturated hydraulic conductivity value of a field soil than the errors encountered when using the better techniques. Variability in measurements is attributable to local heterogeneity. It is difficult to say whether averaging a group of point measurements can adequately define the effects of macropores, cracks, roots, coarse fragments, structure, or preferential flow. cextainly, the larger the area of influence a technique has, the less it's values will be affected by local heterogeneity. Cracks and macropores of several square centimet:rs area are common in these and other soils.

The volume of soil sampled with one measurement by the three techniques fell in the order: pumping test method > Guelph permeameter > velocity permeameter. The hydraulic conductivity value estimated by the pumping test rethod is influenced most by the soil profile near the pimping well. The soil's influence decreases with distance from the well. The radius of influence is greater in highly permeable soils and soil layers. If the radius and depth of influence are conservatively taken to be two meters and one meter respectively, the volume of soil sampled by the pumping test method is about $12 \mathrm{~m}^{3}$.

Shallow-well pump-in methods, including the Guelph permeameter, have a volume of sampled soil of about 0.4 times 
the depth of water in the auger hole (Bouwer and t-ckson, 1974). For the Guelph permeameter, this would give a maximum sample volume of about $0.1 \mathrm{~m}^{3}$. The velocity permeameter, though affected by the unsaturated soil below the soil core, measures saturated hydraulic conductivity on the volume of soil within the coring tube. The $7.6 \mathrm{~cm}$ diameter coring tube used in this study has a sample volume of about $230 \mathrm{~cm}^{3}(2.3$ $\left.\times 10^{-4} \mathrm{~m}^{3}\right)$.

The order of sample volumes would suggest that the variability of values found by the velocity permeameter should be higher than that of the Guelph permeameter which, in turn, should be higher than that of the pumping test method. In a method measuring saturated hydraulic conductivity of a small sample volume, such as the velocity permeameter, one large crack or macropore can significantly influence the value obtained. The Guelph permeameter and velocity permeameter give saturated hydraulic conductivity values which represent a single point in the field. At least several measurements with these techniques are needed to determine a field effective value.

Anderson and Cassel (1986) predicted that 6,382 saturated hydraulic conductivity determinations from $7.6 \mathrm{~cm}$ diameter laboratsry cores were needed to estimate a single saturated hydraulic conductivity value within 10 percent of the estimated mean at a 95 percent confidence level for the $B$ horizon of a soil with low saturated hydraulic conductivity 
(see Table 27). Based on these results, a saturated hydraulic conductivity value determined from one pumping test would be much preferable to a value determined from one measurement with either the velocity permeameter or Guelph permeameter. As mentioned before, all three techniques can be conducted by one person with varying degrees of difficulty. None of these techniques is as simple to run as the auger hole method. The time required to run these tests depends largely on the soil type, and in the case of the permeameters on the initial moisture content of the soil. In twelve hours in the field, one person can conduct 1 to 6 Guelph permeameter tests, or 20 to 40 velocity permeameter measurements. On more permeable soils, the pumping test method can be installed and run in twelve hours. However, on heavy clay soils, the test alone will require about twelve hours to run.

Compared to the auger hole method, all three techniques studied are relatively expensive. Both permeameters are available as self-contained kits and cost more than $\$ 1000$. Replicas could probably be fashioned for substantially less (cost of labor not included), but may not bo as convenient nor as accurate. The pumping test method requires several hundred dollars of equipment including a pump, sand, flow measuring equipment, and wells. If the labor and time involved in preparing and conducting tests is included in method costs, then the pumping test method would be more costly than the other methods. 
Table 17. The number of samples ${ }^{1}$ required for various degrees of precision at the $95 \%$ confidence level for saturated hydraulic conductivity of the $\mathrm{A}, \mathrm{Btg}$, and Bg horizons of Portsmouth sandy loam (Anderson and Cassel, 1986).

\begin{tabular}{cccc}
\hline & \multicolumn{4}{c}{ \pm percent } & of estimated mean \\
Horizon & 7939 & 1985 & 80 \\
A & 25528 & 6382 & 256 \\
Btg & 1573 & 394 & 16 \\
Bg & & & \\
& & & \\
1 & Numbers of samples required were computed using \\
the mean and variance of log-transformed data.
\end{tabular}


In this study, great care was taken in the measurement process with all methods. Several possible sources of error in conducting tests include installation of equipment, irregular hole geometry, disturbance of the sampling area, and erroneous readings. It is probable that more attention was paid to procedure and repeatability in the saturated hydraulic conductivity determinations here than would be paid by the practitioners these techniques were designed for. Yet several significant problems (addressed above in individual discussion sections) were indeed encountered. A practitioner, who probably has developed some idea of a soil's range of permeability before taking any measurements, might base his estimate of saturated hydraulic conductivity on one test if it falls within this range, whether or not it is anywhere close to a proper value. It is quite important for practitioners to become aware of the problems they might encounter with the various techniques and different soil conditions so that they can base their estimates of saturated hydraulic conductivity on an appropriate number of measurements taken in a cogent manner. 


\section{CHAPTER VI \\ SUMMARY AND CONCLUSIONS}

Determining an appropriate value for saturated hydraulic conductivity involves a series of trade-offs, including: the variability of point samples in non-homogeneous soils versus the time, labor, and cost of more extensive methods; estimating a single value that represents the entire soil profile versus estimating values for several discrete layers; using a technique that measures infiltration versus waiting for a usable water table situation; and testing at convenience versus conducting tests with optimum initial field conditions. The process is further complicated by swelling soils, layering, anisotropy, entrapped air, and other commonly encountered field conditions.

The purpose of this study was to compare three techniques for measuring saturated hydraulic conductivity in the field. The techniques are the Guelph permeameter, a shallow well pump-in method; the velocity permeameter, a modified air-entry permeameter; and the pumping test method, based on Guyon's method of wells and piezometers. Values obtained from the three techniques were compared for two soils. 
of the three techniques, the pumping test method probably provides the most appropriate saturated hydraulic conductivity values for drainage design, because the calculations are based on water table drawdown and the method has the largest sample volume. However, in most cases, determining saturated hydraulic conductivity values by the pumping test method would not be practical because of the need to have a shallow water table, and time, cost, and labor requirements.

The velocity permeameter is a quick and easy method for determining a point value of hydraulic conductivity in either the vertical or horizontal direction. Values of saturated hydraulic conductivity determined from velocity permeameter measurements in the horizontal direction showed good agreement with values obtained by the pumping test method and auger hole method on two different soils. Several questions surround the use of the velocity permeameter method for determining saturated hydraulic conductivity values for drainage system design. The most important question is "how can 'point' measurements on soil sample volumes of very limited size be used to describe the soil-water flow regi.me in a field?" The answer is "they probably cannot."

For certain applications, such as an input parameter to the Green-Ampt infiltration equation, a field saturated hyaraulic conductivity value determined from infiltration into unsaturated soil may be most appropriate. The velocity permeameter method, like the air-entry permeameter method, is 
based on infiltration into an unsaturated soil core until a field saturated hydraulic conductivity value is found. If the air-entry permeameter is the best method for determining hydraulic conductivity for infiltration parameters, then the velocity permeameter should be a rore than adequate substitute.

The Guelph permeameter, though easy to operate, provided lower estimates of saturated hydraulic conductivity than those from other techniques at both locations. If the Guelph permeameter is to be effective on heavy clay soils, the procedure and/or equipment would have to be changed significantly from that used here to account for climatic change and site preparation problems.

Based on the research presented herein and limited experience with the auger hole method, the conclusions can be stated as:

(1) The auger hole method is the preferred method for estimating saturated hydraulic conductivity for drainage design.

(2) If a more accurate prediction of water table drawdown in response to drainage is needed, the pumping test method should be used.

(3) Vertical tests with the velocity permeameter method should provide good hydraulic conductivity inputs to infiltration equations used in drainage models. 
(4) Methods that estimate saturated hydraulic conductivity based on infiltration into unsaturated soil above the water table probably do not provide good predictions of the saturated hydraulic conductivity of water to subsurface drains. On soils where no shallow water table is present, saturated hydraulic conductivity values should be developed from one of these methods used in conjunction with existing data on drainage system performance on similar soils.

(5) Unless several significant problems can be resolved, the Guelph permeameter method should not be used for the determination of saturated hydraulic conductivity on heavy clay soils.

A summary of advantages and disadvantages of the three investigated methods is presented in Table 18. Also included for comparison are the advantages and disadvantages of estimating saturated hydraulic conductivity using the auger hole method, developed from the literature, personal experience, and the input of other soil scientists.

The results and conclusions presented herein should be used with caution. The results and observations may not be applicable for other soils and locations. More work is needed to further resolve how these methods can best be applied. 
Table 28. Advantages and disadvantages of field methods for determining saturated hydraulic conductivity.

Method

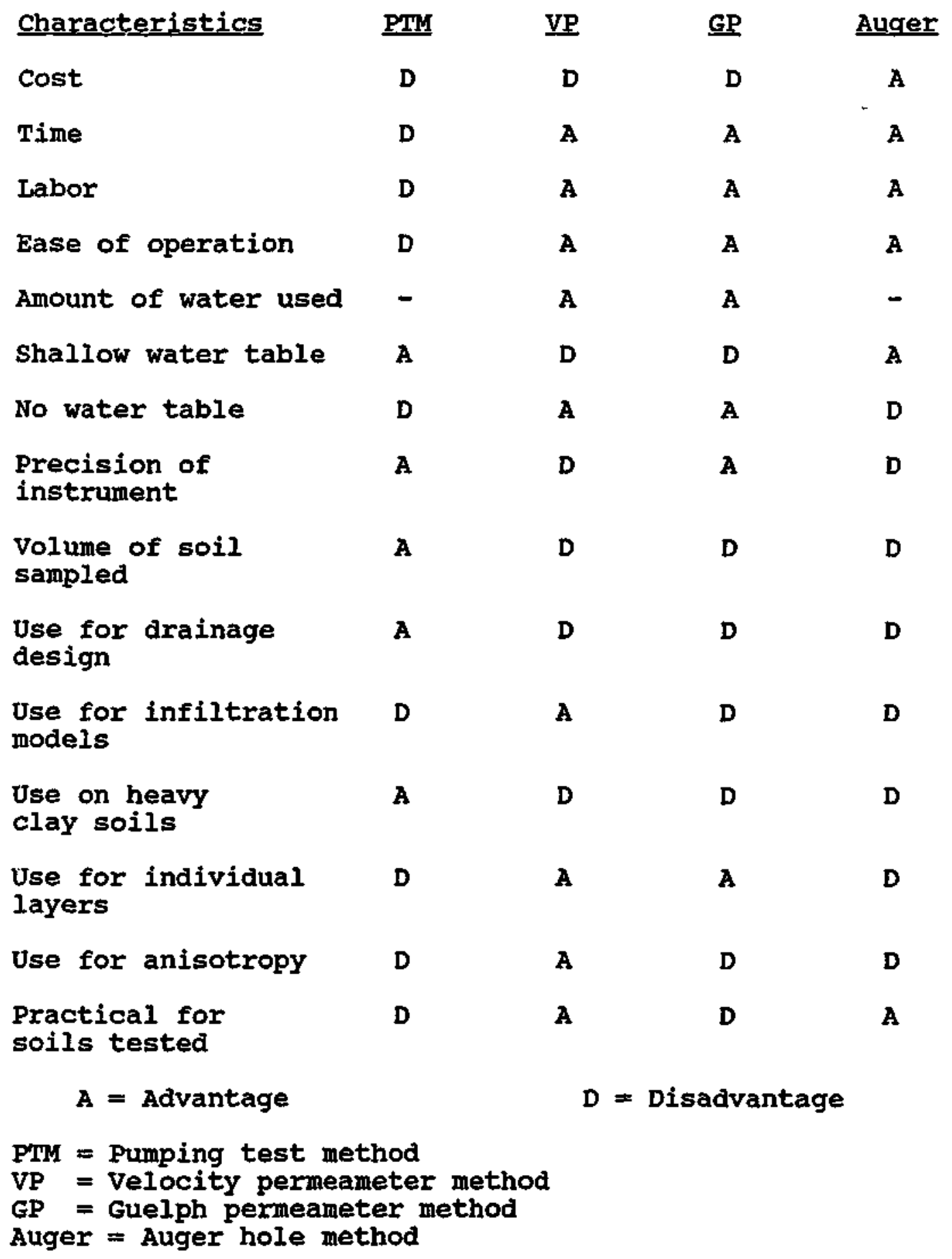




\section{LIST OF REFERENCES}

Amerman, C.R. and J.W. Naney. 1982. Subsurface flow and ground water systems. Hydrologis Modeling of small Watersheds. ASAE, St. Joseph, MI. p277-293.

Amoozegar, A. and A.W. Warrick. 1986. Hydraulic conductivity of saturated soils: Field methods. A. Klute (ed.), Methods of Soil Analysis Part 1: Physical and Mineralogical Methods, 2nd Edition. American Society of Agronomy, Madison, WI. p735770 .

Anderson, S.H. and D.K. Cassel. 1986. Statistical and autogressive analysis of soil physical properties of Portsmouth sandy loam. Soil sci. Soc. Am. J. 50: 1096-1104.

ASAE. 1962. Measuring Saturated Hydraulic Conductivity of Soils. American Society of Agricultural Engineers, st. Joseph, MI.

Baumer, O.W., R.D. Wenberg, and J.F. Rice. 1987. The use of soil water retention curves in DRAIMMOD. Proc. 3rd Intl. Wkshp. on Land Drainage. Dept. of Agr. Eng., ohio state University, Columbus, OH. pAI-AIO.

Bear, J. and A. Verruijt. 1987. Nodeling Groundwater Flow and Pollution. Reidel Publ. Co., Dordrecht, The Netherlands.

Bentley, W.J., R.W. Skaggs, and J.E. Parsons. 1989. Water table drawdown as effected by variation in hydraulic conductivity. ASAE Paper No. 89-2100. Presented at ASAE Sum. Mtg., Quebec city, Canada.

Bouma, J. 1983. Use of soil survey data to select measurement techniques for hydraulic conductivity. Agric. Water. Mgmt. 6 : $177-190$.

Bouma, J. 1986. Using soil survey information to characterize the soil water state. J. Soil. Sci. 37: 1-7.

Bouma, J., A. Jongerius, and D. Schoonderbeek. 1979. Calculation of saturated hydraulic conductivity of some pedal clay soils using micromorphometric data. Soil sci. Soc. Am. J. 43: 261-265. 
Bouma, J., R.F. Paetzold, and R.B. Grossman. 1982. Measuring Hydraulic Conductivity for Use in Soil survey. SSI Report No. 38. USDA-SCS, Washington, DC.

Bouwer, H. 1964. Measuring horizontal and vertical hydraulic conductivity of soil with the double-tube method. Soil sci. Soc. Am. Proc. 28: 19-23.

Bouwer, H. 1966. Rapid field measurement of air-entry value and hydraulic conductivity of soil as significant parameters in flow system analysis. Water Resources Research 2: 729-738.

Bouwer, H. 1969. Infiltration of water into nonuniform soil. J. Irr. \& Dr. p451-462.

Bouwer, H. 1978. Groundwater Hydrology. McGraw-Hill, New York.

Bouwer, H. and R.D. Jackson. 1974. Determining soil properties. J. van schilfgaarde (ed.), Drainage for Agriculture. American Society of Agronomy, Madison, WI. p611674 .

Brakensiek, D.L., R.G. Engelman, and W.J. Rawls. 1981. Variation within texture classes of soil water parameters. Trans. ASAE 24(2): 335-339.

Bruce, R.R. and A. Klute. 1956. The measurement of soil moisture diffusivity. Soil Sci. Soc. Am. Proc. 20: 458-462.

Carter, C.F., F.T. Wratten, V. McDaniel, and B. Halverson. 1984. Hydraulic conductivity measured electronically in an auger hole. Trans. ASAE 27(5): 1400-1404.

Childs, E.C. 1945. The water table, equipotentials and streamilines in drained land. Soil Sci. 59: 405-415.

Childs, E.c. 1952. The measurement of the hydraulic permeability of saturated soil in situ. I. Principles of a proposed method. Roy. Soc. (London) Proc. A.215: 525-535.

Childs, E.C. 1957. The physics of land drainage. $J$. van Schilfgaarde (ed.), Drainage of Agricultural Lands. American Society of Agronomy, Madison, WI. p1-78.

Childs, E.C. 1969. An Introduction to the Physical Basis of Soil Water Phenomena. Wiley and Sons, London, UK.

Dabney, S.M. and H.M. Selim. 1987. Anisotropy of a fragipan soil: vertical vs. horizontal hydraulic conductivity. Soil Sci. Soc. Am. J. 51: 3-6. 
Dane, J.H. and S. Hruska. 1983. In-situ determination of soil hydraulic properties during drainage. J. Soil Sci. Soc. Am. $47(4): 619-624$.

Darcy, H. 1856. Les fontaines publiques de la ville de Dijon. Dalmont, paris.

Davis, J.C. 1986. Statistics and Data Analysis in Geology, 2nd Edition. Wiley \& Sons, New York.

Doty, C.W., R.A. Evans, H.J. Gibson, R.D. Hinson, and W.B. Williams. 1986. Agricultural Water Table Management: A Guide for Eastern North Carolina. North Carolina State University, Raleigh, NC.

Elrick, D.E. and W.D. Reynolds. 1986. An analysis of the percolation test based on three-dimensional saturatedunsaturated flow from a cylindrical test hole. soil science $142(5): 308-321$.

Elrick, D.E., W.D. Reynolds, N. Baumgartner, K.A. Tan, and K.L. Bradshaw. 1987. In-situ measurements of hydraulic properties of soils using the Guelph permeameter and the Guelph infiltrometer. Proc. 3rd Intl. Wkshp. on Iand Drainage. Dept. of Agr. Eng., Ohio state University, Columbus, $O H$. pG13-G23.

Fredericks, E.E. (ed.). 1986. DRAINMOD: Documentation for the water management simulation model. North Central computer Institute, Madison, WI.

Freeze, R.A. and J.A. Cherry. 1979. Groundwater. PrenticeHall, Englewood cliffs, NJ.

Green, W.H. and G.A. Ampt. 1911. The flow of air and water through soils. J. of Agr. Sci. 4: 1-24.

Gardner, w.R. 1956. Calculation of capillary conductivity from pressure plate outflow data. Soil Sci. Soc. Am. Proc. 20: 317320 .

Guyon, G. 1964. Ia mesure de la permeabilite par la methode des piezometres en vue du calcul des dimensions du drainage. Revue Science du Sol 2(2): 12 .

Guyon, G. 1976. Determination de la conductivite hydraulique moyenne d'un sol par la methode du rabattement de nappe, dans le cas d'un substratum profond ou mal caracterise. Bull. Int1. Comm. Irr. \& Dr. 25: 124-135.

Hillel, D. 1982. Introduction to Soil Physics. Academic Press, Orlando, FI. 
Hirschi, M.C. and I.D. Moore. 1980. Estimating soil hydraulic properties from soil texture. ASAE Paper 80-2523.

Hoffman, G.J. and G.O. Schwab. 1964. Tile spacing prediction based on drain outflow. Trans. ASAE 7(4): 444-447.

Hooghoudt, S.B. 1940. Bijdragen tot de kennis van eenige natuurkundige grootheden van den grond, 7. Algemeene beschouwing van het probleem van de detail ontwatering en de infiltratie door middel van parallel loopende drains, greppels, slooten en kanalen. Versl. Landb. Ond. 46: 515-707. Algemeene Landsdrukkerij, The Hague.

Hopmans, J.W. and J.H. Dane. 1985. Effect of temperature dependent hydraulic properties on soil water movement. Soil Sci. Soc. Am. J. 49: 5:l-58.

Kanwar, R.S., H.A. Ri.zvi, M. Ahmed, R. Horton, Jr., and S.J. Marley. 1987. A comparison of two methods for rapid measurement of saturated hydraulic conductivity of soils. Proc. 3rd Intl, Wkshp. on Land Drainage. Dept. of Agr. Eng., Ohio State University, Columbus, OH. pG35-G53.

King, L.G. 1974. Flow through heterogeneous media. J. van Schilfgaarde (ed.), Drainage for Agriculture. American Society of Agronomy, Medison, WI. p271-302.

Kirklam, D. 1946. Proposed method for field measurement of permeability of soil below the water table. Soil Sci. Soc. Am. Proc. 10: 58-68.

Kirkham, D. 1954. Measurement of the hydraulic conductivity in place. Symp. Permeability of Soil, ASTM Special Publication 163: 80-97.

Kirkham, D. 1965. Saturated Conductivity as a characterizer of Soil for Drainage Design. ASTE Special Publ., American Society of Agricultural Engineers, St. Joseph, MI.

Kirkham, D., S. Toksoz, and R.R. van der Ploeg. 1974. Steady flow to drains and wells. $T$. van Schilfgaarde (ed.), Drainage for Agriculture. American Society of Agronomy, Madison, WI. p203-244.

Kluce, A. and C. Dirksen. 1986. F draulic conductivity and diffusivity: Laboratory methods. : K2ute (ed.), Methods of Soil Analysis Part 1: Physical and Nineralogical Methods, 2nd Edition. American Society of Agronomy, Madison, WI. p687-734.

Klute, A., E.J. Scott, and F.D. Whisler, 1965. Steady state water flow in a saturated inclined soil slab. Water Resources Research 1(2): 287-294. 
Knight, J.H. 1983. Infiltration functions from exact and approximate solutions of Richards' equation. Proc. Natl. Conf. Adv. Infiltration. ASAE, St. Joseph, MI. p24-33.

Leeds-Harrison, P.B., C.J.P. Shipway, N.J. Jarvis, and E.G. Youngs. 1986. The influence of soil macroporosity on water retention, transmission and drainage in a clay soil. Soil use \& Mgmt. 2(2): 47-50.

Lesaffre, B. 1987a. Field measurement of saturated hydraulic conductivity and drainable porosity using Guyon's pumping test method. Suppl. Proc. 3rd Intl. Wkshp. on Land Drainage. Dept. of Agr. Eng., Ohio State University, Columbus, OH. PB67-B77.

Lesaffre, B. 1987b. Current drainage design practices in France. Proc. 3rd Intl. Wkshp. on Land Drainage. Dept. of Agr. Eng., Ohio State University, Columbus, OH. pD23-D31.

Luthin, J.N. (ed.). 1957. Drainage of Agricultural Lands. Monograph 7, American Society of America. Madison, WI.

McKeague, J.A., C. Wang, and G.C. Topp. 1982. Estimating saturated hydraulic conductivity from soil morphology. Soil Sci. Soc. Am. J. 46: 1239-1244.

McNeal, B.L. 1974. Soil salts and their effects on water movement. $J$. van Schilfgaarde (ed.), Drainage for Agriculture. American Society of Agronomy, Madison, WI. p409-432.

Merva, G.E. 1979. Falling head permeameter for field measurement of hydraulic conductivity. ASAE Paper No. 792515. ASAE, St. Joseph, MI.

Merva, G.E. 1987. The velocity permeameter technique for rapid determination of hydraulic conductivity in-situ. Proc. 3 rd Int1. Wkshp. on Land Drainage. Dept. of Agr. Eng., Ohio State University, Columbus, OH. pG56-G66.

Merva, G.E., H. Belcher, and L. Protasiewicz. 1987. Water Management for Agricultural Production -- Interim Report to the corrugated plastic Tubing Manufacturers Association.

Moore, I.D., G.J. Burch, and P.J. Wallbrink. 1986. Preferential flow and hydraulic conductivity of forest soils. Soil Sci. Soc. Am. J. 50: 876-881.

Naney, J.W., L.R. Ahuja, and B.B. Barnes. 1983. Variability and interrelation of soil-water and some related soil properties in a small watershed. Proc. Natl. Conf. Adv. Infiltration. ASAE, St. Joseph, MI. p92-101. 
Nassehzadeh-Tabrizi, A. and R.w. Skaggs. 1983. Variation of saturated hydraulic conductivity within a soil series. ASAE Paper No. 83-2044. Presented at ASAE Sum. Mtg., Bozeman, Mo.

Nielsen, D.R., J.W. Biggar, and K.T.Erh. 1973. Spatial variability of field measured soil-water properties. Hilgardia 42 : $215-259$.

O'Neal, A.M. 1949. Soil characteristics significant in evaluating permeability. Soil Science 67(5): 403-409.

O'Neal, A.M. 1952. A key for estimating soil permeability by means of fiela clues. Soil Sci. Soc. Am. Proc. 16: 312-315.

Peters, R.A., N.R. Fausey, and T.G. Carpenter. 1982. Compaction and subsoil hydraulic conductivity. ASAE Paper No. 82-2075.

Peterson, D.F., Jr. 1957. The theory of arainage by pumping from wells. J.N. Iuthin (ed.), Drainage of Agricultural Lands. American Society of Agronomy, Madison, WI. p181-215.

Philip, J.R. 1957a. The theory of infiltration: 1. The infiltration equation and its solution. Soil science 83: 345357.

Philip, J.R. 1957b. The theory of infiltration: 5. The influence of the initial moisture content. Soil science $84: 329-339$.

Puckett, W.E., J.H. Dane, and B.F. Hajek. 1985. Physical and mineralogical data to determine soil hydraulic properties. Soil Sci. Soc. Am. J. 49: 831-836.

Raats, P.A.C., and W.R. Gardner. 1974. Movement of water in the unsaturated zone near a water table. J. van Schilfgaarde (ed.), Drainage for Agriculture. American Society of Agronomy, Madison, WI. p311-358.

Ravina, I. and J. Magier. 1984. Hydraulic conductivity and water retention of clay soils containing coarse fragments. Soil Sci. Soc. Am. 3. 48: 736-740.

Rawls, W.J., D.I. Brakensiek, and K.E. Saxton. 1982 . Estimation of soil water properties. Trans. ASAE 25(5): 1316$1320,1328$.

Rawls, W.J. and D.i. Brakensiek. 1983. A procedure to predict Green and Ampt infiltration parameters. Proc. Natl. Conf. Adv. Infiltration. ASAE, St. Joseph, MI. p102-112. 
Rawls, W.J., D.I. Brakensiek and B. Soni. 1983. Agricultural management effects on soil water processes Part 1: Soil water retention and Green and Ampt infiltration parameters. Trans. ASAE 26(6): 1747-1752.

Reeve, R.C. and J.N. Iuthin. 1957. Methods of measuring soil permeability. J.N. Luthin (ed.), Drainage of Agricultural Lands. American Society of Agronomy, Madison, wI. p395-445.

Reeve, R.C. 1982. Soil Permeability -- Auger-Hole Method. Technical Note No. 2.118, Advanced Drainage Systems, Columbus, OH.

Reynolds, W.D., D.E. Elrick, and G.C. Topp. 1983. A reexamination of the constant head well permeameter method for measuring saturated hydraulic conductivity above the water table. Soil Sci. 136(4): 250-268.

Reynolds, W.D. and D.E. Elrick. 1985. Measurement of fieldsaturated hydraulic conductivity, sorptivity, and the conductivity-pressure head relationship using the "Guelph Permeameter." Proc. NWWA Conf. Char. Mon. Vadose Zone. Nat'l Water Well Assn., Dublin, OH.

Reynolds, W.D. and D.E. Elrick. 1986. A method for simultaneous in-situ measurements in the vadose zone of fieldsaturated hydraulic conductivity, sorptivity and the conductivity-pressure head relationship. Grndwtr. Mon. Rvw. $6(1): 84-95$.

Richards, L.A. 1931. Capillary conductivity of liquids through porous mediums. Physics 1: 318-333.

Rogers, J.S. and C.E. Carter. 1984. Soil core sampling for hydraulic conductivity and bulk density. Soil sci. Soc. Am. J. 51: 1393-1394.

Rogers, J.S. and C.E. Carter. 1987. Auger hole hydraulic conductivity determination in layered soils. Trans. ASAE $30(2): 374-378$.

Rogers, J.S., J.L. Fouss, and C.E. Carter. 1987a. Selecting soil physical data for use in the design and modeling of water management systems. Proc. 3rd Intl. Wkshp. on Land Drainage. Dept. of Agr. Eng., Ohio state University, Columbus, OH. pA121-A128.

Rogers, J.S., J.L. Fouss, and C.E. Carter. 1987b. Field experience with a velocity head permeameter. Proc. 5th Natl. Symp. Drainage Design and Mgmt. ASAE, St. Joseph, MI. p109116. 
Rogers, J.S., V. McDaniel, and C.E. Carter. 1985. Determination of saturated hydraulic conductivity of a Commerce silt loam soil. Trans. ASAE 28(4): 1141-1144.

SAS. 1985. SAS User's Guide: Statistics, Version 5 Edition. SAS Institute, Cary, NC.

Schuh, W.M. and J.W. Bauder. 1986. Effect of soil properties on hydraulic conductivity-moisture relationships. Soil Sci. Soc. Am. J. 50: 848-855.

Sharma, M.L., R.J.W. Barron, and E.S. De Boer. 1983. Spatial structure and variability of infiltration parameters. proc. Natl. Conf. Adv. Infiltration. ASAE, st. Joseph, MI. p113121.

Shirmohammadi, A. and R.w. Skaggs. 1985. Predicting infiltration for shallow water table soils with different surface covers. Trans. ASAE $28(6): 1829-1837$.

Skaggs, R.W. 1976. Determination of the hydraulic conductivity - drainable porosity ratio from water table measurements. Trans. ASAE 19(1): 73-80, 84.

Skaggs, R.w. 1979a. Methods for Design and Evaluation of Drainage-water Management systems for Soils with High water Tables. Prepared for USDA-SCS.

Skaggs, R.W. 1979b. Factors affecting hydraulic conductivity determinations from drawdown measurements. ASAE Paper No. 792075. Presented at ASAE Sum. Mtg., Winnipeg, Canada.

Skaggs, R.W., N.R. Fausey, and B.H. Nolte. 1981. Water management model evaluation for north central ohio. Trans. ASAE 24(4): $922-928$.

Skaggs, R.W. and R. Khaleel. 1982. Infiltration. Hydrologic Modeling of Small Watersheds. ASAE, St. Joseph, MI. p121-166.

Smiles, D.E. and E.G. Youngs. 1963. A multiple-well method for determining the hydraulic conductivity of a saturated soil in situ. J. Hydrol. 1: 279-287.

SoilMoisture. 1986. 2800kI Guelph Permeameter Operating Instructions. Soilmoisture Equipment Corp., Santa Barbara, CA.

Stibbe, E., T.J. Thiel, and G.S. Taylor. 1970. Soil hydraulic conductivity measurement by field monoliths. Proc. soil sci. Soc. Am. 34(6): 952-954. 
Strzepek, K. and I.Garcia. 1987. Optimal design of tile drains under uncertainty in soil properties. Proc. 5th Natl. Symp. Drainage Design and Mgmt. ASAE, St. Joseph, MI. p53-62.

Taylor, G.S., T. Goins, and N. Holowaychuk. 1961. Drainage Characteristics of Toledo and Hoytville Soils. Ohio Agr. Exp. Sta., Res. Bull. 876.

Todd, D.K. 1959. Ground Water Hydrology. John Wiley \& Sons, New York.

Uhland, R.E. and A.M. O'Neal. 1951. Soil Permeability Determinations for Use in Soil and water conservation. USDASCS, Washington, D.C.

USDA-SCS. 1973. Drainage of Agricultural Iand. Water Information Center, Port Washington, NY.

USDA-SCS. 1984. Soil survey of Wayne County, ohio.

USDA-SCS. 1987. Soil Survey of Sandusky County, ohio.

van Beers, w.F.J. 1970. The Auger-Hole Method. Bulletin 1, Intl. Inst. Iand Recl. and Impr. Wageningen, The Netherlands.

van Schilfgaarde, J. 1957. Approximate solutions to drainage flow problens. J.N. Iuthin (ed.), Drainage of Agricultural Lands. American Society of Agronomy, Madison, WI. p79-112,

van Schilfgaarde, J. (ed.) . 1974a. Drainage for Agriculture. American Society of Agronomy, Madison, WI.

van Schilfgaarde, J. 1974b. Nonsteady flow to drains. J. van Schilfgaarde (ed.), Drainage for Agriculture. ASA, Madison, WI. p245-270.

Wang, C., J.A. McKeague, and G.C. Topp. 1985. Comparison of estimated and measured horizontal Ksat values. Can. J. Soil Sci. 65: 707-715.

Watson, K.K. 1966. An instantaneous profile method for determining the hydraulic conductivity of unsaturated porous materials. Water Resources Research 2: 709-715.

Watson, K.K. 1974. Some applications of unsaturated flow theory. J. van Schilfgaarde (ed.), Drainage for Agriculture. ASA, Madison, WI. p359-400.

Wells, L.G. and R.W. Skaggs. 1976. Upward water movement in field cores. Trans. ASAE 19(2): 275-283. 
Wells, L.G., A.D. Ward, I.D. Moore, and R.E. Phillips. 1986. Comparison of four infiltration models in characterizing infiltration through surface mine profiles. Trans. ASAE 29(3): 785-793.

winger, R.J.,Jr. 1960. In-place permeability tests and their use in subsurface drainage. 4th Intl. Congr. Comm. Irr. \& Dr., Madrid. 48p.

Youngs, E.G. 1964, Water movement in soils. The State and Movement of Water in Living Organisms. Cambridge University Press. p89-112.

Youngs, E.G. 1976. Determination of the variation of hydraulic conductivity with depth in drained lands and the design of drainage installations. Agr. Water. Mgmt. 1: 57-66.

Zobeck, T.M., N.R. Fausey, and N.S. Al-Hamdan. 1985. Effect of sample cross-sectional area on saturated hydraulic conductivity in two structured clay soils. Trans. ASAE $28(3)$ : 791-794. 